\title{
Sex Differences in the Epilepsies and Associated Comorbidities: Implications for Use and Development of Pharmacotherapies
}

\author{
Catherine A. Christian, Doodipala Samba Reddy, Jamie Maguire, and Patrick A. Forcelli
}

Department of Molecular and Integrative Physiology, Neuroscience Program, and Beckman Institute for Advanced Science and Technology, University of Illinois at Urbana-Champaign, Urbana, Illinois (C.A.C.); Department of Neuroscience and Experimental Therapeutics, College of Medicine, Texas A\&M University Health Science Center, Bryan, Texas (D.S.R.); Neuroscience Department, Tufts University School of Medicine, Boston, Massachusetts (J.M.); and Departments of Pharmacology and Physiology and Neuroscience, Georgetown University, Washington, D.C. (P.A.F.)

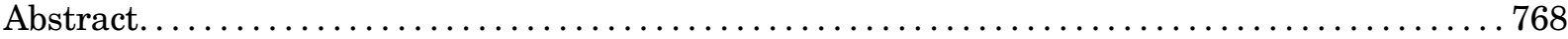

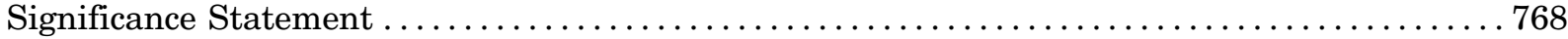

I. Introduction to Epilepsy, Seizures, and the Importance of Investigating Sex Differences ...... 768

A. Note on Terminology: Sex and Gender .................................. 769

II. Sex Differences in Epilepsies and Comorbidities: Clinical Conditions and Animal Models ..... 769

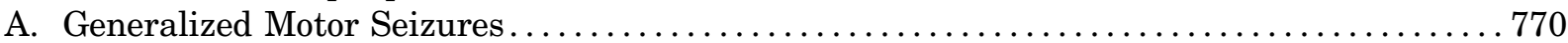

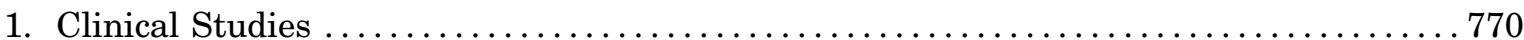

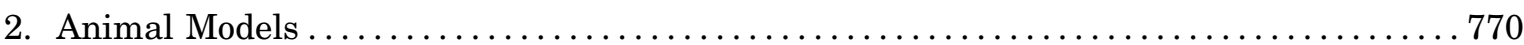

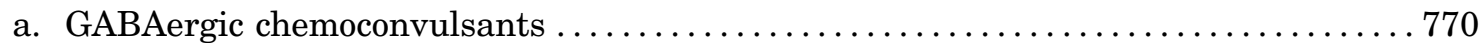

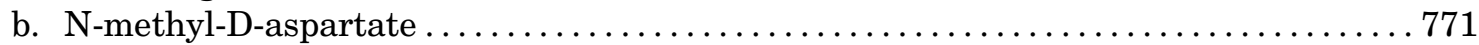

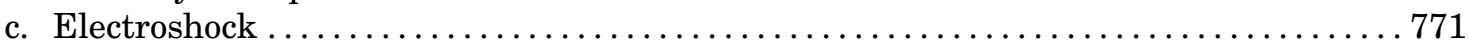

d. Inbred genetic models ............................................. 771

e. Other genetic models........................................... 771

B. Generalized Nonmotor Seizures (Absence Seizures) $\ldots \ldots \ldots \ldots \ldots \ldots \ldots \ldots \ldots \ldots \ldots \ldots . \ldots 771$

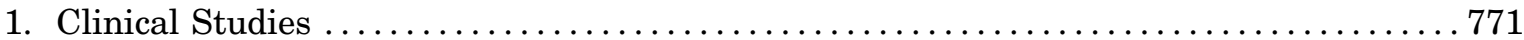

2. Preclinical Genetic Models......................................... 772

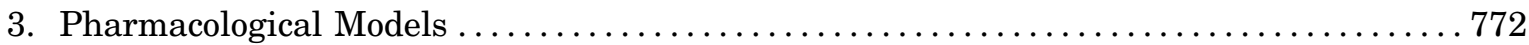

C. Focal Seizures and Temporal Lobe Epilepsy.................................. 772

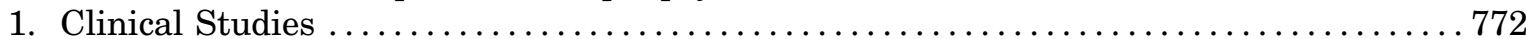

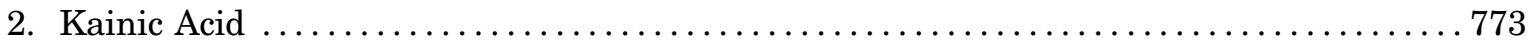

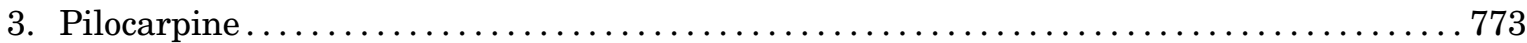

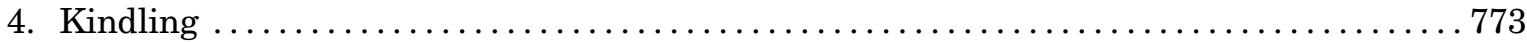

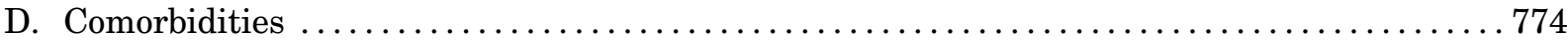

1. Psychiatric and Affective Disorders $\ldots \ldots \ldots \ldots \ldots \ldots \ldots \ldots \ldots \ldots \ldots \ldots \ldots \ldots \ldots \ldots \ldots \ldots 74$

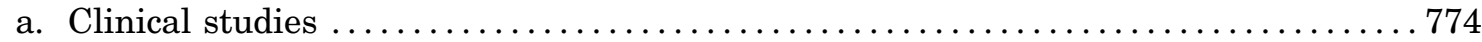

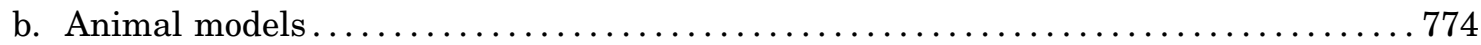

2. Reproductive Endocrine Disorders and Sexual Dysfunction $\ldots \ldots \ldots \ldots \ldots \ldots \ldots \ldots . \ldots 774$

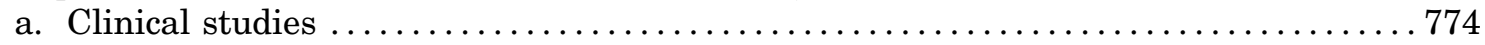

b. Animal models .................................................. 776

3. Cognitive and Learning Deficits ........................................ 779

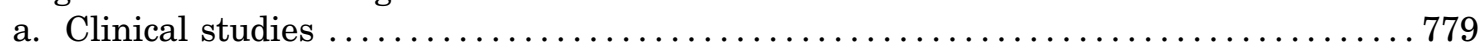

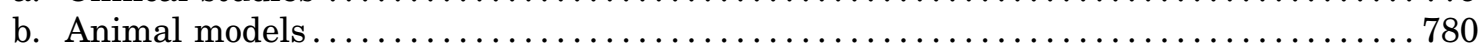

Address correspondence to: Dr. Catherine A. Christian, Department of Molecular and Integrative Physiology, 407 S. Goodwin Ave., 524 Burrill Hall, University of Illinois at Urbana-Champaign. Urbana, IL. E-mail: cathchri@illinois.edu

This work was supported by National Institutes of Health National Institute of Neurological Disorders and Stroke [Grants R01 NS105825 (to C.A.C.); R03 NS103029 (to C.A.C.); R21 NS052158 (to D.S.R.); R01 NS051398; CounterACT Program U01 NS083460 (to D.S.R.); R01 NS102937 (to J.M.); R01 NS105628 (to J.M.); R01 NS097762 (P.A.F.)] and the Eunice Kennedy Shriver National Institute of Child Health and Human Development [Grant R01 HD091994 (to P.A.F.)].

https://doi.org/10.1124/pr.119.017392. 


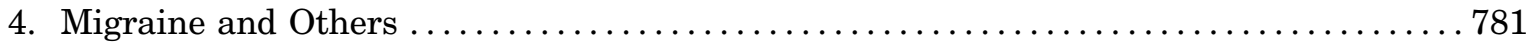

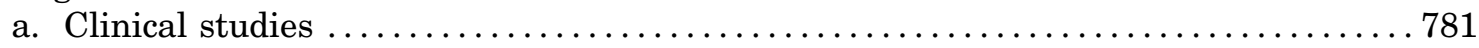

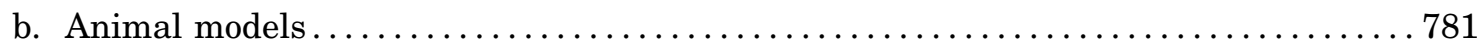

III. Catamenial Epilepsy: Fluctuations in Seizure Occurrence across the Menstrual Cycle...... 782

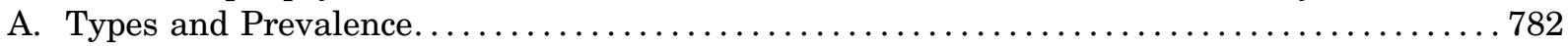

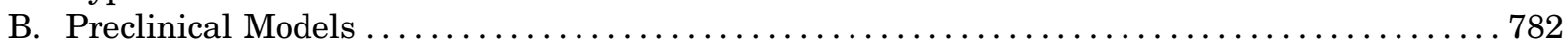

IV. Potential Neurobiological Bases for Sex Differences in Seizure Susceptibility and Epilepsy ... 783

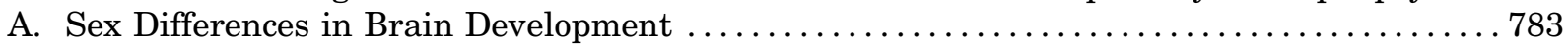

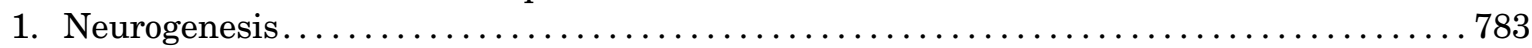

2. Chloride Homeostasis and GABAergic Neurotransmission .................... 784

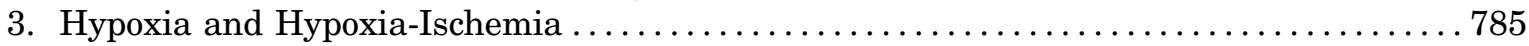

B. Hormonal and Neurosteroid Mechanisms in Adulthood ....................... 786

1. Estrous Cycle-Associated Changes in Seizure Susceptibility .................. 786

2. Effects of Estradiol, Progesterone, and Testosterone on Seizure Susceptibility........ 786

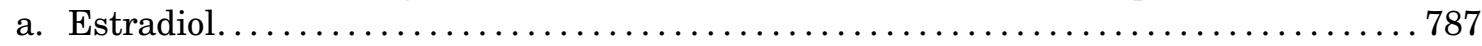

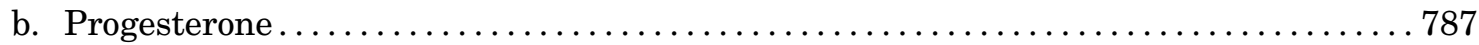

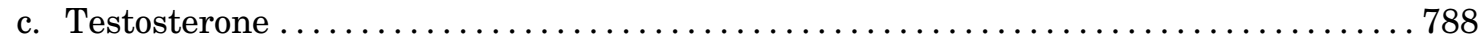

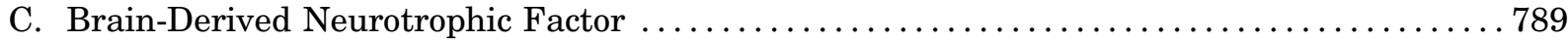

D. Glial Mechanisms: Astrocytes and Microglia................................ 790

E. Stress Response and the Hypothalamic-Pituitary-Adrenal Axis . . . . . . . . . . . . . 791

V. Considerations for Antiseizure Pharmacotherapies, Drug Screening, and Development....... 791

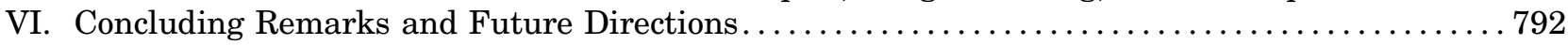

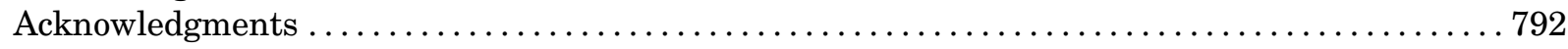

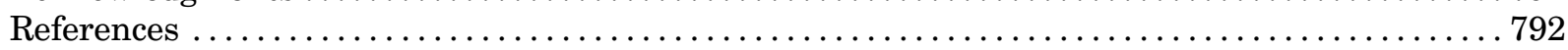

\begin{abstract}
The epilepsies are common neurologic disorders characterized by spontaneous recurrent seizures. Boys, girls, men, and women of all ages are affected by epilepsy and, in many cases, by associated comorbidities as well. The primary courses of treatment are pharmacological, dietary, and/or surgical, depending on several factors, including the areas of the brain affected and the severity of the epilepsy. There is a growing appreciation that sex differences in underlying brain function and in the neurobiology of epilepsy are important factors that should be accounted for in the design and development of new therapies. In this review, we discuss the current knowledge on sex differences in epilepsy and associated comorbidities, with emphasis on those aspects most informative for the development of new pharmacotherapies. Particular focus is placed on sex differences in the prevalence and presentation of various focal and generalized epilepsies; psychiatric, cognitive, and
\end{abstract}

physiologic comorbidities; catamenial epilepsy in women; sex differences in brain development; the neural actions of sex and stress hormones and their metabolites; and cellular mechanisms, including brainderived neurotrophic factor signaling and neuronal-glial interactions. Further attention placed on potential sex differences in epilepsies, comorbidities, and drug effects will enhance therapeutic options and efficacy for all patients with epilepsy.

Significance Statement-Epilepsy is a common neurological disorder that often presents together with various comorbidities. The features of epilepsy and seizure activity as well as comorbid afflictions can vary between men and women. In this review, we discuss sex differences in types of epilepsies, associated comorbidities, pathophysiological mechanisms, and antiepileptic drug efficacy in both clinical patient populations and preclinical animal models.

\section{Introduction to Epilepsy, Seizures, and the Importance of Investigating Sex Differences}

Epilepsy is the fourth most common neurologic disorder, and approximately 1 in 26 people will develop epilepsy in their lives (England et al., 2012). "Epilepsy" is an umbrella term referring to a group of disorders characterized by spontaneous recurrent seizures. A seizure is a paroxysmal discharge of hypersynchronous neuronal activity that can either stay confined to one

ABBREVIATIONS: ASD, antiseizure drug; BDNF, brain-derived neurotrophic factor; CSD, cortical spreading depression; DHT, dihydrotestosterone; FSH, follicle-stimulating hormone; GABA $A_{A}$, GABA receptor, type-A; GAERS, Genetic Absence Epilepsy Rats from Strasbourg; GBL, gammabutyrolactone; GEPR, genetically epilepsy-prone rat; GFAP, glial fibrillary acidic protein; GnRH, gonadotropin-releasing hormone; HI, hypoxia/ischemia; HPA, hypothalamic-pituitary-adrenal; HPG, hypothalamic-pituitary-gonadal; KA, kainic acid; KCC2, potassium-chloride cotransporter 2; LH, luteinizing hormone; NKCC1, sodium-potassium-chloride cotransporter 1; NMDA, N-methyl-Daspartate; PCOS, polycystic ovarian syndrome; PR, progesterone receptor; PRL, prolactin; PTZ, pentylenetetrazole; SE, status epilepticus; SUDEP, sudden unexpected death in epilepsy; SWD, spike-and-wave discharge; THDOC, tetrahydrodeoxycorticosterone; TLE, temporal lobe epilepsy; TrkB, tropomyosin receptor kinase B; WAG/Rij, Wistar Albino Glaxo/Rijswijk. 
brain region (focal), start synchronously across many brain regions (generalized), or start as a focal seizure and then generalize (as with focal-to-bilateral tonicclonic seizures). As described in further detail below, there are many different epilepsy syndromes, classified by the International League Against Epilepsy primarily by whether the seizures are focal, generalized, combined focal-generalized, or unknown, together with behavioral manifestations, electroencephalographic and imaging signatures, and other clinical factors, including age of onset, family history, and probable etiology (Scheffer et al., 2017). Furthermore, seizures and epilepsy can arise from many different causes and etiologies, including genetic mutations, or can be acquired in response to a neural insult such as a fever, infection, stroke, or traumatic brain injury (Lucke-Wold et al., 2015; Pitkanen et al., 2016; Ramantani and Holthausen, 2017). Postinsult epilepsies often arise after a process of epileptogenesis, consisting of myriad neural circuit reorganization and functional changes in which a group of brain cells or a brain region converts from one that will not generate a seizure to one that can spontaneously (that is, without precipitation by an immediate trigger) produce a seizure, the electrical signal of which is referred to as ictal activity.

Boys, girls, men, and women of all ages across the human lifespan are affected by seizures and epilepsy. Current treatment options focus primarily on antiseizure drugs (ASDs), with the selection, number, and dosage depending on the type of epilepsy and the age of the patient. In some cases, typically in children, dietarybased therapies are used as adjunctive treatments in addition to ASDs (Martin-McGill et al., 2018). Unfortunately, a large proportion of patients (at least one-third) are refractory to current treatments (Kwan and Brodie, 2000; Kobau et al., 2008). Although resection of the tissue that is the seizure focus (the area from which the seizures arise) is an option for some patients, it is not feasible for others and can often produce adverse side effects. In addition, a variety of psychiatric, cognitive, and physiologic comorbidities are present at higher rates in people with epilepsy compared with the general population.

In the ongoing quest to identify cures for epilepsies, there is a growing appreciation that sex differences in underlying brain function and in the neurobiology of epilepsy are important factors that should be accounted for in the design and development of new therapies. This review is aimed at providing an overview of the current knowledge on sex differences in epilepsy and associated comorbidities, with particular emphasis on those aspects that should be informative for and taken into consideration in the development of new pharmacotherapies.

\section{A. Note on Terminology: Sex and Gender}

Although "sex" and "gender" are often used interchangeably, there are important distinctions between these two terms. As defined by the World Health Organization, "sex" refers to biologic and physical features, from genetic to physiologic to organismal, that are distinct and usually classified as male or female and largely determined by sex chromosomes. "Gender," however, refers to a psychosocial construct of norms, roles, and interactions typically classified as characteristics of men or women but culminating in an overall identification and self-perception of an individual along a spectrum of gender identities (Manandhar et al., 2018). A person may identify with a gender that is not the same as the biologic sex assigned at birth (transgender); therefore, it is erroneous to equate sex and gender. The study of epilepsy in transgender persons is a nascent area of research, and as such, there is an absence of epidemiologic studies in this population (Johnson and Kaplan, 2017). Therefore, at this point in time for the purposes of literature review, we must rely on the descriptions in clinical studies of the gender of subjects as men or women and operate under the supposition that this also reflects the respective sex. In addition, it is important to note that the term "gender" should not be applied to preclinical animal studies, as the gender identification of a given animal cannot be assessed meaningfully. Therefore, the proper usage of terminology in preclinical studies is to describe the sex of the animal (Torgrimson and Minson, 2005). As our goal in this review is to cohesively discuss both clinical and animal studies of epilepsy, we will use the term "sex" throughout for consistency.

\section{Sex Differences in Epilepsies and Comorbidities: Clinical Conditions and Animal Models}

The epilepsies, as a whole, are slightly more common in males as compared with females (McHugh and Delanty, 2008). This finding has been replicated in several epidemiologic studies (Hauser et al., 1993; Jallon et al., 1997, 1999, 2001; Dogui et al., 2003; Christensen et al., 2007; Adelow et al., 2009; Hesdorffer et al., 2011a; Fiest et al., 2017), although the difference tends to be small and, in some cases, of borderline or no significance. That said, in a populationbased study of the Danish National Hospital Register, arguably the largest sample available, a heightened male prevalence was present in most age groups (Christensen et al., 2007).

A variety of factors have been proposed to account for this difference, including lifestyle and environmental considerations. However, the epilepsies are a diverse group of conditions that differ in symptomology, etiology, and prevalence across sex. In the sections below, we first briefly review the human epidemiologic data and then describe relevant animal models of 1) generalized motor seizures, 2) generalized nonmotor (absence) seizures, and 3) focal seizures. We also refer the reader 
to several reviews of sex differences in human epilepsies (McHugh and Delanty, 2008; Savic, 2014).

\section{A. Generalized Motor Seizures}

In keeping with the current International League Against Epilepsy operational guidelines for classification of seizures and the epilepsies (Fisher et al., 2017), this category of seizure includes tonic-clonic (formerly known as "grand mal"), tonic, atonic, and myoclonic seizures.

1. Clinical Studies. Some studies have reported a greater rate of generalized tonic-clonic seizures in males (Hauser et al., 1993; Kishk et al., 2019), although other studies have found either no sex difference (Carlson et al., 2014) or increased generalized tonicclonic seizures in females (Mullins et al., 2007). The variability in these effects across studies may reflect relatively small sample sizes and/or differences in reporting across countries. Similarly, atonic seizures were more common in males in the Epilepsy Phenome/ Genome Project data set (Carlson et al., 2014). This finding differs from those regarding generalized genetic epilepsies, including juvenile myoclonic epilepsy, which has been reported to occur in females at higher rates (Kleveland and Engelsen, 1998; Christensen et al., 2005). Some X-linked syndromes, such as Rett syndrome, are more common in females (Fehr et al., 2011) because of high in utero or early life mortality in males; others, such as seizures in Fragile $\mathrm{X}$ syndrome, have been reported to be more common in males (BerryKravis et al., 2010). For some other early life epilepsies, such as infantile spasms, there are mixed reports, with some suggesting a higher prevalence in males than in females (Cowan et al., 1989; Luthvigsson et al., 1994; Pellock et al., 2010) and others finding no sex difference (Trevathan et al., 1999; Chen et al., 2004; Jia et al., 2018).

2. Animal Models. The animal models described in this section all display some degree of generalized tonic, clonic, tonic-clonic, or myoclonic seizure activity, although for many of the pharmacological models, the seizure phenotype is highly dose-dependent. We do not include common models of status epilepticus (SE) or other models of what have been referred to as "limbic" seizures in this section but rather discuss them in the context of focal seizures.

a. GABAergic chemoconvulsants. GABA antagonists are one of the most commonly families of chemoconvulsants in epilepsy research. Of this class of drugs, pentylenetetrazole (PTZ) remains a component of the National Institute of Neurological Disorders and Stroke-funded Epilepsy Therapy Screening Program (https://panache.ninds.nih.gov/CurrentModels.aspx). PTZ and the other GABA antagonists, in a dose-dependent manner, evoke absence-like generalized spike-andwave discharges (SWDs), clonic seizures, and generalized tonic-clonic seizures. Surprisingly, although these drugs (PTZ, picrotoxin, bicuculline, etc.) share a common target, they differ in terms of sex differences (Table 1).

The threshold for picrotoxin-induced generalized tonic-clonic seizures is higher in male than female rats (Pericic et al., 1985; Schwartz-Giblin et al., 1989). Similarly, the latency to picrotoxin-induced akinetic seizures is also longer in males than females (Tan and Tan, 2001). This sex difference is also evident in cats, with female cats displaying a greater frequency of spinal motor neuron discharge than males following picrotoxin (Pericic et al., 1986). In mice, males showed increased sensitivity to picrotoxin compared with females (Pericic et al., 1986). In addition, mortality rates after picrotoxin are greater in male mice than female mice (Pericic et al., 1986) and are elevated in proestrous compared with estrous rats (Tan and Tan, 2001). Sex hormones influence picrotoxin responses, with estradiol treatment increasing sensitivity to pictrotoxin in male rats (Pericic et al., 1996). By contrast, testosterone increases susceptibility in females and decreases susceptibility in males (Tan and Tan, 2001). Consistent with the picrotoxin effects, female rats display greater sensitivity to allylglycine-induced convulsive seizures than do male rats (Thomas and Yang, 1991). Thus, in rats, females are more sensitive to picrotoxin than males, a pattern that is reversed in mice.

Interestingly, the threshold for PTZ-evoked clonic seizures is $\sim 10 \%$ lower in male rats compared with female rats (Kokka et al., 1992); this finding is somewhat counterintuitive when compared with the data on picrotoxin given that these drugs share a similar mechanism of action (i.e., both are GABA receptor channel blockers). In mice, PTZ responses are greater in females (Medina et al., 2001), and female mice display lower thresholds for response (Min et al., 2013), which is generally consistent with the effects of picrotoxin. Chronic administration of PTZ produces a progressive worsening of seizure severity (i.e., a kindling effect).

TABLE 1

Sex differences in models of epilepsy and seizure induction

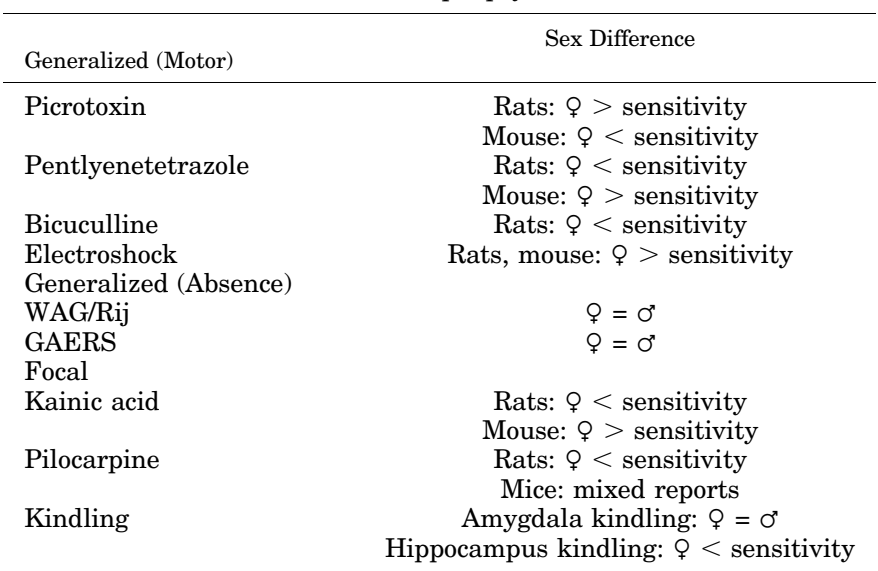


Male and female rats acquire PTZ kindling at similar rates despite differing sensitivities to acute PTZ (Haeri et al., 2016).

As with PTZ, the threshold for myoclonus, running/ bouncing clonus, and tonic hindlimb extension following intravenous bicuculline is lower in male rats compared with females (Finn and Gee, 1994; Pericic and Bujas, 1997). Similarly, males show lower thresholds than females to myoclonus, running/bouncing clonus, and tonic hindlimb extension induced by methyl-6,7-dimethoxy-4-ethyl-beta-carboline-3-carboxylate, a negative allosteric modulator of $\mathrm{GABA}_{\mathrm{A}}$ receptors (Finn and Gee, 1994).

b. $N$-methyl-D-aspartate. Injection of the glutamate receptor agonist N-methyl-D-aspartate (NMDA) in rat pups primed by gestational betamethasone exposure is a common model of infantile spasms, and in this model, sex differences in seizures are not evident (Chachua et al., 2011), a pattern consistent with the clinical literature.

c. Electroshock. As with chemoconvulsant models, maximal electroshock remains a vital part of the screening pipeline for antiseizure medications. The endpoint of this model, tonic hindlimb extension, is particularly relevant for tonic and tonic-clonic seizures.

Female rats display lower maximal electroshock thresholds than do male rats (Woolley et al., 1961; Kokka et al., 1992). Consistent with this finding, a comprehensive analysis by sex in 10 strains found that females displayed, on average, a 10\%-15\% lower threshold for electroshock-evoked minimal, maximal, and psychomotor seizures (Frankel et al., 2001).

d. Inbred genetic models. Two of the most well established genetically epilepsy-prone rat (GEPR) models of epilepsy are the GEPR-3 and GEPR-9 strains. In response to acoustic stimulation, GEPRs display wild running, bouncing clonus, and, depending on the substrain, tonic extension. Neither the GEPR-3 nor the GEPR-9 substrains display sex differences in the ontogeny of audiogenic seizures (Reigel et al., 1989). However, in both the -3 and -9 strains, the penetrance of the audiogenic phenotype is greater in females than males (Kurtz et al., 2001). Moreover, female GEPR-9s display shorter latencies to seizures and more severe seizure scores than do age-matched GEPR-9 males (Mishra et al., 1988a,b). Inhibitors of adenosine metabolism cause heightened mortality in females compared with male GEPR-9s (Kommajosyula et al., 2016). Similarly, in the GEPR-3 strain, females display shorter latencies to wild running than do matched males (Mishra et al., 1989) and greater anticonvulsant responses to transient receptor potential cation channel subfamily $\mathrm{V}$ receptor 1 antagonists than males (Cho et al., 2018).

The Ihara's Epilepsy Rat model displays a striking sex difference in penetrance; though essentially all male rats display tonic-clonic seizures, only $\sim 20 \%$ of females show similar responses (Amano et al., 1996). The Noda Epileptic Rat model also displays generalized tonicclonic seizures with a high penetrance $(>95 \%)$ in both sexes (Noda et al., 1998).

The El/Suz mouse (Suzuki and Nakamoto, 1982) is a selectively bred polygenic model of generalized epilepsy. These mice display handling-induced seizures and behavioral comorbidities (Bond et al., 2003; McFadyen-Leussis and Heinrichs, 2005) and are hyper-responsive to stress (Forcelli et al., 2007). Though the penetrance of the seizure phenotype does not differ as a function of stress in this strain (Leussis and Heinrichs, 2006), female El mice but not male El mice display increased cell density in the amygdala (Forcelli et al., 2007).

The DBA/1 inbred strain of mice has been used as a model of sudden unexpected death in epilepsy (SUDEP) (Faingold et al., 2010). In response to acoustic stimulation, these animals display tonic seizures, which end with hindlimb extension and respiratory arrest. Although the rate of SUDEP is higher in males than females in clinical populations (Hesdorffer et al., $2011 b$ ), the rate of SUDEP in DBA/1 mice is equivalent across sexes (Faingold and Randall, 2013).

$e$. Other genetic models. The explosion of genetic models of epilepsy over the last three decades makes a thorough characterization of effects difficult for several reasons. First, many models for the same "syndrome" exist, and in many cases, these models differ from one another. Second, differing genetic backgrounds of mice exert strong modulatory effects on seizure phenotype (Hawkins et al., 2016; Kang et al., 2018). Thus, only a few examples are provided below.

In the $\mathrm{Brd} 2^{+/-}$model of juvenile myoclonic epilepsy, males show reduced clonic seizure threshold, whereas females have reduced tonic-clonic threshold (Velíšek et al., 2011). Males and females also differ in open-field performance, with males displaying decreased anxietylike behavior compared with wild-type littermates and females displaying increased anxiety-like behavior (Chachua et al., 2014). In models of Dravet syndrome (e.g., $S c n 1 a^{+/-}$mice), there have been reports of females showing greater mortality than males (Niibori et al., 2020) as well as reports of no sex differences (Kang et al., 2018). Therefore, more comprehensive screening for sex differences across genetic models is clearly needed.

\section{B. Generalized Nonmotor Seizures (Absence Seizures)}

1. Clinical Studies. Absence seizures are particularly well studied in the context of childhood and juvenile absence epilepsy syndromes. These seizures are characterized by disrupted consciousness and generalized SWDs at a characteristic $3-\mathrm{Hz}$ frequency (Panayiotopoulos, 2008). Absence epilepsies have been reviewed elsewhere (Tenney and Glauser, 2013). Among the available clinical epidemiologic data for 
sex differences in epilepsy, those for absence epilepsy are stronger and generally more consistent than other epilepsy types. Specifically, multiple studies have reported childhood absence epilepsy and juvenile absence epilepsy both occur at higher rates in females compared with males (Hauser et al., 1993; Camfield et al., 1996; Waaler et al., 2000; Larsson and EegOlofsson, 2006; Mullins et al., 2007).

2. Preclinical Genetic Models. Sex differences in preclinical absence epilepsy models have been reviewed in detail previously (van Luijtelaar et al., 2014) and are summarized in brief here. Two of the most common models for absence epilepsy are the Wistar Albino Glaxo/Rijswijk (WAG/Rij) strain of inbred rats (van Luijtelaar and Coenen, 1986) and the Genetic Absence Epilepsy Rats from Strasbourg (GAERS) (Vergnes et al., 1982). Both of these strains display a high (near 100\%) penetrance of SWDs that have been proposed to model generalized nonconvulsive seizures in humans. In both these strains, unlike typical absence epilepsy, seizures increase in frequency with age. Although human absence epilepsy is more common in females than males, in the WAG/Rij rats, the SWD burden is the same across sexes (Coenen and Van Luijtelaar, 1987).

As in the WAG/Rij, in the GAERS, the penetrance and frequency of SWDs does not differ as a function of sex (van Luijtelaar et al., 2014). Though seizures do not differ, however, comorbid social behavior impairments do; female, but not male, GAERS display deficits in sociability (Henbid et al., 2017). By contrast, the Brown Norway rat strain also displays SWDs, albeit with a different penetrance than the other models. In these rats, the phenotype is more common in males than females (Jando et al., 1995). SWDs discharges have also been reported in wild-type Sprague-Dawley rats, with discharges emerging earlier in females than in males (Pearce et al., 2014).

In addition to the above rat strains, several mouse strains display absence-like seizures, including mice with deletion of the $\alpha 1$ subunit of the $\mathrm{GABA}_{\mathrm{A}}$ receptor (Arain et al., 2012), the stargazer mouse (Noebels et al., 1990), and mice lacking gria4 (Beyer et al., 2008). Though for these latter strains, to the best of our knowledge, sex differences have not been carefully examined, both the stargazer and gria4 models show absence seizures in both sexes. In $\alpha 1$ subunit of the $\mathrm{GABA}_{\mathrm{A}}$ receptor-knockout mice, sex differences depend on genetic background of the strain; in animals on a C57 background, females display a greater incidence of absence seizures than males but the incidence does not differ as a function of sex when the animals are on a DBA/2J background (Arain et al., 2012).

3. Pharmacological Models. Inhibition of cholesterol synthesis in the first month of life produces a permanent alteration in brain development that leads to the emergence of atypical SWDs in rats. Sex differences in this model emerge before puberty, with females showing two- to threefold increases in SWD duration compared with males (Persad et al., 2002). Consistent with the enhanced sensitivity of females in this model, females show profound downregulation of $\alpha 1$ and $\gamma 2$ subunits of the $\mathrm{GABA}_{\mathrm{A}}$ receptor in the somatosensory thalamus, whereas males show no significant change (Li et al., 2007).

The gamma hydroxybutyrate and gammabutyrolactone (GBL) models of absence epilepsy are acute, druginduced models with cross-species validity (Venzi et al., 2015). In the GBL model, males display a greater seizure burden than females. The increased sensitivity in males is primarily due to longer discharge duration as compared with an increase in the frequency of discharges (Santos et al., 2018).

\section{Focal Seizures and Temporal Lobe Epilepsy}

1. Clinical Studies. Though some studies have reported greater incidence of focal seizures in males (Hauser et al., 1993), others have reported similar occurrence of focal seizures in both sexes (Manford et al., 1992). This pattern also holds true for temporal lobe epilepsy (TLE), with reports of increased frequency in males (Hauser and Kurland, 1975), no differences as a function of sex in symptomatic TLE (Christensen et al., 2005), and increased cryptogenic cases of TLE in females (Christensen et al., 2005). Focal seizure semiology has also been reported to differ by sex, with one report suggesting that autonomic, visceral, epigastric, and psychic symptoms, as well as déjà vu, are more common in females. Many other symptoms, however, displayed no difference between sexes in this study (Carlson et al., 2014). This profile differed from that observed in a smaller study, which found increased occurrence of isolated auras in females but no other sex differences (Janszky et al., 2004). Beyond semiology, it has also been suggested that the pattern of ictal spread can differ as a function of sex. For example, in a small study incorporating both clinical electroencephalographic and postictal positron emission tomography imaging, both hypometabolism and ictal spread to the ipsilateral frontal cortex were reported to be more common in males, whereas hypometabolism and ictal spread in contralateral temporal cortex was more common in females (Savic and Engel, 1998). Consistent with this observation, a more recent voxel-based morphometry study of 120 persons with TLE reported greater predominance of temporal lobe changes in females and higher rates of frontal lobe changes in males (Santana et al., 2014). Although these findings rely on smaller samples than large epidemiologic studies, they are intriguing and merit follow-up efforts.

Although status epilepticus (SE) is not confined to TLE, we include it in this section because it is one of the most common models used to induce TLE in rodents (see below). Clinical data regarding sex differences in SE are varied, with some studies reporting higher rates of $\mathrm{SE}$ 
in males compared with females (DeLorenzo et al., 1996; Hesdorffer et al., 1998; Coeytaux et al., 2000; Knake et al., 2001) and others reporting a slight female preponderance (Vignatelli et al., 2003, 2005; Leitinger et al., 2019).

2. Kainic Acid. Kainic acid (KA) is a glutamate receptor agonist and has, for the past three decades, been commonly used in modeling TLE (Ben-Ari et al., 1979). KA, when administered either intracerebrally or systemically, produces repeated "limbic" seizures characterized by clonus of the face and forelimbs as well as loss of postural control. Prolonged seizure activity (i.e., SE) triggered by KA results in the emergence of spontaneous recurrent seizures in the days to weeks following the initial insult.

Female Wistar rats display shorter latencies but fewer limbic seizures after KA administration (MejiasAponte et al., 2002). Unlike rats, female C57BL/6 mice display greater sensitivity to KA than males. This is marked by greater mortality, more severe behavioral seizures, and more neurodegeneration (Zhang et al., 2008).

In the intrahippocampal KA model of TLE in mice, males show greater seizure severity, greater hippocampal cell loss, increased hippocampal gliosis, poorer survival, and more severe long-term memory deficits than females ( $\mathrm{Li}$ and $\mathrm{Liu}, 2019$ ). Another report shows that across three strains of mice, intrahippocampal KA results in faster onset of spontaneous seizures in females than in males; indeed, in females, there is no obvious latent period (Twele et al., 2016). Electrographic seizure patterns in the model also differ as a function of sex. Males display frequent focal hippocampal discharges in addition to convulsive seizures and nonconvulsive spike-and-wave discharges. By contrast, focal hippocampal discharges are absent in females despite a similar rate of convulsive seizures and spike-and-wave discharges (Twele et al., 2016).

3. Pilocarpine. Like KA, treatment with the muscarinic agonist, pilocarpine (or alternatively lithium and pilocarpine), produces repetitive seizures and SE (Honchar et al., 1983; Turski et al., 1983). As with KA, this model also produces spontaneous recurrent seizures after a period of epileptogenesis (Leite et al., 1990).

In the lithium-pilocarpine model, female rats display longer latencies to seizure onset compared with male littermates (Persinger et al., 1988; Peternel et al., 2009). Similar results have been reported after pilocarpine alone (Mejias-Aponte et al., 2002), with females displaying longer latency to seizures, a lower rate of SE, and a lower rate of mortality. In addition to lower susceptibility to pilocarpine-evoked status, females, as compared with males, display reduced lipid peroxidation and reduced glutathione peroxidase activity after pilocarpine (Peternel et al., 2009).
In mice, there have been mixed reports, with some showing equivalent susceptibility to pilocarpine-induced SE between sexes (Muller et al., 2009; Oliveira et al., 2015) and another showing a greater rate of status in males than in females across the lifespan (Buckmaster and Haney, 2012). Both of these studies reported equivalent survival between sexes. However, it is clear that strain, and even substrain, differences can influence seizure susceptibility, which may account for these disparate findings (Muller et al., 2009).

4. Kindling. Originally described in the late 1960 s, kindling is a process by which repeated stimulation of the brain produces permanent reductions in seizure threshold (Goddard et al., 1969). Kindling can be accomplished through electrical stimulation of a variety of brain regions (most commonly amygdala or hippocampus), through repeated chemoconvulsant treatment, and even through repeated electroshock seizures. In electrical kindling models, the threshold current needed to produce an epileptiform pattern of activity that outlasts the stimulation (i.e., an afterdischarge), is a common dependent measure. Across models, behavioral seizure severity is also a common measure (Racine, 1972).

In the amygdala kindling model, female rats display a greater reduction in afterdischarge threshold over the course of kindling than males and display a greater response rate to phenytoin treatment (Ebert et al., 1994; Borowicz et al., 2003). In response to callosal stimulation, female rats kindle at a similar rate to male rats but display a more rapid dendritic reorganization and simplification in the neocortex than males (Teskey et al., 1999). Pharmacological kindling through repeated administration of subconvulsant doses of nicotine (Bastlund et al., 2005) is faster in female rats than male rats, and females show greater kindlingassociated oxidative stress responses throughout hippocampus, cortex, and striatum (Gomes et al., 2013). Unlike nicotine kindling, repeated ethanol withdrawal, which also produces a kindling-like phenomenon, is only evident in males. Interestingly, the protective effect in females in the repeated ethanol withdrawal model is independent of ovarian hormones (Veatch et al., 2007). Sex differences are also apparent in epileptogenic seizures produced from hippocampal kindling, with males exhibiting a significantly faster progression to a fully kindled state as well as greater behavioral and electrographic seizure activity (Reddy et al., 2019).

Corneal (electroshock) kindling in mice is an alternative to traditional kindling methods (e.g., amygdala or hippocampal kindling). In this model, kindling is induced by repeated transcorneal minimal electroshock seizures (Matagne and Klitgaard, 1998). Although the ultimate rate of kindling in this model does not differ as a function of sex, female mice are more sensitive to the initial stimuli and show an early emergence 
of behavioral seizures than do males (Potschka and Loscher, 1999).

\section{Comorbidities}

\section{Psychiatric and Affective Disorders.}

a. Clinical studies. Psychiatric comorbidities are common in epilepsy (Josephson and Jetté, 2017) and estimated to occur in $25 \%-50 \%$ of patients (LaFrance et al., 2008), although higher incidence has been reported, with the highest prevalence observed in association with TLE (Bragatti et al., 2010) and drugresistant epilepsy (depression $=55 \%$; anxiety $=28.7 \%$ ) (Kwon and Park, 2014; Jansen et al., 2019). The incidence of depression in epilepsy has been reported in $11 \%-80 \%$ of patients compared with $4.9 \%-17 \%$ in the general population (LaFrance et al., 2008). Similarly, the incidence of anxiety is higher in patients with epilepsy (15\%-20\%) (Brandt et al., 2010) compared with $5 \%-7 \%$ in the general population (LaFrance et al., 2008; Kanner, 2011; Kwon and Park, 2014; Brandt and Mula, 2016; Salpekar and Mula, 2018). It is important to note that the incidence of psychiatric comorbidities is even more prevalent in epilepsy as compared with other chronic illnesses such as cancer, diabetes, or asthma (Hermann et al., 1996). Furthermore, patients with psychiatric disorders, such as depression, are at a higher risk for developing epilepsy (Josephson and Jetté, 2017). Therefore, it is thought that psychiatric disorders and epilepsy may share a common underlying pathophysiological mechanism (Kanner, 2003).

Despite the high incidence of psychiatric comorbidities in epilepsy and the well established sex differences in anxiety and depression in the general population (Altemus et al., 2014), few studies have investigated sex differences in psychiatric comorbidities in epilepsy. The incidence of anxiety and depression is twice as common in females than in males in the general population (Altemus et al., 2014), and this is also true for patients with epilepsy. A retrospective study found that the incidence of depression was $15.5 \%$ in males and $26.8 \%$ in females with epilepsy (Chan et al., 2015). Similarly, anxiety disorders were found in $9.65 \%$ of males and $17.4 \%$ in females with epilepsy (Chan et al., 2015). These few studies suggest that there may be sex differences in psychiatric comorbidities in epilepsy. This represents a significant concern for epilepsy treatment given that psychiatric comorbidities are associated with worse epilepsy outcomes (Josephson and Jetté, 2017). Further studies are required to understand the extent of sex differences in psychiatric comorbidities in epilepsy and the impact on epilepsy outcomes.

b. Animal models. Similar to clinical studies, the majority of studies investigating sex differences in psychiatric disorders in experimental epilepsy models have focused solely on males, leaving us with limited information regarding sex differences in psychiatric comorbidities in preclinical epilepsy models. Existing studies suggest that there are sex differences in seizures in experimental animals as highlighted above [for review, see Scharfman and MacLusky (2006)]. In the few studies that have examined associated psychiatric comorbidities, increased anxiety- and depression-like behaviors have been observed in numerous experimental epilepsy models, including both genetic (Aguilar et al., 2018) and acquired epilepsy models (Mazarati et al., 2008; Becker et al., 2015; Hooper et al., 2018; Zeidler et al., 2018). However, none of these studies to date have demonstrated sex differences in anxiety- or depression-like behaviors in epilepsy models, although only a few have looked. In fact, Zeidler et al. (2018) state that no significant sex differences in depression- or anxiety-like behaviors were observed in chronically epileptic mice in the intrahippocampal $\mathrm{KA}$ model of epilepsy but provide the disclaimer that their experiments were not designed to test for sex differences. One study demonstrated subtle sex differences in behavior in a genetic epilepsy model, including differences in head dips off the open arms, an effect primarily driven by females (Aguilar et al., 2018). Some outcome measures also showed a main effect of sex but not a strain-bysex interaction (Aguilar et al., 2018). Although overall these findings do not support sex differences in psychiatric comorbidities in epilepsy by using traditional behavioral tests and assessments of standardized outcome measures, there is an increased appreciation that males and females may exhibit different behaviors in these tests, and care should be taken in how to properly interpret these data (Shansky, 2018). Furthermore, the limited information on this subject is evident from this review, and additional studies are required for a better understanding of the mechanisms contributing to sex differences in comorbid psychiatric disorders in epilepsy.

2. Reproductive Endocrine Disorders and Sexual Dysfunction.

a. Clinical studies. Both men and women with epilepsy are at increased risk for reproductive endocrine disorders compared with the general population (Herzog, 2008; Koppel and Harden, 2014). Up to $90 \%$ of men with epilepsy may present semen abnormalities, including low sperm count or abnormal sperm morphology or motility, and a population-based study quantified a $40 \%$ lower birth rate in men with epilepsy (Taneja et al., 1994; Artama et al., 2004; Herzog, 2008). It should be noted, however, that lower birth rates can be affected by many social factors (Mameniškienè et al., 2017) and are not necessarily a direct representation of fertility. Furthermore, changes in semen quality and sperm count are highly associated with the use of certain enzyme-inducing ASDs, such as valproic acid, carbamazepine, and oxcarbazepine (Roste et al., 2003; Isojarvi et al., 2004; Hamed et al., 2015; Ocek et al., 2018) and may thus be independent of epilepsy-induced 
changes. In women, common ailments include anovulatory menstrual cycles, oligomenorrhea (irregular cycle periodicity and infrequent menstruation), polycystic ovaries, and polycystic ovarian syndrome (PCOS) (Cummings et al., 1995; Bauer et al., 1998, 2000a,b; Morrell et al., 2002; Herzog et al., 2003a; Lofgren et al., 2007). Specifically, an estimated $10 \%-25 \%$ of women with TLE are diagnosed with PCOS compared with $4 \%-6 \%$ of the general population (Webber et al., 1986; Herzog and Schachter, 2001), and another $12 \%$ of women with TLE develop hypothalamic amenorrhea compared with $1.5 \%$ of the general population (Herzog et al., 1986b). Although much focus has been placed on these comorbidities in the context of TLE and other focal epilepsies, several studies have also documented these comorbidities in women with generalized epilepsy disorders (Morrell et al., 2002; Lofgren et al., 2007). In addition, although ASD treatment is highly associated with development of reproductive endocrine problems in both men and women (for examples, see Isojarvi et al., 1993, 2004; Murialdo et al., 1997; Harden, 2005a; Ocek et al., 2018), several lines of evidence indicate that seizure activity itself is a primary driver of these comorbid issues. In particular, multiple groups have documented a pattern in which women with TLE and seizures originating on the left side of the brain (i.e., leftsided TLE) show increased rates of PCOS, whereas women with TLE seizures originating in the right hemisphere (right-sided TLE) exhibit higher rates of hypothalamic amenorrhea (Herzog, 1993; Drislane et al., 1994; Herzog et al., 2003a,b; Kalinin and Zheleznova, 2007; Quigg et al., 2009). The findings indicate that distinct reproductive endocrine disorders may be related to the area of the brain primarily affected by seizure activity and suggest that specific neural pathways act as substrates to drive altered endocrine functions.

Investigations of the pathophysiology of reproductive endocrine comorbidities of epilepsy have naturally focused on the hypothalamic-pituitary-gonadal (HPG) axis, which links the brain to the control of fertility and reproduction in all mammalian species. Gonadotropinreleasing hormone $(\mathrm{GnRH})$ neurons in the hypothalamus release the $\mathrm{GnRH}$ peptide to stimulate gonadotrope cells of the anterior pituitary to produce the gonadotropin hormones, luteinizing hormone (LH), and folliclestimulating hormone (FSH). In both sexes, LH and FSH act on the gonads to induce gametogenesis and production of sex steroid hormones. $\mathrm{LH}$ and FSH can be readily detected in the peripheral bloodstream. Therefore, measurements of these hormones are commonly used as surrogate readouts of activity at the hypothalamic level of the HPG axis in humans, including in patients with epilepsy. An important feature of both LH and FSH is that these hormones are released in intermittent boluses, or pulses. Therefore, the pattern of pulsatility of these hormones as well as changes in mean basal levels are important indicators of disruptions to the hypothalamic-pituitary axis in people with epilepsy. In brief, several studies of both women and men with epilepsy have documented changes in the frequency of LH pulses (Meo et al., 1993; Drislane et al., 1994; Quigg et al., 2002; Herzog et al., 2003a), although others did not find a difference in LH pulsatility (Murialdo et al., 1995). Furthermore, impaired LH response to exogenous GnRH treatment is also commonly observed in both women and men with epilepsy (Herzog et al., 1982; Bilo et al., 1988; Murialdo et al., 1995), along with changes in mean LH or FSH levels (Bilo et al., 1988; Meo et al., 1993; Morrell et al., 2002; Herzog et al., 2003a). These changes in pituitary gonadotropin levels suggest that activity at the hypothalamic level, as well as further upstream in the brain, is altered such that pituitary response to $\mathrm{GnRH}$ and/or gonadotropin synthesis and release are commonly affected in both women and men with epilepsy, particularly TLE. These pathophysiological changes are challenging to assess in human patients but are beginning to be addressed in animal models.

As described in further detail below, the sex steroid hormones estradiol, progesterone, and testosterone exert strong effects on neural function with major implications for seizure activity. Therefore, disruptions to normal patterns of sex steroid synthesis and release can have profound impacts on seizure control. In this regard, it is notable that both women and men with epilepsy commonly show changes in circulating levels of these hormones. Although these changes often arise as side effects of treatment with ASDs, particularly valproic acid (Isojarvi et al., 1993, 2004; Harden, 2005a; Roste et al., 2005; Isojarvi, 2008; Ocek et al., 2018), epilepsy and seizure activity have also been independently associated with changes in hormone levels, particularly regarding testosterone. In men, for example, decreased testosterone has been documented in men with TLE, with recovery to normal levels often seen after temporal lobe resection and improved seizure control (Bauer et al., 2000c, 2004). It should be noted, however, that not all studies have found changes in testosterone in male patients (Mikkonen et al., 2004). Furthermore, testosterone may be lower in men with TLE compared with men with seizure foci outside of the temporal lobe (Bauer et al., 2004), suggesting specific etiologies related to downstream hormone changes dependent on the neural circuits primarily affected by the seizure activity. Conversely, elevated testosterone is often observed in women with TLE (Herzog et al., 2003a) or idiopathic generalized epilepsy (Lofgren et al., 2007). Particularly interesting findings were that women with left-sided TLE showed higher testosterone compared with women with right-sided TLE (Herzog et al., 2003a) and that women with right-sided TLE showed significantly decreased estradiol levels compared with women with left-sided TLE (Herzog et al., 2003b). 
These results further suggest that downstream hormone changes can reflect impairments and disruption to specific neural circuits.

Another pituitary hormone critical to proper regulation of HPG axis function is prolactin (PRL), which is produced under the control of dopaminergic synaptic inputs projecting from the hypothalamic arcuate nucleus into the posterior pituitary. This direct synaptic connection is thus anatomically poised to provide an uninterrupted link between seizure activity in the brain and altered pituitary PRL release. Because elevated PRL levels suppress the GnRH-LH axis, hyperprolactinemia can be another mechanism of impaired reproductive endocrine function in patients with epilepsy. With respect to changes in PRL in women with epilepsy, some studies have documented increased levels (Bilo et al., 1988), whereas others have not found baseline differences (Dana-Haeri et al., 1984; Herzog et al., 2003a). Acute postictal increases in prolactin have also been reported in women with epilepsy (Collins et al., 1983; Dana-Haeri et al., 1983; Pritchard et al., 1985). Approximately 10\% of men with TLE may show signs of hyperprolactinemia (Herzog et al., 1986a), although other studies have documented acute increases in PRL immediately after seizure activity without a change in mean levels (Abbott et al., 1980; Collins et al., 1983; Dana-Haeri et al., 1983; Pritchard et al., 1985; Quigg et al., 2002). Still other studies documented similar postictal increases in PRL, but the sex of the subjects was not specified (Trimble, 1978; Sperling et al., 1986). Therefore, seizure-associated changes in PRL levels may be seen in both men and women with epilepsy, particularly TLE. Indeed, acute measurement of serum PRL postictally has been suggested as a possible diagnostic tool to distinguish epileptic seizures from psychogenic nonepileptic seizures (Chen et al., 2005a).

In addition to impairments of reproductive endocrine systems, many men and women with epilepsy also complain of sexual dysfunction. Although some studies have failed to find higher rates of such complaints in people with epilepsy (Jensen et al., 1990), others have documented a variety of symptoms [for comprehensive reviews, see Harden (2005b), Luef and Madersbacher (2015)]. For example, several studies have documented hyposexuality, decreased sexual drive, and lower arousability in substantial proportions of men and women with epilepsy (Demerdash et al., 1991; Christianson et al., 1995; Murialdo et al., 1995; Morrell and Guldner, 1996; Daniele et al., 1997; Duncan et al., 1997; Silveira et al., 2001; Baird et al., 2003; Kuba et al., 2006; Henning et al., 2019). Furthermore, deficits in arousability, genital blood flow, and erectile function appear to reflect physiologic impairments (Morrell et al., 1994; Guldner and Morrell, 1996; Morrell and Guldner, 1996). Disproportionate rates of sexual dysfunction observed in patients with right-sided TLE compared with leftsided TLE also suggest primary neural components drive these comorbidities (Daniele et al., 1997; Herzog et al., 2003b) in addition to more frequent observations of temporal lobe seizure foci in women with epilepsy that exhibit sexual dysfunction compared with patients that do not exhibit the comorbidity (Demerdash et al., 1991). It should be noted, however, that sexual dysfunction can also be associated with ASD treatment (Herzog et al., 2005; Luef and Madersbacher, 2015), although some studies have not observed such an effect (Henning et al., 2019). In summary, various presentations of sexual dysfunction are commonly observed in both men and women with epilepsy.

b. Animal models. The investigation of reproductive endocrine comorbidities of epilepsy is one of the few areas of preclinical research in which the studies investigating female animals far outnumber those examining males. This is primarily due to the commonalities between the estrous cycle of female rodents and menstrual cycle in humans [Fig. 1; see also Fig. 2 in Scharfman and MacLusky (2014b)] such that disruptions to the estrous cycle are useful experimental models with which to investigate the pathophysiological mechanisms of reproductive endocrine disorders in epilepsy. In this regard, female rodents tested in various models of epilepsy have also shown high propensity for developing disrupted estrous cycles and other indicators of reproductive endocrine dysfunction. For example, female Wistar rats tested in the intrahippocampal KA model of TLE were found to spend decreased time in the stages of proestrus and estrus and increased time in metestrus (Amado et al., 1987). In recent studies examining female mice in a similar intrahippocampal KA model, prolongation of estrous cycle period, typically characterized by more time spent in diestrus, was observed in the majority of mice ( $\mathrm{Li}$ et al., 2016, 2018). Furthermore, these differences did not appear for at least 6 weeks after the KA injection, indicating that it was the chronic epileptic condition, and not the acute effects of KA excitotoxicity, that drove the cycle disruption ( $\mathrm{Li}$ et al., 2016). In studies employing the pilocarpine post-SE model of TLE, Wistar rats showed more time spent in diestrus from 2 to 6 weeks after injection (Amado and Cavalheiro, 1998), and Sprague-Dawley rats showed a variable response, with one-third showing immediate cessation of cycling after pilocarpine-induced SE, one-third developing irregular cycles over time, and the remaining animals maintaining regular cyclicity (Scharfman et al., 2008). Disrupted estrous cycles have also been described in pilocarpinetreated mice (Fawley et al., 2012). Lastly, amygdala kindling models have also been linked with estrous cycle disruption, producing increased time in estrus and/or decreased time in diestrus in Sprague-Dawley and Wistar rats in some studies (Edwards et al., 1999d; Pan et al., 2013) and cycle period lengthening without induction of persistent estrus in others (Hum et al., 2009). In summary, these studies indicate that disruptions to the 
A
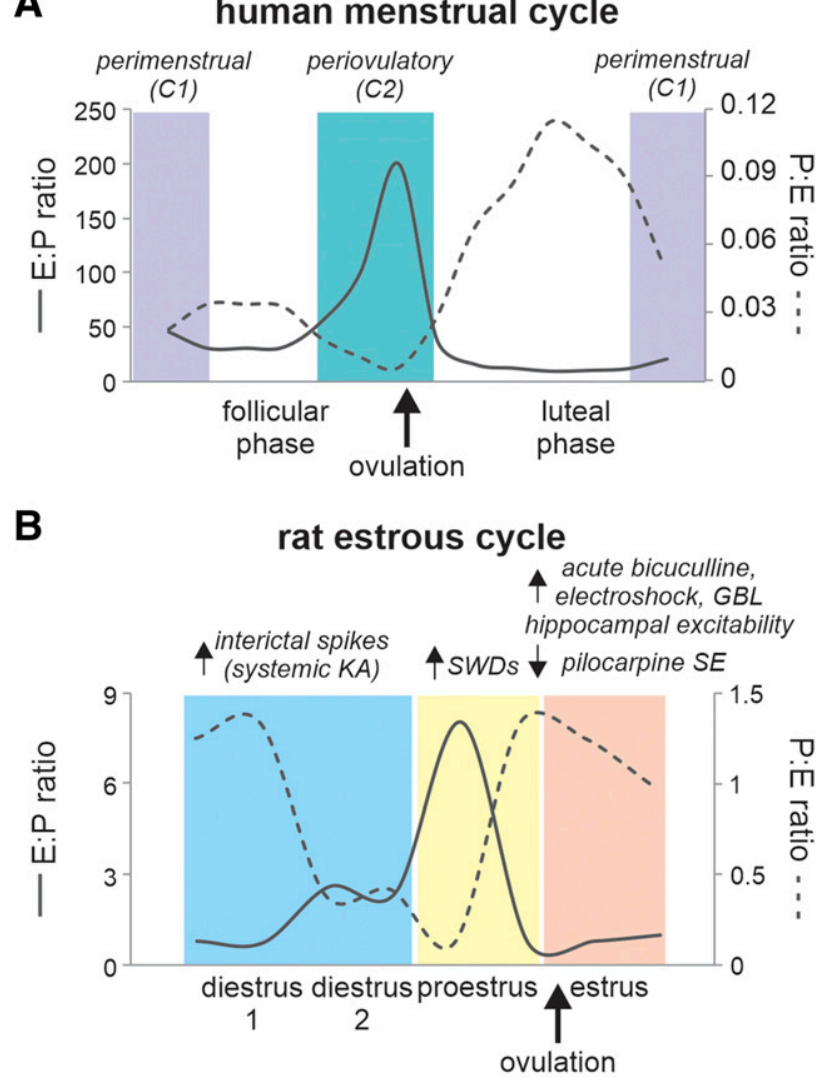

C

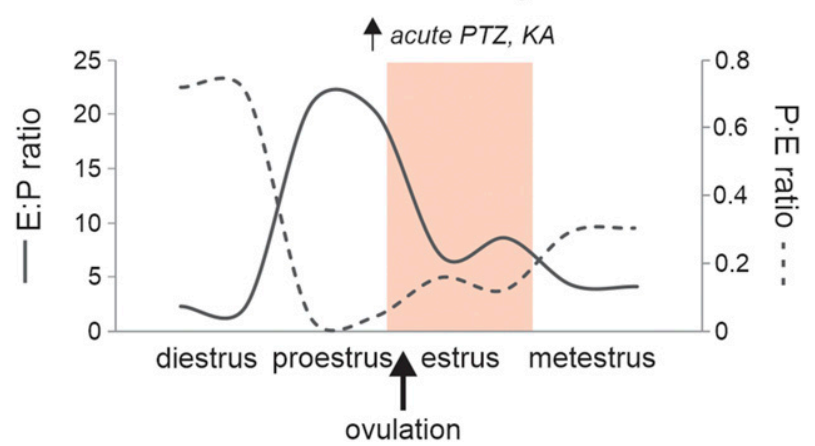

Fig. 1. Changes in seizure susceptibility associated with fluctuations in ratios of estradiol $(\mathrm{E}, \mathrm{pg} / \mathrm{ml})$ and progesterone $(\mathrm{P}, \mathrm{ng} / \mathrm{ml})$ levels in the human menstrual and rodent estrous cycles. (A) E:P (solid line) and P:E (dashed line) ratios in the human menstrual cycle and associated catamenial seizure clustering. Hormone data are adapted from Thorneycroft et al. (1971). See section III. Catamenial Epilepsy: Fluctuations in Seizure Occurrence across the Menstrual Cycle for discussion of catamenial seizure clustering. (B) E:P and P:E ratios in the rat estrous cycle. Hormone data are adapted from Smith et al. (1975). (C) E:P and P:E ratios in the mouse estrous cycle. Hormone data are adapted from Walmer et al. (1992). See section IV.B.1. Estrous CycleAssociated Changes in Seizure Susceptibility for discussion of changes in seizure susceptibility associated with the estrous cycle in rats and mice.

estrous cycle are commonly observed in rodent models of epilepsy.

Changes in pituitary gonadotropin ( $\mathrm{LH}$ and FSH) release or content, as observed in human patients, have also been documented in several rodent models of chronic epilepsy and acute seizure induction in both males and females (Bhanot and Wilkinson, 1982; Fujii et al., 1984; Amado and Cavalheiro, 1998), although changes in LH pulsatility patterns have not yet been tested in either sex. These changes appear to be at least partially due to paroxysmal activity in limbic structures, as several studies have shown changes in $\mathrm{LH}$ and/or FSH release following electrical stimulation of hippocampus and/or amygdala in both male and female animals (Velasco and Taleisnik, 1969; Gallo et al., 1971; Kawakami et al., 1973a,b).

The major advantage of animal models is increased direct access to the hypothalamic components of the HPG axis, particularly the GnRH neurons. In this regard, earlier studies limited to immunocytochemical staining for the GnRH peptide yielded conflicting results, with decreased GnRH immunoreactivity found in female rats after intra-amygdalar injection of KA or systemic pilocarpine induction of SE (Amado et al., 1993; Friedman et al., 2002) but no difference in $\mathrm{GnRH}$ staining in pilocarpine-injected female mice (Fawley et al., 2012). A recent study, however, provided the first direct documentation of functional changes in $\mathrm{GnRH}$ neuron activity and excitability, showing that in female mice, the rate and pattern of $\mathrm{GnRH}$ neuron firing was altered in the intrahippocampal KA model of TLE and that the direction of change in KA-injected mice compared with controls shifted from diestrus to estrus. Specifically, GnRH neurons from KA-injected mice showed higher firing on diestrus and suppressed firing on estrus, and these differences were most profound in the mice that concomitantly showed prolonged cycle length. Moreover, male mice tested in the same model showed a more modest effect, with only a subset of GnRH neurons (those with cell bodies in the medial septum) displaying elevated firing activity ( $\mathrm{Li}$ et al., 2018) (Fig. 2).

As in human patients with epilepsy, several animal studies have documented changes in circulating levels of the sex steroids in preclinical models of TLE, with variations dependent on the species and specific epilepsy induction model (Table 2). For example, amygdala-kindled female Wistar rats that became acyclic developed higher baseline estradiol levels along with higher estradiol and testosterone levels following progesterone treatment (Edwards et al., 1999d). Decreased progesterone levels were also documented in female rats tested in the intrahippocampal KA model of TLE (Amado et al., 1987). Sprague-Dawley rats treated in the pilocarpine post-SE model of TLE, however, did not show differences in estradiol or progesterone when measured on diestrus but did show elevated testosterone (Scharfman et al., 2008), whereas Wistar rats tested in the pilocarpine model displayed increased estradiol and decreased progesterone (Amado and Cavalheiro, 1998). By contrast, in a recent study using the intrahippocampal KA model of TLE in female mice, the pattern of change in estradiol or progesterone levels as measured 2 months after KA injection changed with 

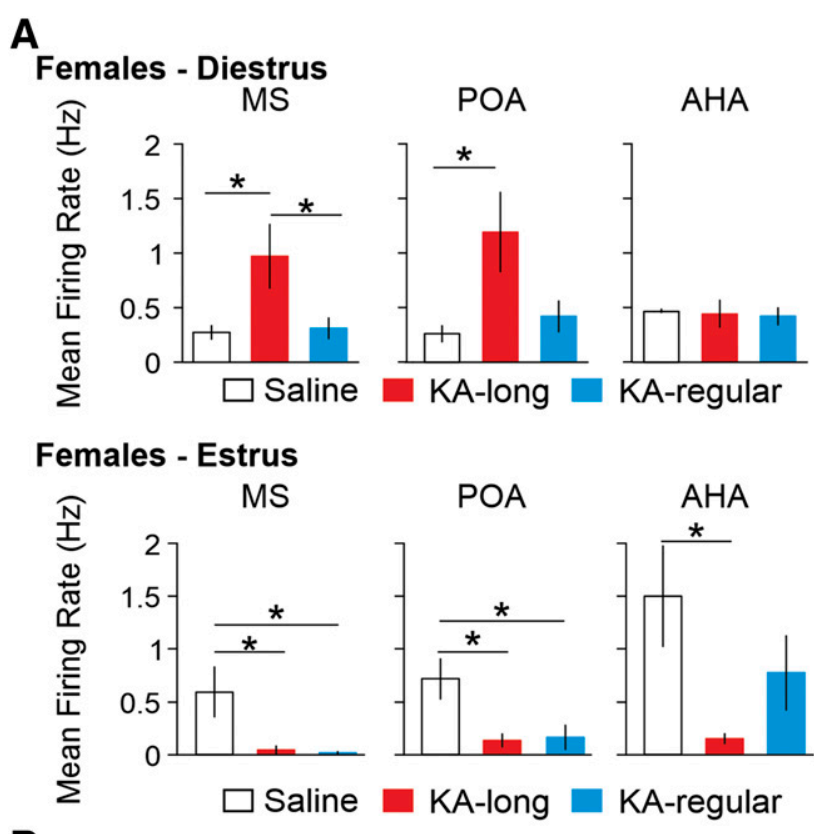

B

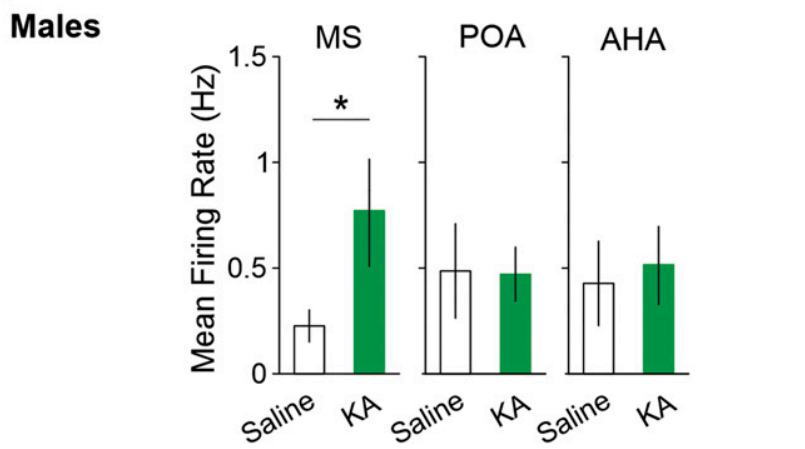

Fig. 2. Sex differences in impacts of epilepsy on GnRH neuron firing activity. Mean \pm S.E.M. for mean firing rate of $\mathrm{GnRH}$ neurons from saline-injected controls (white bars) and KA-injected female mice recorded on diestrus and on estrus (A) and male mice (B). KA-injected females are divided into KA-long (red bars) and KA-regular (blue bars) groups based on estrous cycle length (long $=\geq 7$ days, regular $=4-6$ days). Cells are classified based on anatomic location of somata in medial septum (MS), preoptic area (POA), and anterior hypothalamic area (AHA). Adapted from Li et al. (2018).

estrous cycle stage and depended on whether the mice developed prolonged, disrupted estrous cycles. Specifically, progesterone levels were suppressed in KAinjected mice that developed long cycles but not in
KA-injected mice that retained normal cycle periodicity, and this pattern was observed on both diestrus and estrus. Regarding estradiol, however, no differences were observed between groups in levels of this hormone on diestrus, but KA-injected mice, independent of estrous cycle period, displayed elevated levels compared with controls ( $\mathrm{Li}$ et al., 2018). With respect to male animals, in one study, amygdala-kindled rats appeared to show increased testosterone, but acute maximal electroshock-induced seizures transiently decreased testosterone levels (Edwards et al., 1999a). These findings suggested that focal and generalized seizures may have different downstream impacts on testosterone production and/or metabolism. Male mice treated in the intrahippocampal KA model of TLE, however, did not show a change in testosterone levels when measured 2 months after KA injection (Li et al., 2018). So far, PRL has received less attention in studies of animal models of epilepsy, with conflicting reports of higher PRL levels described in amygdala-kindled female rats (Edwards et al., 1999d), decreased levels observed in male rats following acute electrical stimulation in the amygdala (Kawakami et al., 1973a), and no change observed in pilocarpine-treated female rats (Scharfman et al., 2008). In summary, although the specific directions and degrees of change in sex steroid levels may display species differences and vary across epilepsy models, these effects may have important implications for understanding and interpreting features of epileptiform activity that are both distinct between and common to male and female animals.

To date, sexual dysfunction in animal models of epilepsy has received less investigatory emphasis than reproductive endocrine disorders. In one study, male cats displayed reduced sexual behavior for at least 6 months following intra-amygdalar injection of aluminum hydroxide to induce focal epilepsy (Feeney et al., 1998). In studies using the pilocarpine post-SE model of TLE in Wistar rats, males showed longer latency to initiate sexual activity and reduced numbers of mounts and intromissions, and females displayed reduced sexual interest in a male rat (proceptivity) and suppressed receptivity (readiness to allow copulation as exhibited by the lordosis response) following estradiol

TABLE 2

Summary of observed changes in circulating sex steroid levels in various rodent models of TLE

\begin{tabular}{|c|c|c|c|c|}
\hline $\begin{array}{l}\text { TLE model } \\
\text { Amygdala kindling }\end{array}$ & Species & Estradiol & Progesterone & Testosterone \\
\hline Male & Rats & - & - & $\uparrow$ Edwards et al., 1999a \\
\hline Female & Rats & $\uparrow$ Edwards et al., 1999c & - & - \\
\hline $\begin{array}{l}\text { Systemic pilocarpine } \\
\text { Female }\end{array}$ & Rats & $\begin{array}{c}\uparrow \text { Amado and Cavalheiro, } 1998 \\
\leftrightarrow \text { Scharfman et al., } 2008\end{array}$ & $\begin{array}{c}\downarrow \text { Amado and Cavalheiro, } 1998 \\
\leftrightarrow \text { Scharfman et al., } 2008\end{array}$ & $\uparrow$ Scharfman et al., 2008 \\
\hline $\begin{array}{l}\text { Intrahippocampal KA } \\
\text { Male } \\
\text { Female }\end{array}$ & $\begin{array}{l}\text { Mice } \\
\text { Rats } \\
\text { Mice }\end{array}$ & $\begin{array}{c}- \\
-\overline{-} \\
\uparrow \text { (Estrus) Li et al., } 2018\end{array}$ & $\begin{array}{c}- \\
\downarrow \text { Amado et al., } 1987 \\
\downarrow \text { (Diestrus and estrus) Li et al., } 2018\end{array}$ & $\begin{array}{c}\leftrightarrow \text { Li et al., } 2018 \\
- \\
-\end{array}$ \\
\hline
\end{tabular}


and progesterone priming treatment sufficient to induce estrus in control rats (Andersen et al., 2012; Alvarenga et al., 2013). Therefore, in line with the common observation of hyposexuality in people with epilepsy, animal models also appear to display at least some degree of sexual dysfunction in both sexes. Given the increased feasibility of measuring sex behavior in rodent models of epilepsy in the absence of confounding antiepileptic drug treatment, further investigation in this area is likely to yield insights into physiologic links between epileptiform and seizure activity and altered sexual function.

\section{Cognitive and Learning Deficits.}

a. Clinical studies. A large body of work has accumulated evidence for functional sex differences in human cognition and various forms of learning and memory, at least when assessed on average, although the specific features and underlying mechanisms are a matter of ongoing debate (Andreano and Cahill, 2009; Hamson et al., 2016; Asperholm et al., 2019). As many forms of epilepsy reflect seizure activity and, in some cases, pathologic damage to brain regions that participate in these cognitive functions, it is not surprising that cognitive and learning deficits are major comorbidities of epilepsy. Comprehensive discussion of the links between epilepsy and cognition across the lifespan, and the various forms of memory and neurocognitive function that can be affected, are beyond the scope here and are available in many recent reviews (Bell et al., 2011; Lin et al., 2012; Helmstaedter and Witt, 2017; Semple et al., 2019). It should be noted as well that there is growing appreciation for a comorbid relationship between epilepsy and Alzheimer disease, as discussed in other recent reviews (Chin and Scharfman, 2013; Sen et al., 2018). Assessing sex differences in the relationship between epilepsy and Alzheimer disease, however, is somewhat complicated by differential incidence and progression of Alzheimer disease and other forms of aging-related dementia in women and men (Hebert et al., 2013; Pike, 2017; Ferretti et al., 2018). The documented increase in risk for Alzheimer disease in postmenopausal women compared with age-matched men (Ferretti et al., 2018), however, underscores the need to identify causal mechanisms that produce sexspecific outcomes as well as features common to both sexes. Such insights will require studies aimed at understanding the mechanisms of sex differences in epilepsy and Alzheimer disease separately as well as the comorbid interactions between the two neurologic disorders in the context of both aging-dependent and -independent changes. In this section, we will focus on those studies that suggest sex differences in the presentation of cognitive comorbidities in children and adults, without the confounds of dementia-related disorders that could lead to cognitive impairment independently of the effects of epilepsy and seizures. Furthermore, we will focus particularly on those studies that specifically assessed and described whether a sex difference was observed.

Children with epilepsy are at particular risk for cognitive impairments and learning deficits, and sex can play a role in the presentation and features of these comorbidities. For example, in a study of children and adolescents with intractable epilepsy examining impairments in episodic verbal and visual memory, girls exhibited better delayed recall of stories and learning of a word list, but no sex difference was observed in performance on delayed recall of words or in visual tasks (Smith et al., 2009). Both boys and girls with epilepsy exhibit higher rates of autism, intellectual disability, and attention-deficit/hyperactivity disorder compared with children in the general population (Socanski et al., 2013; Aaberg et al., 2016; Williams et al., 2016). Although some studies document higher numbers of boys with epilepsy affected than girls (Aaberg et al., 2016), these findings may reflect an underlying male bias of these neurodevelopmental disorders in the general population, independent of specific effects of epilepsy and seizure activity (Rucklidge, 2010; Baron-Cohen et al., 2011; May et al., 2019). Other studies, however, have found similar rates of attention-deficit/hyperactivity disorder in both boys and girls with epilepsy [for review, see Williams et al. (2016)]. In addition, an analysis of data on children with epilepsy from the National Longitudinal Survey of Children and Youth in Canada found a slight preponderance of learning disabilities in girls (Prasad et al., 2014). The outcomes of epilepsy in children are also of interest given the increased potential for plasticity and functional compensation early in development. In this regard, it is interesting that patients who exhibit left-sided temporal lobe seizures by 1 year of age, when examined in early adulthood, can display sexspecific outcomes in cognitive impairment, and this effect is influenced by the lateralization of language function. Specifically, males were found to show generalized cognitive impairment of both verbal and nonverbal functions, independent of whether the left hemisphere remained dominant for speech. This effect contrasted with the outcomes in female patients examined, in which only some verbal functions were impaired, but nonverbal functions were largely unaffected if the left hemisphere remained dominant for speech (Strauss et al., 1992). Altogether, these and other studies suggest that neurobehavioral outcomes are prominent comorbidities in children with epilepsy, that these comorbidities can exhibit sex-specific features or prevalence, and that the long-lasting outcomes later in life can continue to exhibit sex differences in presentation and/or underlying mechanism.

Neuropsychological testing of adults with epilepsy has yielded interesting insights into sex differences in various forms of learning and memory, both in relation to epilepsy and to human cognition in general. To a large 
extent, and perhaps as to be expected, most of the focus in this domain has been in studying patients with TLE. In general, most studies indicate that women with epilepsy typically display better verbal memory than men with epilepsy (Berenbaum et al., 1997; Helmstaedter et al., 1999, 2004; Berger et al., 2017, 2018), although it should be noted that not all studies show a sex difference (Davies et al., 1998). After surgical resection of epileptogenic tissue of the anterior temporal lobe, women often continue to display superior performance (Trenerry et al., 1995; Berenbaum et al., 1997; Davies et al., 1998; Bengtson et al., 2000; Bjornaes et al., 2005; Berger et al., 2017). Overall, therefore, it appears that women in general display better performance on verbal learning and memory tests, and this sex difference confers a degree of resilience to decline in these measures in the face of epilepsy. Similarly, women without epilepsy, women with TLE, and women with generalized epilepsy all show better delayed face recognition memory when compared with men in these respective groups (Bengner et al., 2006). With regard to spatial memory as measured by hippocampal activation during an object location memory task in a virtual environment, it appears that in healthy controls, women display a left-lateralized activation pattern, whereas men display a right-lateralized pattern (Frings et al., 2006). In patients with TLE, by contrast, the lateralization pattern in this same task appears determined by the side of the seizure focus, not sex (Frings et al., 2008). Taken together, these studies suggest that various forms of memory and/or the organization of underlying neural substrates for these functions are changed in epilepsy, with impacts and features reflecting the sex of the patient.

b. Animal models. As would be expected from the observations of prominent cognitive comorbidities in patients with epilepsy, similar changes have also been well documented in various animal models of epilepsy. For a recent comprehensive review of behavioral comorbidities in preclinical models of epilepsy, see Holmes (2015). As is the case regarding other aspects of preclinical studies of epilepsy and seizure activity, however, few studies have specifically investigated the potential impact of sex as a biologic variable on these measures. Two recent studies of different genetic mouse models, however, have yielded some interesting sexspecific differences. First, the EL mouse, which displays autism-like behavioral features and comorbid epilepsy, appears to respond to ketogenic diet treatment in a sex-specific manner, with females showing greater improvement in sociability and stronger reduction in stereotyped repetitive self-grooming behavior (Ruskin et al., 2017). In addition, a recent study investigating heterozygous potassium voltage-gated channel subfamily $\mathrm{Q}$ member 2 knockout mice, which do not show spontaneous seizures but do show a reduced seizure threshold, observed male-specific increases in compulsive marble-burying and social dominance (Kim et al., 2020). By contrast, a recent study investigating both males and females in the GEPR-3 rat model documented that these rats display impaired novel object recognition, and a greater proportion of animals failed to explore the objects compared with Sprague-Dawley control counterparts, but it did not observe a sex difference in this effect (Aguilar et al., 2018).

With respect to pharmacological models of seizure induction and epilepsy, one study examining the behavioral consequences of KA-induced SE in newborn (4-6 days of age) rat pups documented that males showed stronger deficits in spatial learning as tested in a Barnes maze at 16-19 days of age than did the corresponding female pups (Akman et al., 2015). Conversely, however, in another study in which newborn rat pups were exposed to subconvulsive doses of domoic acid [which can lead to behavioral abnormalities suggestive of focal seizures as well as a lowering of seizure threshold (Gill et al., 2010)], the female, but not male, rats showed impaired spatial learning in a Morris water maze (Doucette et al., 2007). A series of studies all testing C57BL/6J mice have also documented varying effects. For example, one study of adult mice tested 2 months after pilocarpine-induced SE showed malespecific impairments in object exploration and reduced immobility in a forced swim test but no sex differences on other parameters, including open-field exploration and object recognition (Oliveira et al., 2015). Another recent study examining the short-term effects (within 5 days) of systemic KA induction of SE documented that male mice showed worse performance than females on novel object recognition, but it should be noted that the males also showed increased seizure susceptibility in response to the $\mathrm{KA}$ injection ( $\mathrm{Li}$ and Liu, 2019). Therefore, the sex differences in behavioral consequences may simply reflect sex differences in the initial seizure severity. Conversely, direct unilateral injection of $\mathrm{KA}$ into the hippocampus can produce deficits in spatial memory in mice in a manner that does not appear to differ between males and females (Zeidler et al., 2018).

Although most investigations have focused on the neurobehavioral consequences of epilepsy and seizure activity, one recent study provides an intriguing potential sex-specific link between underlying performance on the Morris water maze in control conditions and subsequent seizure susceptibility. When Wistar rats were tested first in the Morris water maze and then challenged with PTZ seizure induction, the female rats displayed a correlation between maze performance and later seizure susceptibility that was absent in the males, with better maze performance correlating with reduced subsequent seizure susceptibility (Haeri et al., 2016). Altogether, only a few studies of animal models of epilepsy document sex differences in cognitive comorbidities, and others document the lack of a sex difference in a given behavioral parameter tested. However, there 
have not been sufficient studies performed to suggest that sex differences in cognitive comorbidities in animal models are largely absent. Systematic inclusion of both male and female animals, and formal statistical testing for the presence of any sex differences, would greatly help to improve our understanding of which cognitive comorbidities, if any, show a sex-specific predominance.

\section{Migraine and Others.}

a. Clinical studies. In addition to the prominent psychiatric, reproductive, and cognitive comorbidities described in the previous sections, people with epilepsy are also at increased risk for a variety of other somatic conditions. Among these, urinary tract infection, hypothyroidism, and migraine are in the top 10 conditions for women, whereas cancer, coronary artery disease, and gastroesophageal reflux disease are in the top 10 for men (Wilner et al., 2014). Of these, the best studied is migraine, which also exhibits a higher prevalence in women in the general population worldwide (Stewart et al., 1992, 2008; Sakai and Igarashi, 1997; Vetvik and MacGregor, 2017).

The relationship between migraine and epilepsy is of particular interest for several reasons. First, both are episodic disorders (Haut et al., 2006; Rogawski, 2012); second, migraine is the most common type of headache observed in patients with epilepsy (Mainieri et al., 2015); third, the presence of comorbid migraines can negatively impact the prognosis of becoming seizurefree (Velioğlu et al., 2005); and fourth, many ASDs are effective as prophylactic treatments for migraines, producing a reduction in the number of episodes (Sprenger et al., 2018). Of note, migraine is far more commonly observed in patients with epilepsy than epilepsy is observed in migraine sufferers, simply because migraine on its own is far more prevalent (Bigal et al., 2003). Several studies have documented higher rates of migraine in people with epilepsy (for review, see Bigal et al., 2003; Haut et al., 2006; Rogawski, 2012), although there are exceptions (Brodtkorb et al., 2008; Tonini et al., 2012). Intriguingly, however, the sex difference in migraine prevalence observed in the general population appears to be largely equalized in the face of epilepsy. Whether focusing on acute postictal headache or periictal headache, or migraine in general, relatively similar rates have been observed in both men and women with epilepsy (Forderreuther et al., 2002; KaraaliSavrun et al., 2002; Ito et al., 2004; Syvertsen et al., 2007; Mameniskiene et al., 2016), and the sex of the patient does not appear to influence the type of headache (e.g., migraine, tension, or unclassified) associated with seizure activity (Leniger et al., 2001). This does not exclude the possibility, however, that the underlying mechanisms and triggers of migraine and other headaches in epilepsy may be different between men and women.

b. Animal models. There is growing investigation of the underlying neurobiological mechanisms of migraine in animal models (for review, see Bolay et al., 2011; Ferrari et al., 2015; Pavlovic et al., 2017). Most of the focus in animal models has been on measures of cortical spreading depression (CSD), which is postulated to underlie the migraine aura (Charles and Baca, 2013). In this regard, it is intriguing that CSD susceptibility in rodent models also exhibits certain sex differences. For example, the threshold for triggering CSD in wild-type C57BL/6 mice appears to be lower in females, in both the potassium chloride and tetanic stimulation models of CSD induction (Brennan et al., 2007). Furthermore, mouse models of familial hemiplegic migraine type 1, which harbor mutations in the Cacna1a gene encoding the $\alpha 1 \mathrm{~A}$ subunit of Cav2.1 channels, exhibit sex differences, with females exhibiting increased susceptibility to CSD and neurologic motor deficits than males and increased propagation of CSD into subcortical structures (Eikermann-Haerter et al., 2009, 2011).

In terms of potential links between migraine and epilepsy, only a handful of studies have addressed this issue in animal models. Nevertheless, a study of Wistar audiogenic rats indicated intriguing sex differences that reversed with exposure of the rats to audiogenic kindling stimulation. Specifically, when tested prior to audiogenic kindling, the female and male rats showed higher and lower CSD conduction velocity, respectively, compared with controls of the same sex. After audiogenic kindling, however, the female rats showed lower CSD propagation than controls, whereas males showed higher CSD propagation (Guedes et al., 2009). Conversely, mice that harbor heterozygous or homozygous knockout mutations of proline-rich transmembrane protein 2 , which underlie a group of disorders including epilepsy and migraine, do not appear to exhibit sex differences in PTZ or audiogenic seizure induction or in different motor or cognitive behaviors (Michetti et al., 2017). Lastly, a pair of recent studies examining a mouse model of familial hemiplegic migraine type 2, a subtype of severe migraine with aura and comorbid epilepsy, have documented sex differences in some parameters but not others. These mice, which carry a mutation in the astrocyte-specific $\alpha 2$-isoform of the $\mathrm{Na}^{+} / \mathrm{K}^{+}$ATPase, may exhibit sex differences in certain behavioral comorbidities, including open-field exploration, and elevated cortical and hippocampal glutamate levels in adult females (Bottger et al., 2016). In tests of CSD susceptibility, a sex difference was not observed in young mice, but susceptibility was lowered specifically in aged, reproductively senescent females; however, these mice do not appear to show a sex difference in susceptibility to epileptiform activity (Kros et al., 2018). Altogether, the few studies that have accounted for seizures or epilepsy have primarily focused on models of rare, more severe subtypes of migraine. Therefore, it is unclear how the findings may relate more broadly to heterogeneous epilepsies and to the milder forms 
of migraine observed more generally in people with epilepsy.

\section{Catamenial Epilepsy: Fluctuations in Seizure Occurrence across the Menstrual Cycle}

Perhaps the most prominent sex difference in epilepsy is that women with epilepsy commonly show a pattern of cyclical occurrence of seizure exacerbations during particular phases of the menstrual cycle (Newmark and Penry, 1980; Reddy, 2004b; Herzog and Fowler, 2008). In this section, we will review this phenomenon, "catamenial epilepsy," with particular focus on the clinical presentations and ongoing development of preclinical models to study this sex-specific aspect of epilepsy etiology and treatment.

\section{A. Types and Prevalence}

The types of epilepsies and seizures that are susceptible to catamenial fluctuations are not yet thoroughly defined. However, it appears that seizures in both focal epilepsies (such as TLE) and certain primary generalized epilepsies (such as juvenile myoclonic epilepsy) can exhibit catamenial exacerbations. Catamenial epilepsy is a widespread condition that affects between $25 \%$ and $70 \%$ of women with epilepsy who are of reproductive age (Reddy, 2009). The reason for the large range is due to differences in definition or diagnostic criteria. As a result of cyclic fluctuations in hormones and subsequent changes in the levels of neurosteroids, women suffering from catamenial epilepsy experience exacerbations of epileptic seizures associated with particular phases in the menstrual cycle (Herzog, 1999; Reddy, 2004b). Presently, there is no specific Food and Drug Administration-approved drug therapy for the treatment of catamenial epilepsy. In many cases, women diagnosed with epilepsy who are experiencing increased cyclic-related seizures are prescribed conventional ASDs. Unfortunately, many patients still experience menstrual cycle-related seizures despite drug treatment, indicating their condition is not responding to conventional ASDs; these seizures can thus be classified as pharmacoresistant.

Catamenial epilepsy is observed in women with both ovulatory and anovulatory cycles. In one study (Herzog et al., 2004), about $16.5 \%$ of subjects were found to have anovulatory cycles and an inadequate luteal phase. Altogether, three types of catamenial seizures have been identified, perimenstrual, periovulatory, and inadequate luteal phase, based on seizure exacerbation in relation to the menstrual cycle (Herzog et al., 1997; Reddy, 2009) [see Fig. 2 in Harden and Pennell (2013)]. The specific pattern of incidence can be identified simply by charting menses and seizures, along with measuring mid-luteal-phase serum progesterone levels to distinguish between normal and inadequate luteal phase cycles (Herzog and Fowler, 2008; Quigg et al., 2009). The diagnosis of catamenial epilepsy is mainly based on the assessment of menstruation and seizure records. Using the first day of menstrual bleeding as the first day of a regular 28-day cycle, the menstrual cycle is divided into four phases: 1) menstrual phase, days -3 to +3 ; 2) follicular phase, days +4 to +9 ; 3 ) ovulatory phase, days +10 to +16 ; and 4 ) luteal phase, days +17 to -4 . The number of seizures in each phase is checked for at least two cycles, and a twofold or greater increase in frequency during a particular phase of the menstrual cycle can be used as diagnostic criteria of catamenial epilepsy. In perimenstrual catamenial epilepsy, the most common clinical type, women with epilepsy experience an increase in seizure activity on days -3 to 3 of the cycle (Reddy, 2009).

\section{B. Preclinical Models}

Preclinical models have been developed that mimic the perimenstrual seizures of catamenial epilepsy. This seizure condition can be induced with pharmacologic agents or by electrical stimulation in rodents with suitable manipulation of neuroendocrine milieu (Reddy, 2009; Scharfman et al., 2009; Reddy et al., 2012). Neurosteroid levels fluctuate during the ovarian cycle phases. They are generally found in high concentrations during the luteal phase and lower concentrations during the perimenstrual phase. Furthermore, perimenstrual catamenial epilepsy could be triggered by physiologic reductions of neurosteroids. There is some clinical evidence stating that some neurosteroids have been found to be deficient in blood plasma of patients with perimenstrual catamenial seizures (ElKhayat et al., 2008; Tuveri et al., 2008). Such premises have been used to model neurosteroid withdrawal in rodents to obtain a better understanding of the underlying mechanism.

There are several features for an ideal catamenial epilepsy model (Scharfman et al., 2005, 2008; Reddy, 2016). It should reflect pathophysiology similar to those of catamenial seizures in women with epilepsy, exhibit appropriate menstrual seizure phenotype consistent with the neuroendocrine fluctuations of women with epilepsy, exhibit appropriate latency following steroid hormone fluctuations or withdrawal period, and respond to drug therapy with resistance to certain anticonvulsants. Because catamenial epilepsy is a complex neurologic disorder that encompasses many causes and seizure phenotypes, it is highly unlikely that any single animal model will truly recapitulate the full spectrum of clinical catamenial seizure features. Therefore, it is necessary to screen potential therapeutic products and investigate pathologic mechanisms in a battery of animal models prior to clinical trials. In this regard, both rat and mouse models were recently developed with the basic premise of creating a hormonal milieu of the perimenstrual period (Reddy, 2016), using both healthy rats and epileptic rats as well as healthy mice and kindled (epileptic) mice. This was done by creating 
a variety of manipulations through the use of pseudopregnancies, the exogenous administration of progesterone, and the utilization of a spontaneous seizure model. For example, gonadotropin is used to increase endogenous neurosteroid levels (Reddy et al., 2001). When gonadotropin is administered, it induces superovulation and the release of progesterone, followed by its conversion to allopregnanolone (Fig. 3). Concurrently, when allopregnanolone levels peak, they can be blocked by administration of the neurosteroid synthesis inhibitor, finasteride, to create a state of neurosteroid withdrawal. During this neurosteroid withdrawal phase, the seizure threshold in these animals drops significantly lower before returning to normal levels within 72 hours.

The above paradigms were recently replicated in mouse models, which allow for more mechanistic studies, and two distinct mouse models of perimenstrual catamenial epilepsy were developed (Gangisetty and Reddy, 2010; Reddy et al., 2012). These models are based on the premise that seizure susceptibility decreases when neurosteroid levels are high (luteal phase) and increases during their withdrawal (perimenstrual periods) in females in association with specific changes in the $\mathrm{GABA}_{\mathrm{A}}$ receptor subunit plasticity. First, a chronic seizure condition was created by using the hippocampus kindling model in female mice. Second, the fully kindled mice were subjected to fluctuating levels of neurosteroids, mimicking the ovarian cycle. Then, two distinct pharmacological approaches were used to induce elevated neurosteroid levels: 1) chronic exogenous progesterone treatment protocol and 2) gonadotropin regimen for induction of endogenous synthesis. The gonadotropin-induced neurosteroid synthesis and withdrawal paradigm appears more physiologically relevant than the exogenous progesterone treatment. In this model, elevated neurosteroid levels are induced by sequential gonadotropin treatment and withdrawal induced by finasteride (Reddy et al., 2012). This mouse model of perimenstrual catamenial epilepsy is useful for the investigation of disease mechanisms and exploring the efficacy of new therapeutic approaches. However, there are some limitations with these preclinical models because the actual endocrine conditions that exist in the menstrual cycle are different from those observed in rodent models. As discussed above, in rodents, the estrous cycle duration is 4-7 days, and the menstrual cycle in women lasts about 28 days. In addition, rodents do not exhibit a true luteal phase as observed in the menstrual cycle. This is a major concern with most animal models developed in rodents.

\section{Potential Neurobiological Bases for Sex Differences in Seizure Susceptibility and Epilepsy}

The underlying mechanisms that give rise to the sex differences in various types of epilepsy and associated comorbidities are ongoing areas of investigation. In this section, while not exhaustive, we will discuss some of the developmental, neurobiological, endocrinological, and metabolic effects that are likely to be involved in driving sex-specific outcomes in the context of epilepsy and/or comorbidities.

\section{A. Sex Differences in Brain Development}

Sex differences are evident throughout the full trajectory of brain development. In humans, brain volume differences between males and females are evident from birth and are present throughout the lifespan [see review in Paus (2010)], including highly ictogenic regions such as hippocampus and amygdala.

Early in development, gonadal hormone-mediated organizational effects lead to terminal differentiation of neurons and circuits to adopt sex-specific patterns [for review, see McCarthy and Arnold (2011)]. This was first described in the landmark paper of Phoenix et al. (1959), in which guinea pigs were exposed to testosterone in utero, a treatment that resulted in masculinization of females as measured by adult copulatory behavior. The window for these organizational effects is developmentally restricted but permanent [for review, see Arnold (2009)]. These organizational effects are complemented by activational effects, i.e., hormonemediated changes in function that are reversible with removal of the hormonal influence. These effects set up dimorphic patterns that may influence both the expression and treatment of the epilepsies.

Given that infancy is one of the peak periods of new onset seizure occurrence, sex differences in brain development may have stark impacts on responses to treatment. In the sections below, we describe sex differences in the context of early-life epilepsies, with a focus on preclinical models to understand mechanisms.

1. Neurogenesis. One of several ways sex differences manifest is through divergent rates of neurogenesis. This topic has been previously reviewed extensively (Porter, 2008) and is presented in brief below. First, basal rates of neurogenesis differ during development as a function of sex; newborn male rats display a higher rate of neurogenesis in the hippocampus than females (Bowers et al., 2010). In contrast to the hippocampus, newborn female rats display higher rates of neurogenesis in the amygdala than male rats (Krebs-Kraft et al., 2010). This baseline difference in neurogenesis may, in turn, set up divergent responses to epileptogenic insults.

Aberrant neurogenesis is well characterized as a pathologic feature of TLE in adult animal models (Parent et al., 1997; Gray and Sundstrom, 1998; Scharfman et al., 2000). Though similar findings have been reported in younger animals (Porter et al., 2004), this differs substantially across models and age, with some studies reporting decreased cell birth (McCabe et al., 2001; Liu et al., 2003), some reporting increased 


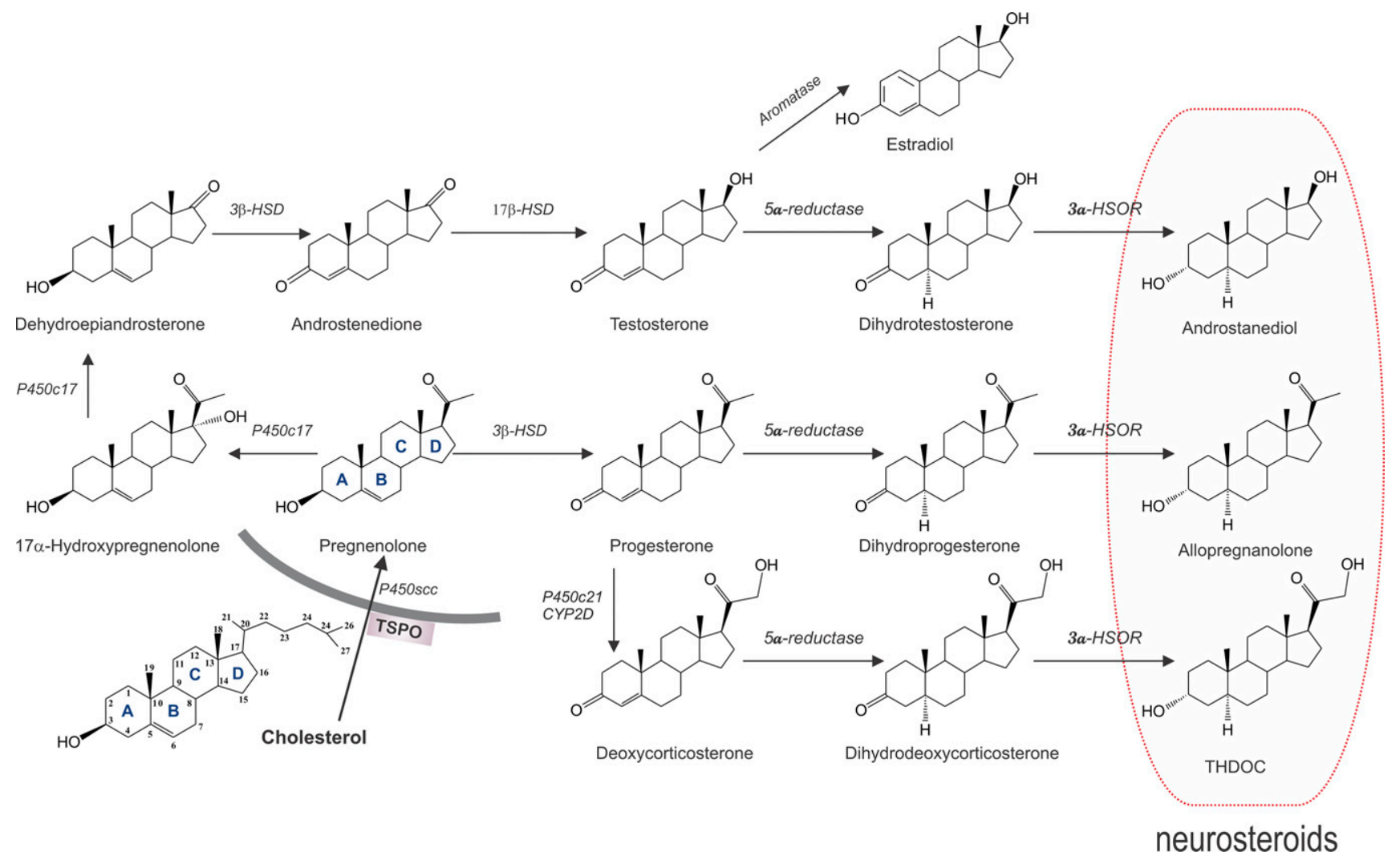

Fig. 3. Biosynthetic pathways of neurosteroid synthesis in the brain and nervous system. Enzymatic pathways for the production of three prototype neurosteroids allopregnanolone (now called brexanolone), allotetrahydrodeoxycorticosterone (THDOC), and androstanediol are illustrated from cholesterol and intermediate steroid precursors. Cholesterol is converted to pregnenolone by P450scc in the inner mitochondrial membrane. Pregnenolone is the precursor for progesterone and other neurosteroids. Progesterone, deoxycorticosterone, and testosterone undergo two sequential A-ring reduction steps catalyzed by $5 \alpha$-reductase and $3 \alpha$-HSOR to form the $5 \alpha, 3 \alpha$-reduced neurosteroids. The conversion of progesterone, deoxycorticosterone, or testosterone into neurosteroids occurs in several regions within the brain. The $5 \alpha$-reductase, $3 \alpha$-HSOR, and other enzymes are present in the brain. $3 \beta$-HSD, $3 \beta$-hydroxysteroid dehydrogenase; $3 \alpha-H S O R$, $3 \alpha$-hydroxysteroid oxidoreductase; $17 \beta$ - $H S D$, $17 \beta$-hydroxysteroid dehydrogenase; P450c21, cytochrome P450 21-hydroxylase; P450scc, cholesterol side-chain cleavage enzyme. Adapted from Reddy (2013).

(Sankar et al., 2000), and some reporting no change (Bender et al., 2003). There are only sparse reports examining sex differences in survival of neurons after early-life seizures. For example, female rats that received febrile seizures at postnatal day 17 displayed greater survival of newborn cells in the hippocampus than males (Lemmens et al., 2005), but the rate of neurogenesis did not differ by sex. In a different model (KA-induced SE), female newborn rats showed less survival of cells in the dentate gyrus than males (Hilton et al., 2003). Ultimately, the number of neurons present after injury or stimulation is determined by the balance of proliferation and survival. The role of neurogenesis in epilepsy is complex, with recent studies in adult animals showing that basal neurogenesis is protective against seizures (Iyengar et al., 2015; Jain et al., 2019b), whereas aberrant neurogenesis following SE contributes both to adverse cognitive outcomes and seizure burden (Cho et al., 2015). How these findings will translate to the developing brain, and how these findings are modulated by sex, remains to be determined.

2. Chloride Homeostasis and GABAergic Neuro transmission. Sex differences in the development of GABAergic neurotransmission have been extensively reviewed by others (Akman et al., 2014) and are summarized below, with a focus on features of particular relevance to epilepsy and pharmacotherapy.

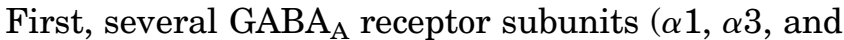
$\gamma 2$ ) display differing expression profiles as a function of sex and brain region (Ravizza et al., 2003; Li et al., 2007; Chudomel et al., 2009). Consistent with this observation, a study of children undergoing positron emission tomography imaging prior to epilepsy surgery found greater flumazenil binding in females compared with males (Chugani et al., 2001). Moreover, in postmortem tissue from adults, $\alpha 1, \alpha 2, \alpha 5$, and $\beta 3$ subunit expression is greater in males than females (Pandya et al., 2019). As subunit composition impacts both the kinetics of GABAergic neurotransmission and the pharmacology of GABA $\mathrm{A}_{\mathrm{A}}$ receptors (Olsen and Sieghart, 2009), a deeper understanding of sex differences in receptor expression and function may enable more appropriate targeting of pharmacotherapy.

Perhaps one of the best-explored sex differences during development in the context of epilepsy is the shift from depolarizing to hyperpolarizing GABA, which is regulated by the expression of solute transporters that set the chloride gradient. Of particular interest 
are the sodium-potassium-chloride cotransporter 1 (NKCC1) and the potassium-chloride cotransporter 2 (KCC2). NKCC1 transports chloride into the cell, whereas KCC2 transports chloride out of the cell. Early in development, NKCC1 is highly expressed relative to KCC2, which results in a net chloride loading of neurons. Thus, in immature neurons, $\mathrm{GABA}_{\mathrm{A}}$ receptor activation results in chloride efflux and depolarization (Ben-Ari et al., 2007). This depolarizing GABA has been suggested to contribute to the relatively poor efficacy of first-line antiseizure medications (e.g., phenobarbital) for the treatment of neonatal seizures (Dzhala et al., 2005). Over the course of early postnatal development, expression of NKCC1 decreases, expression of KCC2 increases, and an adult-like chloride equilibrium potential is reached. However, the relative timing of this "switch" from depolarizing to hyperpolarizing GABA differs as a function of both brain region (Glykys et al., 2009) and sex (outlined below).

Although the developmental time course of KCC2 and NKCC1 expression has been characterized across brain regions in rats (Wang et al., 2002), it has only been done so in a thorough manner for males. Similarly, though spatio-temporal trajectories for both transcripts have been reported for the human brain, and samples for both males and females were included, the data were not disaggregated by sex (Kang et al., 2011). Fortunately, a handful of studies have directly compared expression in at least a subset of brain regions across sexes in animal models. In the hypothalamus of newborn rats, NKCC1 expression is significantly greater in males compared with females, and KCC2 expression is higher in female rats than males at postnatal day 5 (Perrot-Sinal et al., 2007). Similarly, KCC2 expression in cortex increases earlier in females than males (Kang et al., 2015). In the substantia nigra pars reticulata, KCC2 mRNA levels are regulated in a hormonedependent manner, with females displaying higher KCC2 levels than males at postnatal day 15 (Galanopoulou and Moshe, 2003). Consistent with this pattern of expression, gramicidin-perforated patch recordings demonstrated hyperpolarizing GABA in female rats and depolarizing GABA at the same developmental stage (Galanopoulou et al., 2003). In adult animals, however, infusion of GABA agonists into the substantia nigra potently suppresses seizures, and during development, a sex difference appears; in males, a proconvulsant effect is observed, whereas in females, either no effect or an anticonvulsant effect is observed (Veliskova and Moshe, 2001). This effect may be explained by the earlier emergence of hyperpolarizing GABA in female rats.

Likewise, in the entorhinal cortex and hippocampus, KCC2 levels are higher in females than in males (Murguia-Castillo et al., 2013). Functionally, this expression results in hyperpolarizing GABA in females at ages as young as postnatal day 4, whereas in males, the majority of neurons display depolarizing GABA responses until postnatal days 14-18 (Galanopoulou, 2008). In sum, females display a more "adult-like" expression pattern of NKCC1/KCC2 at earlier developmental ages, which results in a mature chloride gradient and hyperpolarizing GABA signaling. In the hippocampus, these divergent patterns of maturation of GABAergic transmission interact with seizure history in a complex manner. KA-induced seizures on postnatal days 4-6 induce an early shift toward hyperpolarizing GABA in males and cause a regression toward depolarizing GABA in females (Galanopoulou, 2008). In humans, NKCC1 expression in cortex peaks around birth and then falls to adult levels in the months after birth. By contrast, KCC2 levels rise slowly and consistently over the first year of life (Dzhala et al., 2005). Though expression during development has not been stratified by sex in human tissue, this overall expression is consistent with rodent studies, with a heightened ratio of NKCC1 to KCC2 expression early in development.

As several common classes of antiseizure medications used in neonates (e.g., barbiturates, benzodiazepines) exert seizure-suppressive effects through GABA-mediated inhibition, sex differences may be of particular importance in understanding effects (or lack thereof) as randomized controlled trials in these populations become more common. At the very least, subgroup analyses based on sex, which have not been reported in the few recent trials comparing phenobarbital to other therapies in neonates, are warranted.

3. Hypoxia and Hypoxia-Ischemia. In classic pharmacological models used in preclinical epilepsy research, little to no evidence exists for sex differences in immature animals with respect to induction, seizure threshold, or mortality [see Table 3 in Akman et al. (2014)]. This effect differs from models of hypoxia or hypoxia/ischemia (HI). HI encephalopathy is one of the most common causes of neonatal seizures. Growing clinical evidence suggests that females display more favorable outcomes after HI (Smith et al., 2014). Similarly, survival and long-term outcomes are enhanced in female, as compared with male, low-birthweight infants (Ito et al., 2017). For a thorough review of this topic, see Hill and Fitch (2012).

What mechanisms may underlie these differences in outcome? In mice, 1) females display smaller infarct volume and fewer seizures, 2) males display increased microglial activation and inflammatory cytokine production, and 3) females display less severe behavioral impairment (Mirza et al., 2015; Al Mamun et al., 2018). Moreover, males show a transient but significantly heightened seizure burden following HI at postnatal day 7, an effect that is not observed in females (Kang et al., 2015). Similar findings after neonatal HI have been reported in rats, with males displaying more severe brain damage and neurologic deficits than 
females (Hill et al., 2011). This enhanced sensitivity in males appears to be at least partly mediated by testosterone, as treatment with testosterone worsens outcomes in females (Hill et al., 2011). Moreover, it has been suggested that the X-linked inhibitor of apoptosis may confer a protective advantage to females (Hill and Fitch, 2012).

Clinically, phenobarbital remains the first-line therapy for neonatal seizures following hypoxia or hypoxiaischemia (Rennie and Boylan, 2007). However, as described above, early in postnatal development, GABA action can result in excitation of neurons, and drugs such as phenobarbital can thus result in a paradoxical increase in activity. In rodent models, phenobarbital displays a range of efficacy; after graded global hypoxia in rats (Cleary et al., 2013), it displays modest efficacy at suppressing seizures, but this action is significantly potentiated by the NKCC1 inhibitor bumetanide. By contrast, in a carotid ligation model in mice, phenobarbital suppressed seizures, and the addition of bumetanide was either without effect or worsened seizure activity (Kang et al., 2015). Interestingly, the exacerbation of seizure activity by bumetanide was preferential to females (Kipnis et al., 2019). In other models, sex has not been explicitly addressed; however, phenobarbital alone failed to suppress seizure activity but abolished seizures in combination with bumetanide in in vitro hippocampal seizures evoked by either low magnesium (Dzhala et al., 2008) or high potassium (Dzhala et al., 2005). Similarly, in vivo seizures triggered by KA are poorly controlled by phenobarbital in postnatal day 10 rats but are significantly reduced by bumetanide (Cleary et al., 2013). Based largely on the hypothesis that the immature chloride gradient in the developing brain contributes to the high level of refractoriness seen with phenobarbital (Painter et al., 1999), the Neonatal Seizure Treatment with Medication Off-patent consortium trial (Pressler et al., 2015) examined adjunctive treatment with bumetanide for neonatal seizures. The trial was ultimately terminated because of a combination of adverse reactions (ototoxicity) and little evidence for seizure reduction. Given the small sample size (4 female, 10 male), it is difficult to draw any conclusions regarding sex differences, but it is interesting to note that decreases in seizure burden were evident in a subset of subjects of both sexes. Although the trial failed to demonstrate clear efficacy, future studies targeting this mechanism in early-life seizures may still be merited that take into account etiology of seizure given that bumetanide appears to have different responses across animal models based on the etiology of the seizure and the effect of sex.

\section{B. Hormonal and Neurosteroid Mechanisms in Adulthood}

1. Estrous Cycle-Associated Changes in Seizure Susceptibility. Fluctuations in seizure susceptibility across the estrous cycle, akin to catamenial patterns of seizure clustering, have been documented in both acute models of seizure induction and models of chronic epilepsy in female rodents (Fig. 1). With respect to acute induction of seizures, most studies have documented increased susceptibility on proestrus and estrus. For example, PTZ threshold differs across the estrous cycle, with the lowest threshold seen during estrus and the highest seen during diestrus (Riazi et al., 2004). Similarly, thresholds to bicuculline-induced myoclonus are lower during estrus than during diestrus (Finn and Gee, 1994), and susceptibility to seizures induced by systemic KA injection is also higher on estrus compared with diestrus (Maguire et al., 2005). Moreover, sensitivity to GBL peaks during estrus and is lowest during metestrus and diestrus (Santos et al., 2018). After discharge, threshold with kindling stimulation changes over the estrous cycle and is lowest in proestrus (the time of peak circulating estradiol levels) and highest during metestrus (during the peak of progesterone secretion). Hippocampal excitability measured in ex vivo slices from rats is higher on proestrus and estrus relative to metestrus (Scharfman et al., 2003). Similarly, the number of SWDs increases during proestrus in WAG/Rij rats (van Luijtelaar et al., 2001). By contrast, however, a significantly lower percentage of females reach $\mathrm{SE}$ as an endpoint after systemic pilocarpine injection during estrus (Scharfman et al., 2005), and the frequency of interictal spikes observed following systemic KA injection in rats is higher on metestrus and diestrus (D'Amour et al., 2015). Furthermore, minimal and maximal electroshock thresholds are also modulated as a function of estrous cycle stage in female rats. Minimal seizure threshold is elevated during diestrus, lower during proestrus, and lowest during estrus. The maximal seizure severity, as measured by the duration of tonic flexion, is greatest during diestrus and shortest during estrus (Woolley and Timiras, 1962a). Together, these studies indicate dynamic fluctuations in seizure susceptibility across estrous cycle stages.

2. Effects of Estradiol, Progesterone, and Testosterone on Seizure Susceptibility. Steroid hormones, specifically estradiol, progesterone, and testosterone, are intimately involved in sex differences in epilepsy. Estradiol is one of the three molecules that comprise estrogen and has been known to play a role in the exacerbation of seizures in women with epilepsy (Logothetis et al., 1959; Bäckström, 1976; Bäckström et al., 1984; Jacono and Robertson, 1987; Younus and Reddy, 2016). Plasma estradiol levels are found to increase during both the follicular and luteal phase of the normal menstrual cycle, and in the late luteal phase, there is a precipitous decline in progesterone that triggers menstruation. Therefore, an increase in the ratio of estrogen to progesterone during the perimenstrual period may possibly contribute to the development 
of perimenstrual seizures (Bonuccelli et al., 1989; Herzog et al., 1997).

a. Estradiol. Proconvulsant effects of estradiol have been observed across diverse animal models of seizure susceptibility (Table 3). Estradiol facilitates chemoconvulsant PTZ kindling in ovariectomized female rats (Hom and Buterbaugh, 1986). Estradiol decreases the latency to KA-evoked status in ovariectomized rats (Woolley, 2000) but interestingly decreases post-status cell loss (Reibel et al., 2000). Estradiol also reduces electroshock seizure threshold (Woolley and Timiras, 1962c) and accelerates both hippocampal and amygdala kindling (Edwards et al., 1999c). Similarly, in ovariectomized females, estradiol facilitates kindling from the anterior neocortex (Buterbaugh, 1989), dorsal hippocampus (Buterbaugh and Hudson, 1991), and amygdala (Hom and Buterbaugh, 1986; Buterbaugh, 1987). Estradiol also facilitates amygdala kindling in male rats (Saberi and Pourgholami, 2003). It should be noted, however, that some anticonvulsant effects of estradiol have also been observed. For example, in ovariectomized rats, the latency to NMDA-evoked seizures can be increased by estradiol (Vathy et al., 1998). In addition, ovariectomy results in an increased sensitivity to NMDA marked by longer total seizure duration and greater numbers of seizures than control animals; this effect is normalized by estradiol (Kalkbrenner and Standley, 2003).

b. Progesterone. Progesterone has primarily anticonvulsant and antiepileptic properties in animals and humans, although in a randomized placebo-controlled trial, progesterone was primarily effective in treating women with a perimenstrual catamenial pattern only (Jacono and Robertson, 1987; Herzog, 1999; Reddy, 2009). Progesterone has long been known to have antiseizure activity in a variety of animal models of epilepsy (Table 3). In recent years, numerous studies have confirmed the powerful anticonvulsant activity of progesterone in diverse animal seizure models (Reddy et al., 2004, 2010). For example, progesterone suppresses PTZ-evoked seizures in female mice (Frye et al., 2002) and protects against NMDA-evoked seizures in male mice (Członkowska et al., 2000). Consequently, seizure susceptibility is typically low during physiologic conditions associated with high progesterone. In women with epilepsy, natural cyclic variations in progesterone during the menstrual cycle could influence catamenial seizure susceptibility, as detailed above. It should be noted, though, that progesterone receptor (PR) agonists may increase the number of spontaneous seizures in female chronically epileptic rats (Shiono et al., 2019).

Progesterone acts on the brain through two different mechanisms. The first pathway involves binding to PRs and exerting effects through both genomic and nongenomic mechanisms. The second pathway involves modulating $\mathrm{GABA}_{\mathrm{A}}$ receptors via synthesis of neurosteroids (Fig. 3). Neurosteroids rapidly alter neuronal excitability through direct interaction with $\mathrm{GABA}_{\mathrm{A}}$ receptors (Macdonald and Olsen, 1994; Belelli et al., 2002). In the process of neurosteroidogenesis, progesterone is converted to allopregnanolone by sequential A-ring reductions. Another neurosteroid, tetrahydrodeoxycorticosterone (THDOC), is produced by reduction of deoxycorticosterone. It was demonstrated that PRs require longer periods of time to exhibit their effects, whereas neurosteroid synthesis via progesterone conversions occur rapidly, suggesting that these conversions could potentially be more relevant to developing pharmaceutical treatments. This hypothesis was supported by comparing wild-type and PR knockout mice to show that progesterone can still produce anticonvulsant effects in mice that lack PRs. Blockade of progesterone conversion to neurosteroids by finasteride treatment prevented the anticonvulsant effects, indicating that these outcomes were mediated by allopregnanolone (Reddy et al., 2004).

Because endocrine fluctuations in plasma levels of progesterone and other steroids can mediate neurosteroid availability, there are apparent differences between sexes concerning concentrations of neurosteroids in the brain. Though neurosteroids are capable of shaping inhibition and producing behavioral effects in both males and females, the regulation of neurosteroid activity may be sex-specific (Gulinello and Smith, 2003). Differences in maximal $\mathrm{GABA}_{\mathrm{A}}$ receptor potentiation are observed between male and female rats for THDOC

TABLE 3

Effects of sex steroid treatment on seizure susceptibility in preclinical rodent models

\begin{tabular}{|c|c|c|c|}
\hline Generalized (Motor) & Estrogen & Progesterone & Testosterone \\
\hline Picrotoxin & $\uparrow=$ Anticonvulsant & $\sigma^{\prime \prime}=$ Increased sensitivity & 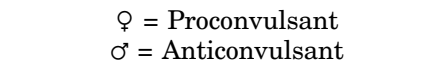 \\
\hline Pentlyenetetrazole & Rats, $\odot=$ proepileptogenic & Rat: anticonvulsant & Rat: anticonvulsant \\
\hline NMDA & $\begin{array}{c}\text { Sensitivity: OVX > control } \\
\wp=\text { Anticonvulsant }\end{array}$ & Mice, $\sigma^{\prime \prime}=$ anticonvulsant & \\
\hline $\begin{array}{l}\text { Electroshock } \\
\text { Generalized (Absence) }\end{array}$ & Proconvulsant & Anticonvulsant & Both pro- and anticonvulsant effects \\
\hline $\begin{array}{l}\text { WAG/Rij } \\
\text { Focal }\end{array}$ & More seizures during proestrus & & \\
\hline $\begin{array}{l}\text { Kainic acid } \\
\text { Pilocarpine }\end{array}$ & Rat: proconvulsant & Rats, $O:$ agonists increase seizure frequency & Rat: castration is anticonvulsant \\
\hline Kindling & Rats: proepileptogenic & Rats, $\odot=$ proepileptogenic & Proepileptogenic \\
\hline
\end{tabular}


but not for allopregnanolone or androgenic neurosteroids (Wilson and Biscardi, 1997). Sex differences in the expression of $3 \alpha$-hydroxysteroid dehydrogenase are evident during puberty but subside in the brain as it matures into adulthood; sex-specific gonadal and adrenal endocrine activity have a significant effect on the ability of allopregnanolone to modify anxiolytic (i.e., anxiety-reducing) actions based on variations in biosynthesis of steroid hormones (Mitev et al., 2003). Sex differences are evident in the anticonvulsant activity of neurosteroids; however, the potential mechanisms remain unclear. It is likely that differences in postsynaptic or extrasynaptic $\mathrm{GABA}_{\mathrm{A}}$ receptor expression and function may underlie the sex differences in seizure sensitivity and the anticonvulsant activity of neurosteroids (Reddy et al., 2019) (Fig. 4). In this regard, progesterone has also anecdotally been reported to increase typical absence seizures in humans (Grunewald et al., 1992). Moreover, allopregnanolone, which is synthesized from progesterone, significantly increases SWDs in WAG/Rij rats (Budziszewska et al., 1999), consistent with postulated roles for neurosteroidsensitive extrasynaptic $\mathrm{GABA}_{\mathrm{A}}$ receptors in the thalamus in driving absence seizure activity (Banerjee and Snead, 1998; Cope et al., 2009; Errington et al., 2011).

c. Testosterone. Testosterone is synthesized by both the testes and the ovaries and, to a much lesser degree, the adrenal gland, and it can also be synthesized de novo in the brain from cholesterol. Testosterone is converted in the brain to estradiol by aromatase or to the nonaromatizable androgen dihydrotestosterone (DHT) by $5 \alpha$-reductase (Meinhardt and Mullis, 2002; Swerdloff et al., 2017). The aromatase and $5 \alpha$-reductase enzymes are expressed by both neurons and glia, although there are regional differences in which cell types are the dominant sources of each enzyme (MacLusky et al., 1987; Martini et al., 1993; Zwain et al., 1997; Melcangi et al., 1998; Zwain and Yen, 1999; Hojo et al., 2004). Castration of male rats as well as testosterone replacement produces both pro- and anticonvulsant effects in the model depending on timing and duration of treatment (Woolley and Timiras, 1962b) (Table 3). On balance, it appears that the actions of estradiol on neuronal excitability and seizure susceptibility are opposite those of DHT, with estradiol and DHT increasing and decreasing these parameters, respectively. Accordingly, aromatase inhibition has demonstrated some efficacy in improving seizure control in men with epilepsy (Harden and MacLusky, 2004, 2005). Several findings support this working model. For example, estradiol treatment of gonadectomized male Wistar rats lowered the threshold to electrical kindling stimulation of the amygdala, an effect that could be mimicked by testosterone treatment but not DHT. Furthermore, in gonad-intact males that produced endogenous testosterone, aromatase inhibition blocked the progressive decrease in threshold typically observed over the kindling period (Edwards et al., 1999b). Similarly, testosterone treatment of male SpragueDawley rats was observed to increase susceptibility to seizures induced by either KA or pilocarpine injection (Mejias-Aponte et al., 2002), and gonadectomy of CF/1 mice increased susceptibility to seizures induced by combined PTZ and strychnine treatment, an effect that could be reversed by testosterone replacement (Pesce et al., 2000). In another study, testosterone treatment also increased seizure susceptibility in male rats and mice, and this seizure exacerbation could be blocked by treatment with the aromatase inhibitor, letrozole (Reddy, 2004c). Conversely, however, testosteronetreated wild-type mice exhibited an increased latency to systemic PTZ-induced seizures, but knockout mice lacking $5 \alpha$-reductase did not show this effect of testosterone (Frye et al., 2001), indicating that the anticonvulsant effects of testosterone were likely mediated by $5 \alpha$-reduction to DHT. DHT was also observed to be anticonvulsant against PTZ-induced seizures in male mice (Reddy, 2004c). It should be noted, however, that in studies examining the effects of gonadectomy and hormone replacement on excitatory synaptic spine density in the rat hippocampus, males exhibited a reduction in spine density following gonadectomy that was reversed by testosterone, but intriguingly, the effect of testosterone appeared to be mediated entirely by DHT (Leranth et al., 2003). This effect was in marked contrast to that of females, in which an upregulation of spine density by testosterone was almost completely blocked by letrozole, and DHT produced only a small effect (Leranth et al., 2004). Altogether, it appears that testosterone can exert robust effects on seizure susceptibility, and the end resulting effect depends critically on the balance of conversion to estradiol or DHT.

DHT can be further converted to the neurosteroid androstanediol ( $5 \alpha$-androstan- $3 \alpha, 17 \beta$-diol, or $3 \alpha$-Diol), which itself can be converted to androsterone ( $5 \alpha$ androstan-3 $\alpha$-ol-17-one) (Kaminski et al., 2005; Reddy and Jian, 2010) (Fig. 3). Similar to progesterone-derived allopregnanolone, androstanediol acts as a positive allosteric modulator of $\mathrm{GABA}_{\mathrm{A}} \mathrm{Rs}_{\mathrm{s}}$ (Reddy and Jian, 2010) and is thus poised to exert anticonvulsant effects. Indeed, androstanediol treatment has been observed to be protective in various forms of seizure induction models, including hippocampal kindling, PTZ, picrotoxin, and $\beta$-carboline ester (Reddy, 2004a,c; Ryan and Frye, 2008; Frye et al., 2009; Reddy and Jian, 2010). There are conflicting reports regarding efficacy against KA-induced seizures (Frye and Reed, 1998; Reddy, 2004a), but these discrepancies may reflect species differences between rats and mice. Intriguingly, a recent study suggests that female mice are more sensitive to the anticonvulsant effects of androstanediol and that this sex effect reflects differences in the expression of $\delta$ subunit-containing $\mathrm{GABA}_{\mathrm{A}} \mathrm{Rs}$ in dentate gyrus granule cells (Reddy et al., 2019). Similarly, androsterone 
A
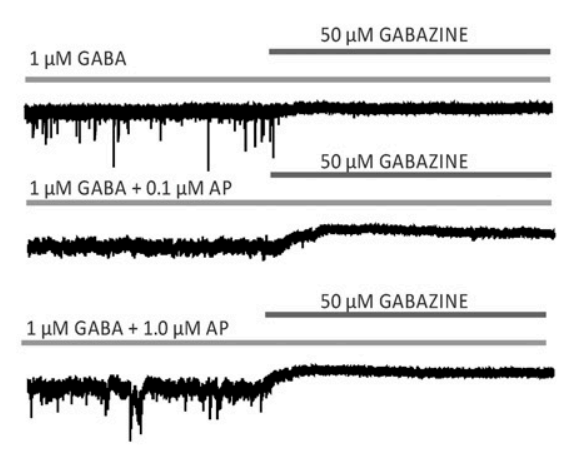

C

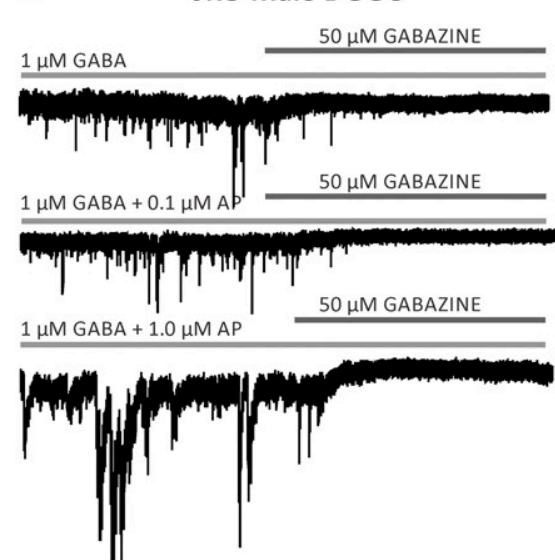

WT Female DGGC

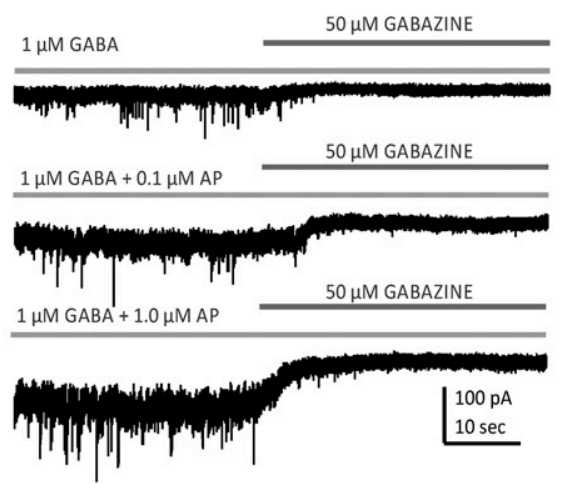

¿KO Female DGGC

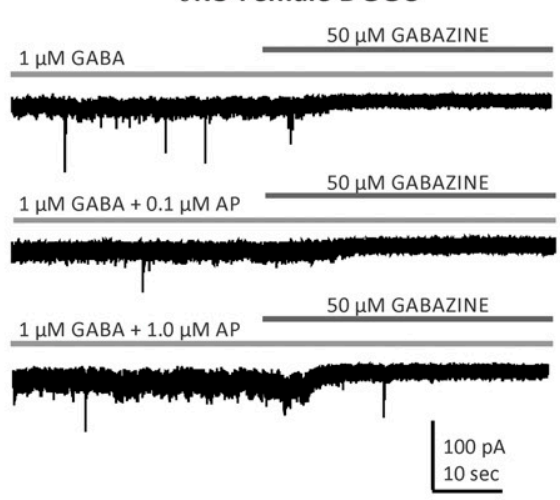

B

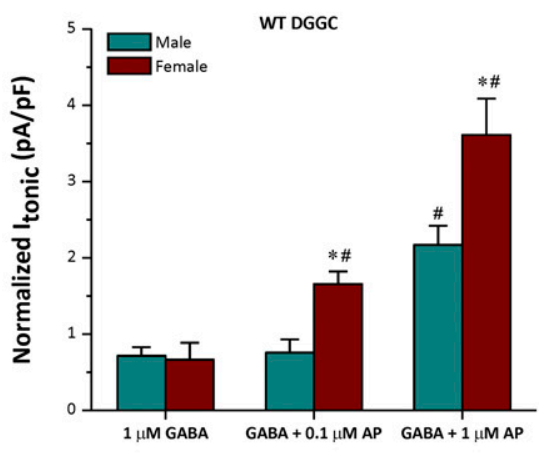

D

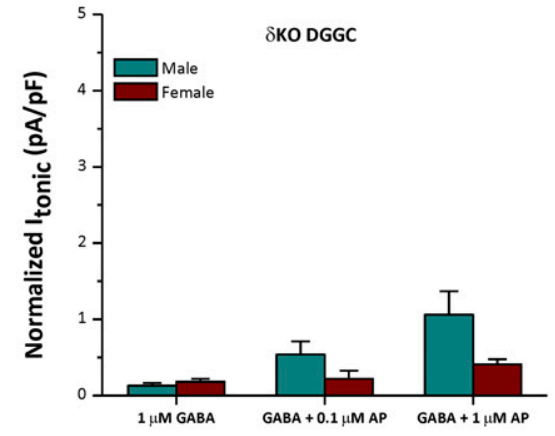

Fig. 4. Sex differences in allopregnanolone potentiation of tonic GABAAR-mediated currents in hippocampal dentate gyrus granule cells (DGGCs) in wild-type (WT) and $\delta$ GABAAR subunit knockout mice $(\delta \mathrm{KO})$. (A) Representative tonic current recordings from DGGCs in slices from WT male and female mice. Allopregnanolone (AP, $0.1-1.0 \mu \mathrm{M}$ ) was applied to the bath in addition to $1 \mu \mathrm{M}$ GABA to measure allosteric enhancement of tonic current. (B) Summarized data of AP concentration response from male and female DGGCs in WT mice. (C) Representative tonic current recordings in the presence of AP or/and GABA from DGGCs in slices from $\delta \mathrm{KO}$ mice. (D) Summarized data of AP concentration response from male and female DGGCs in $\delta \mathrm{KO}$ mice. Tonic current was normalized to cell capacitance $(\mathrm{pA} / \mathrm{pF})$ as a measure of current density. The GABA-A receptor tonic current was expressed as the outward shift in holding current after the application of gabazine $(50 \mathrm{mM}) . * P<0.05$ vs. males; \#P<0.05 vs. $1 \mu \mathrm{M}$ GABA baseline current in the same sex ( $n=6-8$ cells per group). Adapted from Reddy et al. (2019).

treatment appears to produce antiseizure effects across multiple seizure models in male mice and rats, including 6-Hz corneal stimulation, $\mathrm{PTZ}$, 4-aminopyridine, pilocarpine, and maximal electroshock (Kaminski et al., 2005), although actions of androsterone to lower seizure threshold in response to KA have been reported (Mroz et al., 2009). Overall, it appears that both androstanediol and androsterone exert potent anticonvulsant effects; thus, upregulating the downstream multistep conversion of testosterone to either androstanediol or androsterone, or direct treatment with these metabolic products, is a promising avenue of future ASD development. It should be noted, however, that the antiseizure effects of testosterone-derived neurosteroids outlined above may not entirely be the case for absence seizures, reflecting the mechanism of neurosteroid enhancement of inhibition producing stronger postinhibitory rebound burst firing in thalamocortical neurons (van Luijtelaar et al., 2014). In particular, it appears that testosterone itself (and/or DHT) may exert antiabsence effects, but androstanediol, particularly through enhancement of inhibition mediated by $\delta$ subunit-containing $\mathrm{GABA}_{\mathrm{A}} \mathrm{Rs}_{\mathrm{s}}$, produces proabsence effects. In this regard, castrated male WAG/Rij rats, a genetic model of absence seizures, display more SWD than intact males, suggesting that on balance, the overall effects of testosterone are seizure-suppressive (van Luijtelaar et al., 1996).

\section{Brain-Derived Neurotrophic Factor}

Several aspects of brain-derived neurotrophic factor (BDNF) function and regulation suggest roles in epilepsy and neural excitability. For example, BDNF application increases the excitatory:inhibitory ratio of synaptic transmission and elevates neuronal excitability in dentate granule cells resected from patients with TLE (Zhu and Roper, 2001), and levels of BDNF mRNA and protein often appear changed in resected hippocampal tissue from patients with TLE (Murray et al., 2000; Chen et al., 2016; Martinez-Levy et al., 2016). The 
evidence for general roles of BDNF in epilepsy has been comprehensively reviewed elsewhere (McNamara and Scharfman, 2012; Harte-Hargrove et al., 2013; Scharfman and MacLusky, 2014a). Therefore, in this section, we will briefly discuss the aspects of BDNF biology that would suggest potential roles in sex differences in epilepsy. Interestingly, the presence and/or pattern of sex differences in BDNF content across brain areas exhibits prominent species differences. Female rats exhibit higher BDNF content in several regions highly relevant to epilepsy and seizure activity, including hippocampus, cortex, and amygdala (Bland et al., 2005; Bakos et al., 2009; Snigdha et al., 2011), and male rats exhibit lower levels of hippocampal BDNF immunoreactivity compared with females, especially in the mossy fiber pathway (Scharfman et al., 2003). This sex difference, however, is reversed in mice, with males showing higher hippocampal BDNF content (Szapacs et al., 2004). Although humans do not appear to show a sex difference in hippocampal BDNF content, women may have higher BDNF in the prefrontal cortex (Hayley et al., 2015). Furthermore, BDNF expression appears to be highly sensitive to steroid hormone signaling, with estradiol, progesterone, and testosterone treatment, as well as removal of such hormones by gonadectomy, all producing changed BDNF levels in the brain (Solum and Handa, 2002; Franklin and PerrotSinal, 2006; Li et al., 2012). BDNF exerts its neurotrophic effects through activation of tropomyosin receptor kinase $\mathrm{B}$ (TrkB) receptors; heterozygous BDNF knockout mice exhibit a sex difference in the TrkB receptor pathway, with greater TrkB phosphorylation, and thus increased activation of downstream extracellular signal-related kinase signaling, in the frontal cortex and striatum of males compared with females (Hill and van den Buuse, 2011). Of particular relevance to potential sex differences in post-traumatic epileptogenesis, controlled cortical impact injury can produce sex-specific changes in BDNF content. Specifically, male Sprague-Dawley rats, but not females, exhibit increased $\mathrm{BDNF}$ in the frontal cortex ipsilateral to the injury, whereas female rats show increased BDNF in the contralateral hippocampus, an effect that was not observed in males (Chen et al., 2005b). In summary, baseline and dynamic differences in BDNF signaling are poised to produce sex differences in various aspects of neural functioning relevant to seizures and epilepsy.

\section{Glial Mechanisms: Astrocytes and Microglia}

There are nearly as many glial cells as neurons in the human brain (von Bartheld et al., 2016), and neuronglia interactions are essential to normal brain function [for review, see Khakh and Sofroniew (2015)]. Despite the increased interest in the role of glia, particularly astrocytes and microglia, in the pathophysiology of epilepsy [for recent comprehensive reviews, see Eyo et al. (2017), Patel et al. (2019)], there is a lack of information regarding the potential role of glia in sex differences in epilepsy. There is emerging evidence, however, for roles of astrocytes and microglia in sex differences in brain function. For example, several studies have documented sex differences in expression of the astrocyte marker glial fibrillary acidic protein (GFAP) in the hippocampus. GFAP expression in various hippocampal areas in Wistar rats appears to show sex-specific differences that shift from the prepubertal period into adulthood (Conejo et al., 2003, 2005; Arias et al., 2009). The number and morphology of astrocytes in the posterodorsal medial amygdala also exhibits sex differences, with higher numbers of astrocytes and greater astrocyte morphologic complexity in tissue from male rats (Johnson et al., 2008). Hippocampal GFAP expression may also shift with the estrous cycle in female rats, with higher numbers of GFAPimmunopositive cells detected on proestrus compared with diestrus in cornu ammonis 1 and cornu ammonis 3 (Arias et al., 2009). Changes in glial phenotype and morphology across the estrous cycle have also been described (Luquin et al., 1993; Klintsova et al., 1995). It should be noted that mice may not show similar sex differences in hippocampal GFAP immunoreactivity, but GFAP expression appears to be sensitive to estradiol and testosterone (via aromatization to estradiol) (McQueen et al., 1992). Cultures of astrocytes and microglia prepared from female and male rat pups also display sex-specific functional differences of high potential relevance to seizure activity, including increased resistance to oxygen-glucose deprivation and increased clearance of glutamate from extracellular space by cells from females (Liu et al., 2007; Morizawa et al., 2012) as well as increased expression of the inflammatory marker interleukin-1 $\beta$ in cells prepared from males (Loram et al., 2012).

Unfortunately, direct examination of sex differences in glial biology and neuronal-glial interactions in animal models of epilepsy is lacking. In one recent study, increased expression of GFAP was detected in the hippocampi of male C57BL/6J mice compared with females 5 days after systemic KA injection, but this effect may have reflected the increased acute seizure severity observed in the same male mice in that cohort ( $\mathrm{Li}$ and $\mathrm{Liu}, 2019$ ). With respect to potential roles in post-traumatic epileptogenesis, two studies have documented increased microglia activation in proximity to controlled cortical impact and penetrating cortical injury wounds in male mice, as detected by immunoreactivity for the microglial marker ionized calcium-binding adaptor molecule 1 (Acaz-Fonseca et al., 2015; Villapol et al., 2017). It should also be noted, however, that an increased expression of ionized calcium-binding adaptor molecule 1 in males at early time points after the injury may equalize later, such that no sex difference is seen 30 days later (Villapol et al., 2017). Finally, male mice may show a worsened outcome in experimental autoimmune 
encephalitis, a model of multiple sclerosis, and this sex difference is abolished by astrocyte-specific knockout of sodium voltage-gated channel alpha subunit 5 (Pappalardo et al., 2018). With increased development of tools to specifically manipulate the function of glial cells and selectively change the expression of certain genes and proteins in astrocytes and microglia, incorporation of specific assessment of sex differences in the effects of these manipulations, and especially in relation to synaptic function, neuronal excitability, and seizure susceptibility, would likely yield important insights.

\section{E. Stress Response and the Hypothalamic-Pituitary- Adrenal Axis}

Stress is a known risk factor for seizures (Neugebauer et al., 1994; Frucht et al., 2000; Haut et al., 2003, 2007; Nakken et al., 2005; Sperling et al., 2008) [for review, see Lai and Trimble (1997)]. The physiologic response to stress is mediated by the HPA axis, which coordinates the neuroendocrine response to stress through release of corticotropin-releasing hormone from the paraventricular nucleus of the hypothalamus, triggering the release of adrenocorticotropic hormone from the pituitary, which then signals the release of cortisol from the adrenal cortex (corticosterone in rodents). Numerous preclinical studies have demonstrated that stress and stress hormones are proconvulsant [for review, see Joëls (2009)]. Given this information, it is concerning that stress hormones have been shown to be elevated in patients with epilepsy and are positively correlated with seizure frequency (Culebras et al., 1987; Galimberti et al., 2005). Both clinical and preclinical studies support a role for stress, HPA axis activation, and elevated stress hormones in epilepsy [for review, see Maguire and Salpekar (2013)].

In addition to the impact of stress on epilepsy outcomes, HPA axis dysfunction has been demonstrated in preclinical epilepsy models. Seizures have been shown to activate the HPA axis (OToole et al., 2014), which can negatively impact epilepsy outcomes independent of stress. For example, HPA axis dysfunction, characterized by increased plasma corticosterone and deficits in the dexamethasone suppression test, is positively correlated with depression-like behaviors in an acquired epilepsy model (Mazarati et al., 2009). Similarly, seizure-induced activation of the HPA axis increased seizure frequency and comorbid depression-like behaviors in a preclinical epilepsy model (Hooper et al., 2018). Based on the fact that hypercortisolism is a hallmark feature of depression (Zobel et al., 2004; Kondziella et al., 2007), HPA dysfunction associated with epilepsy has been suggested to contribute to comorbid depression in epilepsy (Pineda et al., 2010). In fact, the HPA axis and glucocorticoids have been implicated in the bidirectional relationship between epilepsy and depression (Kanner, 2009), and social defeat stress has been shown to predispose chronically epileptic mice to depression-like behaviors (Becker et al., 2015). However, limited studies have directly tested the mechanistic underpinnings contributing to psychiatric comorbidities in epilepsy.

Clinical and preclinical evidence points to a clear relationship between stress, HPA axis dysfunction, and stress hormones in worsening epilepsy outcomes, including psychiatric comorbidities in epilepsy. There are also well established sex differences in stress reactivity and HPA axis function (Bale and Epperson, 2015; Bangasser et al., 2019) as well as the expression of glucocorticoid receptors (Bourke et al., 2012; Bangasser, 2013), which could impact the relationship between stress, epilepsy, and psychiatric comorbidities. However, to-date, there have not been any studies investigating sex differences in the role of stress, HPA axis, or stress hormones in mediating sex differences in psychiatric comorbidities in epilepsy. Further research is necessary to understand the underlying neurobiology contributing to these comorbidities and potential treatments suitable for both sexes.

\section{Considerations for Antiseizure Pharmacotherapies, Drug Screening, and Development}

Although the response to antiseizure medications is generally not considered to differ as a function of sex, there are well recognized clinical challenges associated with the use of ASDs that can differ by sex. This issue has been reviewed elsewhere (Perucca et al., 2014) and therefore is described only in brief here. First, though sex per se is not associated with clear pharmacokinetic differences for most ASDs, some small differences have been reported. Therefore, sex differences in drug metabolism, clearance rates, volume of distribution, and protein binding are important variables to consider both for existing therapeutics and those under development. For example, diazepam has been reported to be more highly protein-bound in males (Routledge et al., 1981), with a larger volume of distribution in females (Greenblatt et al., 1980). Levetiracetam clearance has been reported to be greater in females (Alzueta et al., 2018), although this effect was reduced when normalized for weight. Moreover, the half-life and clearance of carbamazepine have also been reported to differ as a function of sex, with males displaying longer half-life and lower clearance (Marino et al., 2012), consistent with the reports of greater hepatic CYP3A4 expression in females (Wolbold et al., 2003). Importantly, even in the absence of baseline differences in pharmacokinetics, these parameters change for many ASDs during pregnancy (Pennell, 2003). These issues underscore the importance of therapeutic drug monitoring and appropriate sex- or state- (e.g., pregnancy) specific dosing. Even in the absence of clear sex differences in large clinical trials, postapproval suggestions to adjust dosing have been issued on occasion, as in the case of zolpidem [for review, please see Farkas et al. (2013)]. 
Above and beyond pharmacokinetic issues, drug safety concerns may also differ as a function of sex. For example, many ASDs are associated with teratogenic effects (Tomson et al., 2018). Even in the absence of frank teratogenesis, gestational exposure to ASDs may cause long-lasting cognitive changes in offspring of women with epilepsy (Meador et al., 2011; Meador and Loring, 2016). Several ASDs can impact the metabolism of contraceptive agents, and some contraceptive agents, in turn, can impact ASD metabolism (Crawford, 2002; O'Brien and Guillebaud, 2010). There is also a major need for further studies examining the potential for changes in ASD efficacy and pharmacokinetics with age to address the growing need for treatments for patients in middle-aged and elderly populations of both sexes.

It is common for initial screening and subsequent differentiation screening of ASDs to occur in male rodents. However, some of these models, as reviewed above, display sex differences in response to ASDs. Moreover, hormonal influence (sex, estrous cycle stage) impacts responses in many screening models. Given these established differences, screening across sex should be considered, and, likewise, the relative parameters of the model should be adjusted to ensure sensitivity. For example, enhanced sensitivity to a chemoconvulsant in one sex or the other could produce a suprathreshold response and obscure subsequent effects of a putative antiseizure compound. Furthermore, despite ample evidence for sex differences in early development, sex as a biologic variable in the context of preclinical or clinical treatments for early-life epilepsy has been almost completely ignored. Given the robust evidence regarding sex differences in development of inhibitory neurotransmission, neurophysiology, and response to injury, careful assessment of sex in studies in developing animals is a clear priority.

\section{Concluding Remarks and Future Directions}

The epilepsies and associated comorbidities prominently affect both sexes, but the specific features and treatment options have some clear distinctions. Overall, our review of the clinical literature in epilepsy thankfully found many studies that included both sexes in patient cohorts, whether by design or by convenience. Unfortunately, the current picture for preclinical animal studies is more skewed. In keeping with much of the preclinical and basic research conducted in neuroscience over the last several decades, most studies have primarily used male animals (Prendergast et al., 2014; Will et al., 2017). Emerging directives from funding agencies, such as the U.S. National Institutes of Health mandate to address sex as a biologic variable (Clayton and Collins, 2014), are aimed at correcting this imbalance. Going forward in both clinical and preclinical studies, we suggest that more emphasis needs to be placed on systematic inclusion of both males and females within the same studies to facilitate direct comparisons and encourage funding and publishing support for studies designed to evaluate the extent to which findings previously obtained in male animals are replicated in females.

Although in our review we were able to find many pieces of literature that included both male and female subjects, there are still gaping holes in our knowledge regarding specific sex differences in the underlying neurobiology of seizures, pharmacokinetics of ASDs, and interactions between the brain and endocrine systems, just to name a few aspects. It should also be noted that emerging evidence suggests that some sex differences are "latent," such that the emergent phenotype does not necessarily display a major sex difference, but the underlying mechanisms that give rise to the phenotype are distinct (Koss et al., 2018; Jain et al., 2019a). This prospect has so far received little attention in the field of epilepsy but is an important possibility to consider, particularly given the implications for efficacy of pharmacotherapies and other forms of treatment. Proper assessment of sex differences in underlying neurobiological mechanisms relevant to epilepsy and drug efficacy will improve epilepsy treatment of as many patients as possible, no matter their sex or gender.

\section{Acknowledgments}

This review was inspired by the 2017 Scientific Symposium on "Sex and the Seizure" at the 71st Annual Meeting of the American Epilepsy Society in Washington, D.C.

\section{Authorship Contributions}

Wrote or contributed to the writing of the manuscript: Christian, Reddy, Maguire, Forcelli.

\section{References}

Aaberg KM, Bakken IJ, Lossius MI, Lund Søraas C, Håberg SE, Stoltenberg C, Surén $\mathrm{P}$, and Chin R (2016) Comorbidity and childhood epilepsy: a nationwide registry study. Pediatrics 138:e20160921.

Abbott RJ, Browning MC, and Davidson DL (1980) Serum prolactin and cortisol concentrations after grand mal seizures. J Neurol Neurosurg Psychiatry 43: 163-167.

Acaz-Fonseca E, Duran JC, Carrero P, Garcia-Segura LM, and Arevalo MA (2015) Sex differences in glia reactivity after cortical brain injury. Glia 63:1966-1981.

Adelöw C, Andell E, Amark P, Andersson T, Hellebro E, Ahlbom A, and Tomson T (2009) Newly diagnosed single unprovoked seizures and epilepsy in Stockholm, Sweden: first report from the Stockholm Incidence Registry of Epilepsy (SIRE). Epilepsia 50:1094-1101.

Aguilar BL, Malkova L, N'Gouemo P, and Forcelli PA (2018) Genetically epilepsyprone rats display anxiety-like behaviors and neuropsychiatric comorbidities of epilepsy. Front Neurol 9:476.

Akman O, Moshe SL, and Galanopoulou AS (2014) Sex-specific consequences of early life seizures. Neurobiol Dis 72 (Pt B):153-166.

Akman O, Moshé SL, and Galanopoulou AS (2015) Early life status epilepticus and stress have distinct and sex-specific effects on learning, subsequent seizure outcomes, including anticonvulsant response to phenobarbital. CNS Neurosci Ther 21: 181-192.

Al Mamun A, Yu H, Romana S, and Liu F (2018) Inflammatory responses are sex specific in chronic hypoxic-ischemic encephalopathy. Cell Transplant 27: 1328-1339.

Altemus M, Sarvaiya N, and Neill Epperson C (2014) Sex differences in anxiety and depression clinical perspectives. Front Neuroendocrinol 35:320-330.

Alvarenga TA, Matos G, Scorza FA, Amado D, Cavalheiro EA, Tufik S, and Andersen ML (2013) Sexual response in female rats with status epilepticus. Epilepsia 54: $644-648$.

Alzueta N, Ortega A, and Aldaz A (2018) Influence of sex, age, and weight on levetiracetam pharmacokinetics. Ther Drug Monit 40:628-634.

Amado D and Cavalheiro EA (1998) Hormonal and gestational parameters in female rats submitted to the pilocarpine model of epilepsy. Epilepsy Res 32:266-274. 
Amado D, Cavalheiro EA, and Bentivoglio M (1993) Epilepsy and hormonal regulation: the patterns of $\mathrm{GnRH}$ and galanin immunoreactivity in the hypothalamus of epileptic female rats. Epilepsy Res 14:149-159.

Amado D, Verreschi IT, Berzaghi MP, and Cavalheiro EA (1987) Effects of intrahippocampal injection of kainic acid on estrous cycle in rats. Braz J Med Biol Res 20:829-832.

Amano S, Ihara N, Uemura S, Yokoyama M, Ikeda M, Serikawa T, Sasahara M, Kataoka H, Hayase Y, and Hazama F (1996) Development of a novel rat mutant with spontaneous limbic-like seizures. Am J Pathol 149:329-336.

Andersen ML, Alvarenga TA, Scorza FA, Matos G, Sonoda EY, Hirotsu C, Cavalheiro $\mathrm{EA}$, and Tufik S (2012) Impairment of sexual function in rats with epilepsy. $J$ Sex Med 9:2266-2272.

Andreano JM and Cahill L (2009) Sex influences on the neurobiology of learning and memory. Learn Mem 16:248-266.

Arain FM, Boyd KL, and Gallagher MJ (2012) Decreased viability and absence-like epilepsy in mice lacking or deficient in the GABAA receptor $\alpha 1$ subunit. Epilepsia 53:e161-e165.

Arias C, Zepeda A, Hernández-Ortega K, Leal-Galicia P, Lojero C, and CamachoArroyo I (2009) Sex and estrous cycle-dependent differences in glial fibrillary acidic protein immunoreactivity in the adult rat hippocampus. Horm Behav 55:257-263.

Arnold AP (2009) The organizational-activational hypothesis as the foundation for a unified theory of sexual differentiation of all mammalian tissues. Horm Behav $\mathbf{5 5}$ : $570-578$.

Artama M, Isojärvi JI, Raitanen J, and Auvinen A (2004) Birth rate among patients with epilepsy: a nationwide population-based cohort study in Finland. Am J Epidemiol 159:1057-1063.

Asperholm M, Högman N, Rafi J, and Herlitz A (2019) What did you do yesterday? A meta-analysis of sex differences in episodic memory. Psychol Bull 145 $785-821$.

Bäckström T (1976) Epileptic seizures in women related to plasma estrogen and progesterone during the menstrual cycle. Acta Neurol Scand 54:321-347.

Bäckström T, Zetterlund B, Blom S, and Romano M (1984) Effects of intravenous progesterone infusions on the epileptic discharge frequency in women with partial epilepsy. Acta Neurol Scand 69:240-248.

Baird AD, Wilson SJ, Bladin PF, Saling MM, and Reutens DC (2003) Sexual outcome after epilepsy surgery. Epilepsy Behav 4:268-278.

Bakos J, Hlavacova N, Rajman M, Ondicova K, Koros C, Kitraki E, Steinbusch HW, and Jezova D (2009) Enriched environment influences hormonal status and hippocampal brain derived neurotrophic factor in a sex dependent manner. Neuroscience 164:788-797.

Bale TL and Epperson CN (2015) Sex differences and stress across the lifespan. Nat Neurosci 18:1413-1420.

Banerjee PK and Snead OC III (1998) Neuroactive steroids exacerbate gammahydroxybutyric acid-induced absence seizures in rats. Eur J Pharmacol 359:41-48.

Bangasser DA (2013) Sex differences in stress-related receptors: "micro" differences with "macro" implications for mood and anxiety disorders. Biol Sex Differ 4:2

Bangasser DA, Eck SR, and Ordoñes Sanchez E (2019) Sex differences in stress reactivity in arousal and attention systems. Neuropsychopharmacology 44: 129-139.

Baron-Cohen S, Lombardo MV, Auyeung B, Ashwin E, Chakrabarti B, and Knickmeyer R (2011) Why are autism spectrum conditions more prevalent in males? PLoS Biol 9:e1001081.

Bastlund JF, Berry D, and Watson WP (2005) Pharmacological and histological characterisation of nicotine-kindled seizures in mice. Neuropharmacology 48 975-983.

Bauer J, Blumenthal S, Reuber M, and Stoffel-Wagner B (2004) Epilepsy syndrome, focus location, and treatment choice affect testicular function in men with epilepsy. Neurology 62:243-246.

Bauer J, Burr W, and Elger CE (1998) Seizure occurrence during ovulatory and anovulatory cycles in patients with temporal lobe epilepsy: a prospective study. Eur J Neurol 5:83-88.

Bauer J, Jarre A, Klingmüller D, and Elger CE (2000a) Polycystic ovary syndrome in patients with focal epilepsy: a study in 93 women. Epilepsy Res 41:163-167.

Bauer J, Stoffel-Wagner B, Flügel D, Kluge M, and Elger CE (2000b) The impact of epilepsy surgery on sex hormones and the menstrual cycle in female patients. Seizure 9:389-393.

Bauer J, Stoffel-Wagner B, Flügel D, Kluge M, Schramm J, Bidlingmaier F, and Elger CE (2000c) Serum androgens return to normal after temporal lobe epilepsy surgery in men. Neurology 55:820-824.

Becker C, Bouvier E, Ghestem A, Siyoucef S, Claverie D, Camus F, Bartolomei F, Benoliel J-J, and Bernard C (2015) Predicting and treating stress-induced vulnerability to epilepsy and depression. Ann Neurol 78:128-136.

Belelli D, Casula A, Ling A, and Lambert JJ (2002) The influence of subunit composition on the interaction of neurosteroids with GABA(A) receptors. Neuropharmacology 43:651-661.

Bell B, Lin JJ, Seidenberg M, and Hermann B (2011) The neurobiology of cognitive disorders in temporal lobe epilepsy. Nat Rev Neurol 7:154-164.

Ben-Ari Y, Gaiarsa JL, Tyzio R, and Khazipov R (2007) GABA: a pioneer transmitter that excites immature neurons and generates primitive oscillations. Physiol Rev 87:1215-1284.

Ben-Ari Y, Lagowska J, Tremblay E, and Le Gal La Salle G (1979) A new model of focal status epilepticus: intra-amygdaloid application of kainic acid elicits repetitive secondarily generalized convulsive seizures. Brain Res 163:176-179.

Bender RA, Dubé C, Gonzalez-Vega R, Mina EW, and Baram TZ (2003) Mossy fiber plasticity and enhanced hippocampal excitability, without hippocampal cell loss or altered neurogenesis, in an animal model of prolonged febrile seizures. Hippocampus 13:399-412.

Bengner T, Fortmeier C, Malina T, Lindenau M, Voges B, Goebell E, and Stodieck S (2006) Sex differences in face recognition memory in patients with temporal lobe epilepsy, patients with generalized epilepsy, and healthy controls. Epilepsy Behav 9:593-600
Bengtson M, Martin R, Sawrie S, Gilliam F, Faught E, Morawetz R, and Kuzniecky R (2000) Gender, memory, and hippocampal volumes: relationships in temporal lobe epilepsy. Epilepsy Behav 1:112-119.

Berenbaum SA, Baxter L, Seidenberg M, and Hermann B (1997) Role of the hippocampus in sex differences in verbal memory: memory outcome following left anterior temporal lobectomy. Neuropsychology 11:585-591.

Berger J, Demin K, Holtkamp M, and Bengner T (2018) Female verbal memory advantage in temporal, but not frontal lobe epilepsy. Epilepsy Res 139:129-134.

Berger J, Oltmanns F, Holtkamp M, and Bengner T (2017) Sex differences in verbal and nonverbal learning before and after temporal lobe epilepsy surgery. Epilepsy Behav 66:57-63.

Berry-Kravis E, Raspa M, Loggin-Hester L, Bishop E, Holiday D, and Bailey DB (2010) Seizures in fragile X syndrome: characteristics and comorbid diagnoses. Am J Intellect Dev Disabil 115:461-472.

Beyer B, Deleuze C, Letts VA, Mahaffey CL, Boumil RM, Lew TA, Huguenard JR, and Frankel WN (2008) Absence seizures in $\mathrm{C} 3 \mathrm{H} / \mathrm{HeJ}$ and knockout mice caused by mutation of the AMPA receptor subunit Gria4. Hum Mol Genet 17:1738-1749.

Bhanot R and Wilkinson M (1982) Repeated convulsions induce pseudopregnancy in the intact rat and inhibit steroid-mediated gonadotrophin secretion in the ovariectomized rat. J Endocrinol 95:43-48.

Bigal ME, Lipton RB, Cohen J, and Silberstein SD (2003) Epilepsy and migraine. Epilepsy Behav 4 (Suppl 2):S13-S24.

Bilo L, Meo R, Nappi C, Annunziato L, Striano S, Colao AM, Merola B, and Buscaino GA (1988) Reproductive endocrine disorders in women with primary generalized epilepsy. Epilepsia 29:612-619.

Bjørnaes H, Stabell KE, Røste GK, and Bakke SJ (2005) Changes in verbal and nonverbal memory following anterior temporal lobe surgery for refractory seizures: effects of sex and laterality. Epilepsy Behav 6:71-84.

Bland ST, Schmid MJ, Der-Avakian A, Watkins LR, Spencer RL, and Maier SF (2005) Expression of c-fos and BDNF mRNA in subregions of the prefrontal cortex of male and female rats after acute uncontrollable stress. Brain Res 1051:90-99.

Bolay H, Berman NE, and Akcali D (2011) Sex-related differences in animal models of migraine headache. Headache 51:891-904.

Bond TL, Drage M, and Heinrichs SC (2003) Seizure-prone EL mice exhibit deficits in pup nursing and retrieval assessed using a novel method of maternal behavior phenotyping. Epilepsy Behav 4:57-64

Bonuccelli U, Melis GB, Paoletti AM, Fioretti P, Murri L, and Muratorio A (1989) Unbalanced progesterone and estradiol secretion in catamenial epilepsy. Epilepsy Res 3:100-106.

Borowicz KK, Kleinrok Z, and Czuczwar SJ (2003) Influence of sex hormone antagonists on the anticonvulsant action of conventional antiepileptic drugs against amygdala-kindled seizures in male and female rats. Eur Neuropsychopharmacol 13:257-265.

Bøttger P, Glerup S, Gesslein B, Illarionova NB, Isaksen TJ, Heuck A, Clausen BH, Füchtbauer EM, Gramsbergen JB, Gunnarson E, et al. (2016) Glutamate-system defects behind psychiatric manifestations in a familial hemiplegic migraine type 2 disease-mutation mouse model. Sci Rep 6:22047.

Bourke CH, Harrell CS, and Neigh GN (2012) Stress-induced sex differences: adaptations mediated by the glucocorticoid receptor. Horm Behav 62:210-218.

Bowers JM, Waddell J, and McCarthy MM (2010) A developmental sex difference in hippocampal neurogenesis is mediated by endogenous oestradiol. Biol Sex Differ 1:

Bragatti JA, Torres CM, Londero RG, Assmann JB, Fontana V, Martin KC, Hidalgo MP, Chaves ML, and Bianchin MM (2010) Prevalence of psychiatric comorbidities in temporal lobe epilepsy: the value of structured psychiatric interviews. Epileptic Disord 12:283-291.

Brandt C and Mula M (2016) Anxiety disorders in people with epilepsy. Epilepsy Behav 59:87-91.

Brandt C, Schoendienst M, Trentowska M, May TW, Pohlmann-Eden B, TuschenCaffier B, Schrecke M, Fueratsch N, Witte-Boelt K, and Ebner A (2010) Prevalence of anxiety disorders in patients with refractory focal epilepsy--a prospective clinic based survey. Epilepsy Behav 17:259-263.

Brennan KC, Romero Reyes M, López Valdés HE, Arnold AP, and Charles AC (2007) Reduced threshold for cortical spreading depression in female mice. Ann Neurol 61 $603-606$.

Brodtkorb E, Bakken IJ, and Sjaastad O (2008) Comorbidity of migraine and epilepsy in a Norwegian community. Eur J Neurol 15:1421-1423.

Buckmaster PS and Haney MM (2012) Factors affecting outcomes of pilocarpine treatment in a mouse model of temporal lobe epilepsy. Epilepsy Res 102:153-159.

Budziszewska B, Van Luijtelaar G, Coenen AM, Leśkiewicz M, and Lasoń W (1999) Effects of neurosteroids on spike-wave discharges in the genetic epileptic WAG/Rij rat. Epilepsy Res 33:23-29.

Buterbaugh GG (1987) Acquisition of amygdala-kindled seizures in female rats: relationship between the effect of estradiol and intra-amygdaloid electrode location. Pharmacol Biochem Behav 28:291-297.

Buterbaugh GG (1989) Estradiol replacement facilitates the acquisition of seizures kindled from the anterior neocortex in female rats. Epilepsy Res 4:207-215.

Buterbaugh GG and Hudson GM (1991) Estradiol replacement to female rats facilitates dorsal hippocampal but not ventral hippocampal kindled seizure acquisition. Exp Neurol 111:55-64.

Camfield CS, Camfield PR, Gordon K, Wirrell E, and Dooley JM (1996) Incidence of epilepsy in childhood and adolescence: a population-based study in Nova Scotia from 1977 to 1985 . Epilepsia 37:19-23.

Carlson C, Dugan P, Kirsch HE, and Friedman D; EPGP Investigators (2014) Sex differences in seizure types and symptoms. Epilepsy Behav 41:103-108.

Chachua T, Goletiani C, Maglakelidze G, Sidyelyeva G, Daniel M, Morris E, Miller J, Shang E, Wolgemuth DJ, Greenberg DA, et al. (2014) Sex-specific behavioral traits in the Brd2 mouse model of juvenile myoclonic epilepsy. Genes Brain Behav 13: $702-712$

Chachua T, Yum MS, Velíšková J, and Velíšek L (2011) Validation of the rat model of cryptogenic infantile spasms. Epilepsia 52:1666-1677. 
Chan J, Chen J, Makhija K, Faulkner M, and Singh S (2015) Gender differences in the incidence of psychiatric co-morbidity in patients with epilepsy (P3.196). Neurology 84:P3.196.

Charles AC and Baca SM (2013) Cortical spreading depression and migraine. Nat Rev Neurol 9:637-644.

Chen CC, Chen TF, Lin HC, Oon PC, Wu HM, Wang PJ, Chen TH, and Liou HH (2004) Estimation of prevalence and incidence of infantile spasms in Taiwan using capture-recapture method. Epilepsy Res 58:37-42.

Chen DK, So YT, and Fisher RS; Therapeutics and Technology Assessment Subcommittee of the American Academy of Neurology (2005a) Use of serum prolactin in diagnosing epileptic seizures: report of the therapeutics and technology assessment subcommittee of the American academy of neurology. Neurology 65: 668-675.

Chen NC, Chuang YC, Huang CW, Lui CC, Lee CC, Hsu SW, Lin PH, Lu YT, Chang YT, Hsu CW, et al. (2016) Interictal serum brain-derived neurotrophic factor level reflects white matter integrity, epilepsy severity, and cognitive dysfunction in chronic temporal lobe epilepsy. Epilepsy Behav 59:147-154.

Chen X, Li Y, Kline AE, Dixon CE, Zafonte RD, and Wagner AK (2005b) Gender and environmental effects on regional brain-derived neurotrophic factor expression after experimental traumatic brain injury. Neuroscience 135:11-17.

Chin J and Scharfman HE (2013) Shared cognitive and behavioral impairments in epilepsy and Alzheimer's disease and potential underlying mechanisms. Epilepsy Behav 26:343-351.

Cho KO, Lybrand ZR, Ito N, Brulet R, Tafacory F, Zhang L, Good L, Ure K, Kernie SG, Birnbaum SG, et al. (2015) Aberrant hippocampal neurogenesis contributes to epilepsy and associated cognitive decline. Nat Commun 6:6606

Cho SJ, Vaca MA, Miranda CJ, and N'Gouemo P (2018) Inhibition of transient potential receptor vanilloid type 1 suppresses seizure susceptibility in the genetically epilepsy-prone rat. CNS Neurosci Ther 24:18-28.

Christensen J, Kjeldsen MJ, Andersen H, Friis ML, and Sidenius P (2005) Gender differences in epilepsy. Epilepsia 46:956-960.

Christensen J, Vestergaard M, Pedersen MG, Pedersen CB, Olsen J, and Sidenius $\mathrm{P}$ (2007) Incidence and prevalence of epilepsy in Denmark. Epilepsy Res $\mathbf{7 6}$ 60-65.

Christianson SA, Silfvenius H, Säisä J, and Nilsson M (1995) Life satisfaction and sexuality in patients operated for epilepsy. Acta Neurol Scand 92:1-6.

Chudomel O, Herman H, Nair K, Moshé SL, and Galanopoulou AS (2009) Age- and gender-related differences in GABAA receptor-mediated postsynaptic currents in GABAergic neurons of the substantia nigra reticulata in the rat. Neuroscience $\mathbf{1 6 3}$ : 155-167.

Chugani DC, Muzik O, Juhász C, Janisse JJ, Ager J, and Chugani HT (2001) Postnatal maturation of human GABAA receptors measured with positron emission tomography. Ann Neurol 49:618-626.

Clayton JA and Collins FS (2014) Policy: NIH to balance sex in cell and animal studies. Nature 509:282-283.

Cleary RT, Sun H, Huynh T, Manning SM, Li Y, Rotenberg A, Talos DM, Kahle KT, Jackson M, Rakhade SN, et al. (2013) Bumetanide enhances phenobarbital efficacy in a rat model of hypoxic neonatal seizures [published correction appears in PLoS One (2013) 8]. PLoS One 8:e57148.

Coenen AM and Van Luijtelaar EL (1987) The WAG/Rij rat model for absence epilepsy: age and sex factors. Epilepsy Res 1:297-301.

Coeytaux A, Jallon P, Galobardes B, and Morabia A (2000) Incidence of status epilepticus in French-speaking Switzerland: (EPISTAR). Neurology 55:693-697.

Collins WC, Lanigan O, and Callaghan N (1983) Plasma prolactin concentrations following epileptic and pseudoseizures. J Neurol Neurosurg Psychiatry 46:505-508.

Conejo NM, González-Pardo H, Cimadevilla JM, Argüelles JA, Díaz F, Vallejo-Seco G, and Arias JL (2005) Influence of gonadal steroids on the glial fibrillary acidic protein-immunoreactive astrocyte population in young rat hippocampus. J Neurosci Res 79:488-494.

Conejo NM, González-Pardo H, Pedraza C, Navarro FF, Vallejo G, and Arias JL (2003) Evidence for sexual difference in astrocytes of adult rat hippocampus. Neurosci Lett 339:119-122.

Cope DW, Di Giovanni G, Fyson SJ, Orbán G, Errington AC, Lorincz ML, Gould TM, Carter DA, and Crunelli V (2009) Enhanced tonic GABAA inhibition in typical absence epilepsy. Nat Med 15:1392-1398.

Cowan LD, Bodensteiner JB, Leviton A, and Doherty L (1989) Prevalence of the epilepsies in children and adolescents. Epilepsia 30:94-106.

Crawford P (2002) Interactions between antiepileptic drugs and hormonal contraception. CNS Drugs 16:263-272.

Culebras A, Miller M, Bertram L, and Koch J (1987) Differential response of growth hormone, cortisol, and prolactin to seizures and to stress. Epilepsia 28:564-570.

Cummings LN, Giudice L, and Morrell MJ (1995) Ovulatory function in epilepsy. Epilepsia 36:355-359.

Członkowska AI, Krzaścik P, Sienkiewicz-Jarosz H, Siemiatkowski M, Szyndler J, Bidziński A, and Płaźnik A (2000) The effects of neurosteroids on picrotoxin-, bicuculline- and NMDA-induced seizures, and a hypnotic effect of ethanol. Pharmacol Biochem Behav 67:345-353.

D'Amour J, Magagna-Poveda A, Moretto J, Friedman D, LaFrancois JJ, Pearce P, Fenton AA, MacLusky NJ, and Scharfman HE (2015) Interictal spike frequency varies with ovarian cycle stage in a rat model of epilepsy. Exp Neurol 269:102-119.

Dana-Haeri J, Oxley J, and Richens A (1984) Pituitary responsiveness to gonadotrophin-releasing and thyrotrophin-releasing hormones in epileptic patients receiving carbamazepine or phenytoin. Clin Endocrinol (Oxf) 20:163-168.

Dana-Haeri J, Trimble MR, and Oxley J (1983) Prolactin and gonadotrophin changes following generalised and partial seizures. J Neurol Neurosurg Psychiatry 46: 331-335.

Daniele A, Azzoni A, Bizzi A, Rossi A, Gainotti G, and Mazza S (1997) Sexual behavior and hemispheric laterality of the focus in patients with temporal lobe epilepsy. Biol Psychiatry 42:617-624.

Davies KG, Bell BD, Bush AJ, and Wyler AR (1998) Prediction of verbal memory loss in individuals after anterior temporal lobectomy. Epilepsia 39:820-828.
DeLorenzo RJ, Hauser WA, Towne AR, Boggs JG, Pellock JM, Penberthy L, Garnett L, Fortner CA, and Ko D (1996) A prospective, population-based epidemiologic study of status epilepticus in Richmond, Virginia. Neurology 46:1029-1035.

Demerdash A, Shaalan M, Midani A, Kamel F, and Bahri M (1991) Sexual behavior of a sample of females with epilepsy. Epilepsia 32:82-85.

Dogui M, Jallon P, Tamallah JB, Sakly G, Trabelsi MA, Khalifa K, Yacoub M, and Abroug S (2003) Episousse: incidence of newly presenting seizures in children in the Region of Sousse, Tunisia. Epilepsia 44:1441-1444.

Doucette TA, Ryan CL, and Tasker RA (2007) Gender-based changes in cognition and emotionality in a new rat model of epilepsy. Amino Acids 32:317-322.

Drislane FW, Coleman AE, Schomer DL, Ives J, Levesque LA, Seibel MM, and Herzog AG (1994) Altered pulsatile secretion of luteinizing hormone in women with epilepsy. Neurology 44:306-310.

Duncan S, Blacklaw J, Beastall GH, and Brodie MJ (1997) Sexual function in women with epilepsy. Epilepsia 38:1074-1081.

Dzhala VI, Brumback AC, and Staley KJ (2008) Bumetanide enhances phenobarbital efficacy in a neonatal seizure model. Ann Neurol 63:222-235.

Dzhala VI, Talos DM, Sdrulla DA, Brumback AC, Mathews GC, Benke TA, Delpire E, Jensen FE, and Staley KJ (2005) NKCC1 transporter facilitates seizures in the developing brain. Nat Med 11:1205-1213.

Ebert U, Rundfeldt C, and Löscher W (1994) Sex differences in the anticonvulsant efficacy of phenytoin in amygdala-kindled rats. Brain Res 638:45-52.

Edwards HE, Burnham WM, and MacLusky NJ (1999a) Partial and generalized seizures affect reproductive physiology differentially in the male rat. Epilepsia 40: $1490-1498$.

Edwards HE, Burnham WM, and MacLusky NJ (1999b) Testosterone and its metabolites affect afterdischarge thresholds and the development of amygdala kindled seizures. Brain Res 838:151-157.

Edwards HE, Burnham WM, Mendonca A, Bowlby DA, and MacLusky NJ (1999c) Steroid hormones affect limbic afterdischarge thresholds and kindling rates in adult female rats. Brain Res 838:136-150.

Edwards HE, Burnham WM, Ng MM, Asa S, and MacLusky NJ (1999d) Limbic seizures alter reproductive function in the female rat. Epilepsia 40:1370-1377.

Eikermann-Haerter K, Dileköz E, Kudo C, Savitz SI, Waeber C, Baum MJ, Ferrari MD, van den Maagdenberg AM, Moskowitz MA, and Ayata C (2009) Genetic and hormonal factors modulate spreading depression and transient hemiparesis in mouse models of familial hemiplegic migraine type 1. J Clin Invest 119:99-109.

Eikermann-Haerter K, Yuzawa I, Qin T, Wang Y, Baek K, Kim YR, Hoffmann U, Dilekoz E, Waeber C, Ferrari MD, et al. (2011) Enhanced subcortical spreading depression in familial hemiplegic migraine type 1 mutant mice. $J$ Neurosci 31 : $5755-5763$

El-Khayat HA, Soliman NA, Tomoum HY, Omran MA, El-Wakad AS, and Shatla RH (2008) Reproductive hormonal changes and catamenial pattern in adolescent females with epilepsy. Epilepsia 49:1619-1626.

England MJ, Liverman CT, Schultz AM, and Strawbridge LM (2012) Epilepsy across the spectrum: promoting health and understanding. A summary of the Institute of Medicine report. Epilepsy Behav 25:266-276.

Errington AC, Cope DW, and Crunelli V (2011) Augmentation of tonic GABA(A) inhibition in absence epilepsy: therapeutic value of inverse agonists at extrasynaptic GABA(A) receptors. Adv Pharmacol Sci 2011:790590.

Eyo UB, Murugan M, and Wu LJ (2017) Microglia-neuron communication in epilepsy. Glia 65:5-18.

Faingold CL and Randall M (2013) Effects of age, sex, and sertraline administration on seizure-induced respiratory arrest in the DBA/ 1 mouse model of sudden unexpected death in epilepsy (SUDEP). Epilepsy Behav 28:78-82.

Faingold CL, Randall M, and Tupal S (2010) DBA/1 mice exhibit chronic susceptibility to audiogenic seizures followed by sudden death associated with respiratory arrest. Epilepsy Behav 17:436-440.

Farkas RH, Unger EF, and Temple R (2013) Zolpidem and driving impairmentidentifying persons at risk. N Engl J Med 369:689-691.

Fawley JA, Pouliot WA, and Dudek FE (2012) Pilocarpine-induced status epilepticus and subsequent spontaneous seizures: lack of effect on the number of gonadotropin-releasing hormone-positive neurons in a mouse model of temporal lobe epilepsy. Neuroscience 203:153-159.

Feeney DM, Gullotta FP, and Gilmore W (1998) Hyposexuality produced by temporal lobe epilepsy in the cat. Epilepsia 39:140-149.

Fehr S, Bebbington A, Nassar N, Downs J, Ronen GM, DE Klerk N, and Leonard H (2011) Trends in the diagnosis of Rett syndrome in Australia. Pediatr Res 70: 313-319.

Ferrari MD, Klever RR, Terwindt GM, Ayata C, and van den Maagdenberg AM (2015) Migraine pathophysiology: lessons from mouse models and human genetics. Lancet Neurol 14:65-80.

Ferretti MT, Iulita MF, Cavedo E, Chiesa PA, Schumacher Dimech A, Santuccione Chadha A, Baracchi F, Girouard H, Misoch S, Giacobini E, et al.; Women's Brain Project and the Alzheimer Precision Medicine Initiative (2018) Sex differences in Alzheimer disease - the gateway to precision medicine. Nat Rev Neurol 14:457-469.

Fiest KM, Sauro KM, Wiebe S, Patten SB, Kwon CS, Dykeman J, Pringsheim T, Lorenzetti DL, and Jetté N (2017) Prevalence and incidence of epilepsy: a systematic review and meta-analysis of international studies. Neurology 88: 296-303.

Finn DA and Gee KW (1994) The estrus cycle, sensitivity to convulsants and the anticonvulsant effect of a neuroactive steroid. J Pharmacol Exp Ther 271:164-170.

Fisher RS, Cross JH, D'Souza C, French JA, Haut SR, Higurashi N, Hirsch E, Jansen FE, Lagae L, Moshé SL, et al. (2017) Instruction manual for the ILAE 2017 operational classification of seizure types. Epilepsia 58:531-542.

Forcelli PA, Orefice LL, and Heinrichs SC (2007) Neural, endocrine and electroencephalographic hyperreactivity to human contact: a diathesis-stress model of seizure susceptibility in El mice. Brain Res 1144:248-256.

Förderreuther S, Henkel A, Noachtar S, and Straube A (2002) Headache associated with epileptic seizures: epidemiology and clinical characteristics. Headache 42: 649-655. 
Frankel WN, Taylor L, Beyer B, Tempel BL, and White HS (2001) Electroconvulsive thresholds of inbred mouse strains. Genomics 74:306-312.

Franklin TB and Perrot-Sinal TS (2006) Sex and ovarian steroids modulate brainderived neurotrophic factor (BDNF) protein levels in rat hippocampus under stressful and non-stressful conditions. Psychoneuroendocrinology 31:38-48.

Friedman MN, Geula C, Holmes GL, and Herzog AG (2002) GnRHimmunoreactive fiber changes with unilateral amygdala-kindled seizures. $E p$ ilepsy Res 52:73-77.

Frings L, Wagner K, Halsband U, Schwarzwald R, Zentner J, and Schulze-Bonhage A (2008) Lateralization of hippocampal activation differs between left and right temporal lobe epilepsy patients and correlates with postsurgical verbal learning decrement. Epilepsy Res 78:161-170.

Frings L, Wagner K, Unterrainer J, Spreer J, Halsband U, and Schulze-Bonhage A (2006) Gender-related differences in lateralization of hippocampal activation and cognitive strategy. Neuroreport 17:417-421.

Frucht MM, Quigg M, Schwaner C, and Fountain NB (2000) Distribution of seizure precipitants among epilepsy syndromes. Epilepsia 41:1534-1539.

Frye CA and Reed TA (1998) Androgenic neurosteroids: anti-seizure effects in an animal model of epilepsy. Psychoneuroendocrinology 23:385-399.

Frye CA, Rhodes ME, Walf A, and Harney J (2002) Progesterone reduces pentylenetetrazol-induced ictal activity of wild-type mice but not those deficient in type I 5alpha-reductase. Epilepsia 43 (Suppl 5):14-17.

Frye CA, Rhodes ME, Walf AA, and Harney JP (2001) Testosterone reduces pentylenetetrazole-induced ictal activity of wildtype mice but not those deficient in type I 5alpha-reductase. Brain Res 918:182-186.

Frye CA, Ryan A, and Rhodes M (2009) Antiseizure effects of 3alpha-androstanediol and/or 17beta-estradiol may involve actions at estrogen receptor beta. Epilepsy Behav 16:418-422.

Fujii T, Nonaka C, and Ikeda H (1984) Differential effects of picrotoxin- and pentylenetetrazol-induced convulsions on the secretion of luteinizing hormone and follicle-stimulating hormone in rats. Psychoneuroendocrinology 9 391-397

Galanopoulou AS (2008) Dissociated gender-specific effects of recurrent seizures on GABA signaling in CA1 pyramidal neurons: role of GABA(A) receptors. J Neurosci 28:1557-1567.

Galanopoulou AS, Kyrozis A, Claudio OI, Stanton PK, and Moshé SL (2003) Sexspecific $\mathrm{KCC} 2$ expression and $\mathrm{GABA}(\mathrm{A})$ receptor function in rat substantia nigra. Exp Neurol 183:628-637.

Galanopoulou AS and Moshé SL (2003) Role of sex hormones in the sexually dimorphic expression of KCC2 in rat substantia nigra. Exp Neurol 184: 1003-1009.

Galimberti CA, Magri F, Copello F, Arbasino C, Cravello L, Casu M, Patrone V, and Murialdo G (2005) Seizure frequency and cortisol and dehydroepiandrosterone sulfate (DHEAS) levels in women with epilepsy receiving antiepileptic drug treatment. Epilepsia 46:517-523.

Gallo RV, Johnson JH, Goldman BD, Whitmoyer DI, and Sawyer CH (1971) Effects of electrochemical stimulation of the ventral hippocampus on hypothalamic electrical activity and pituitary gonadotropin secretion in female rats. Endocrinology $\mathbf{8 9}$ 704-713

Gangisetty O and Reddy DS (2010) Neurosteroid withdrawal regulates GABA-A receptor $\alpha 4$-subunit expression and seizure susceptibility by activation of progesterone receptor-independent early growth response factor-3 pathway. Neuroscience 170:865-880.

Gill DA, Bastlund JF, Watson WP, Ryan CL, Reynolds DS, and Tasker RA (2010) Neonatal exposure to low-dose domoic acid lowers seizure threshold in adult rats. Neuroscience 169:1789-1799.

Glykys J, Dzhala VI, Kuchibhotla KV, Feng G, Kuner T, Augustine G, Bacskai BJ, and Staley KJ (2009) Differences in cortical versus subcortical GABAergic signaling: a candidate mechanism of electroclinical uncoupling of neonatal seizures Neuron 63:657-672.

Goddard GV, McIntyre DC, and Leech CK (1969) A permanent change in brain function resulting from daily electrical stimulation. Exp Neurol 25:295-330.

Gomes PX, de Oliveira GV, de Araújo FY, de Barros Viana GS, de Sousa FC, Hyphantis TN, Grunberg NE, Carvalho AF, and Macêdo DS (2013) Differences in vulnerability to nicotine-induced kindling between female and male periadolescent rats. Psychopharmacology (Berl) 225:115-126.

Gray WP and Sundstrom LE (1998) Kainic acid increases the proliferation of granule cell progenitors in the dentate gyrus of the adult rat. Brain Res 790:52-59.

Greenblatt DJ, Allen MD, Harmatz JS, and Shader RI (1980) Diazepam disposition determinants. Clin Pharmacol Ther 27:301-312.

Grünewald RA, Aliberti V, and Panayiotopoulos CP (1992) Exacerbation of typical absence seizures by progesterone. Seizure 1:137-138.

Guedes RC, de Oliveira JA, Amâncio-Dos-Santos A, and García-Cairasco N (2009) Sexual differentiation of cortical spreading depression propagation after acute and kindled audiogenic seizures in the Wistar audiogenic rat (WAR). Epilepsy Res $\mathbf{8 3}$ 207-214

Guldner GT and Morrell MJ (1996) Nocturnal penile tumescence and rigidity evaluation in men with epilepsy. Epilepsia 37:1211-1214.

Gulinello M and Smith SS (2003) Anxiogenic effects of neurosteroid exposure: sex differences and altered GABAA receptor pharmacology in adult rats. J Pharmacol Exp Ther 305:541-548.

Haeri NA, Palizvan MR, Sadegh M, Aghaei Z, and Rafiei M (2016) Prediction of seizure incidence probability in PTZ model of kindling through spatial learning ability in male and female rats. Physiol Behav 161:47-52.

Hamed SA, Moussa EM, Tohamy AM, Mohamed KO, Mohamad ME, Sherif TM, and Abdellah MM (2015) Seminal fluid analysis and testicular volume in adults with epilepsy receiving valproate. J Clin Neurosci 22:508-512.

Hamson DK, Roes MM, and Galea LA (2016) Sex hormones and cognition: neuroendocrine influences on memory and learning. Compr Physiol 6:1295-1337.

Harden C and MacLusky NJ (2004) Aromatase inhibition, testosterone, and seizures. Epilepsy Behav 5:260-263.
Harden C and MacLusky NJ (2005) Aromatase inhibitors as add-on treatment for men with epilepsy. Expert Rev Neurother 5:123-127.

Harden CL (2005a) Polycystic ovaries and polycystic ovary syndrome in epilepsy: evidence for neurogonadal disease. Epilepsy Curr 5:142-146.

Harden CL (2005b) Sexuality in women with epilepsy. Epilepsy Behav 7 (Suppl 2): S2-S6.

Harden CL and Pennell PB (2013) Neuroendocrine considerations in the treatment of men and women with epilepsy [published correction appears in Lancet Neurol (2013) 12:128]. Lancet Neurol 12:72-83.

Harte-Hargrove LC, Maclusky NJ, and Scharfman HE (2013) Brain-derived neurotrophic factor-estrogen interactions in the hippocampal mossy fiber pathway: implications for normal brain function and disease. Neuroscience 239:46-66.

Hauser WA, Annegers JF, and Kurland LT (1993) Incidence of epilepsy and unprovoked seizures in Rochester, Minnesota: 1935-1984. Epilepsia 34:453-468.

Hauser WA and Kurland LT (1975) The epidemiology of epilepsy in Rochester, Minnesota, 1935 through 1967. Epilepsia 16:1-66.

Haut SR, Bigal ME, and Lipton RB (2006) Chronic disorders with episodic manifestations: focus on epilepsy and migraine. Lancet Neurol 5:148-157.

Haut SR, Hall CB, Masur J, and Lipton RB (2007) Seizure occurrence: precipitants and prediction. Neurology 69:1905-1910.

Haut SR, Vouyiouklis M, and Shinnar S (2003) Stress and epilepsy: a patient perception survey. Epilepsy Behav 4:511-514.

Hawkins NA, Zachwieja NJ, Miller AR, Anderson LL, and Kearney JA (2016) Fine Mapping of a Dravet Syndrome Modifier Locus on Mouse Chromosome 5 and Candidate Gene Analysis by RNA-Seq. PLoS Genet 12:e1006398.

Hayley S, Du L, Litteljohn D, Palkovits M, Faludi G, Merali Z, Poulter MO, and Anisman H (2015) Gender and brain regions specific differences in brain derived neurotrophic factor protein levels of depressed individuals who died through suicide. Neurosci Lett 600:12-16.

Hebert LE, Weuve J, Scherr PA, and Evans DA (2013) Alzheimer disease in the United States (2010-2050) estimated using the 2010 census. Neurology 80: 1778-1783.

Helmstaedter C, Brosch T, Kurthen M, and Elger CE (2004) The impact of sex and language dominance on material-specific memory before and after left temporal lobe surgery. Brain 127:1518-1525.

Helmstaedter C, Kurthen M, and Elger CE (1999) Sex differences in material-specific cognitive functions related to language dominance: an intracarotid amobarbital study in left temporal lobe epilepsy. Laterality 4:51-63.

Helmstaedter C and Witt JA (2017) Epilepsy and cognition - a bidirectional relationship? Seizure 49:83-89.

Henbid MT, Marks WN, Collins MJ, Cain SM, Snutch TP, and Howland JG (2017) Sociability impairments in Genetic Absence Epilepsy Rats from Strasbourg: reversal by the T-type calcium channel antagonist Z944. Exp Neurol 296:16-22.

Henning O, Johannessen Landmark C, Traeen B, Svendsen T, Farmen A, Nakken $\mathrm{KO}$, and Lossius M (2019) Sexual function in people with epilepsy: similarities and differences with the general population. Epilepsia 60:1984-1992.

Hermann BP, Trenerry MR, and Colligan RC (1996) Learned helplessness, attributional style, and depression in epilepsy. Bozeman Epilepsy Surgery Consortium. Epilepsia 37:680-686.

Herzog AG (1993) A relationship between particular reproductive endocrine disorders and the laterality of epileptiform discharges in women with epilepsy. Neurology 43:1907-1910.

Herzog AG (1999) Progesterone therapy in women with epilepsy: a 3-year follow-up. Neurology 52:1917-1918.

Herzog AG (2008) Disorders of reproduction in patients with epilepsy: primary neurological mechanisms. Seizure 17:101-110.

Herzog AG, Coleman AE, Jacobs AR, Klein P, Friedman MN, Drislane FW, Ransil BJ, and Schomer DL (2003a) Interictal EEG discharges, reproductive hormones, and menstrual disorders in epilepsy. Ann Neurol 54:625-637.

Herzog AG, Coleman AE, Jacobs AR, Klein P, Friedman MN, Drislane FW, and Schomer DL (2003b) Relationship of sexual dysfunction to epilepsy laterality and reproductive hormone levels in women. Epilepsy Behav 4:407-413.

Herzog AG, Drislane FW, Schomer DL, Pennell PB, Bromfield EB, Dworetzky BA, Farina EL, and Frye CA (2005) Differential effects of antiepileptic drugs on sexual function and hormones in men with epilepsy. Neurology 65: $1016-1020$.

Herzog AG and Fowler KM; NIH Progesterone Trial Study Group (2008) Sensitivity and specificity of the association between catamenial seizure patterns and ovulation. Neurology 70:486-487.

Herzog AG, Harden CL, Liporace J, Pennell P, Schomer DL, Sperling M, Fowler K, Nikolov B, Shuman S, and Newman M (2004) Frequency of catamenial seizure exacerbation in women with localization-related epilepsy. Ann Neurol 56:431-434. Herzog AG, Klein P, and Ransil BJ (1997) Three patterns of catamenial epilepsy. Epilepsia 38:1082-1088.

Herzog AG, Russell V, Vaitukaitis JL, and Geschwind N (1982) Neuroendocrine dysfunction in temporal lobe epilepsy. Arch Neurol 39:133-135.

Herzog AG and Schachter SC (2001) Valproate and the polycystic ovarian syndrome: final thoughts. Epilepsia 42:311-315.

Herzog AG, Seibel MM, Schomer DL, Vaitukaitis JL, and Geschwind N (1986a) Reproductive endocrine disorders in men with partial seizures of temporal lobe origin. Arch Neurol 43:347-350.

Herzog AG, Seibel MM, Schomer DL, Vaitukaitis JL, and Geschwind N (1986b) Reproductive endocrine disorders in women with partial seizures of temporal lobe origin. Arch Neurol 43:341-346.

Hesdorffer DC, Logroscino G, Benn EK, Katri N, Cascino G, and Hauser WA (2011a) Estimating risk for developing epilepsy: a population-based study in Rochester, Minnesota. Neurology 76:23-27.

Hesdorffer DC, Logroscino G, Cascino G, Annegers JF, and Hauser WA (1998) Incidence of status epilepticus in Rochester, Minnesota, 1965-1984. Neurology 50:735-741.

Hesdorffer DC, Tomson T, Benn E, Sander JW, Nilsson L, Langan Y, Walczak TS, Beghi E, Brodie MJ, and Hauser A; ILAE Commission on Epidemiology 
Subcommission on Mortality (2011b) Combined analysis of risk factors for SUDEP. Epilepsia 52:1150-1159.

Hill CA and Fitch RH (2012) Sex differences in mechanisms and outcome of neonatal hypoxia-ischemia in rodent models: implications for sex-specific neuroprotection in clinical neonatal practice. Neurol Res Int 2012:867531.

Hill CA, Threlkeld SW, and Fitch RH (2011) Early testosterone modulated sex differences in behavioral outcome following neonatal hypoxia ischemia in rats. Int J Dev Neurosci 29:381-388.

Hill RA and van den Buuse M (2011) Sex-dependent and region-specific changes in TrkB signaling in BDNF heterozygous mice. Brain Res 1384:51-60.

Hilton GD, Nuñez JL, and McCarthy MM (2003) Sex differences in response to kainic acid and estradiol in the hippocampus of newborn rats. Neuroscience $\mathbf{1 1 6}$ 383-391.

Hojo Y, Hattori TA, Enami T, Furukawa A, Suzuki K, Ishii HT, Mukai H, Morrison JH, Janssen WG, Kominami S, et al. (2004) Adult male rat hippocampus synthesizes estradiol from pregnenolone by cytochromes P45017alpha and P450 aromatase localized in neurons. Proc Natl Acad Sci USA 101:865-870.

Holmes GL (2015) Cognitive impairment in epilepsy: the role of network abnormalities. Epileptic Disord 17:101-116.

Hom AC and Buterbaugh GG (1986) Estrogen alters the acquisition of seizures kindled by repeated amygdala stimulation or pentylenetetrazol administration in ovariectomized female rats. Epilepsia 27:103-108.

Honchar MP, Olney JW, and Sherman WR (1983) Systemic cholinergic agents induce seizures and brain damage in lithium-treated rats. Science 220:323-325.

Hooper A, Paracha R, and Maguire J (2018) Seizure-induced activation of the HPA axis increases seizure frequency and comorbid depression-like behaviors. Epilepsy Behav 78:124-133.

Hum KM, Megna S, and Burnham WM (2009) The effects of right and left amygdala kindling on the female reproductive system in rats. Epilepsia 50:880-886.

Isojärvi J (2008) Disorders of reproduction in patients with epilepsy: antiepileptic drug related mechanisms. Seizure 17:111-119.

Isojärvi JI, Laatikainen TJ, Pakarinen AJ, Juntunen KT, and Myllylä VV (1993) Polycystic ovaries and hyperandrogenism in women taking valproate for epilepsy. N Engl J Med 329:1383-1388.

Isojärvi JI, Löfgren E, Juntunen KS, Pakarinen AJ, Päivänsalo M, Rautakorpi I, and Tuomivaara L (2004) Effect of epilepsy and antiepileptic drugs on male reproductive health. Neurology 62:247-253.

Ito M, Adachi N, Nakamura F, Koyama T, Okamura T, Kato M, Kanemoto K, Nakano T, Matsuura M, and Hara S (2004) Characteristics of postictal headache in patients with partial epilepsy. Cephalalgia 24:23-28.

Ito M, Tamura M, and Namba F; Neonatal Research Network of Japan (2017) Role of sex in morbidity and mortality of very premature neonates. Pediatr Int (Roma) 59: 898-905.

Iyengar SS, LaFrancois JJ, Friedman D, Drew LJ, Denny CA, Burghardt NS, Wu MV, Hsieh J, Hen R, and Scharfman HE (2015) Suppression of adult neurogenesis increases the acute effects of kainic acid. Exp Neurol 264:135-149.

Jacono JJ and Robertson JM (1987) The effects of estrogen, progesterone, and ionized calcium on seizures during the menstrual cycle of epileptic women. Epilepsia $\mathbf{2 8}$ 571-577.

Jain A, Huang GZ, and Woolley CS (2019a) Latent Sex Differences in Molecular Signaling That Underlies Excitatory Synaptic Potentiation in the Hippocampus. $J$ Neurosci 39:1552-1565.

Jain S, LaFrancois JJ, Botterill JJ, Alcantara-Gonzalez D, and Scharfman HE (2019b) Adult neurogenesis in the mouse dentate gyrus protects the hippocampus from neuronal injury following severe seizures. Hippocampus 29:683-709.

Jallon P, Goumaz M, Haenggeli C, and Morabia A (1997) Incidence of first epileptic seizures in the canton of Geneva, Switzerland. Epilepsia 38:547-552

Jallon P, Loiseau P, and Loiseau J (2001) Newly diagnosed unprovoked epileptic seizures: presentation at diagnosis in CAROLE study. Coordination Active du Réseau Observatoire Longitudinal de l' Epilepsie. Epilepsia 42:464-475.

Jallon P, Smadja D, Cabre P, Le Mab G, and Bazin M (1999) EPIMART: prospective incidence study of epileptic seizures in newly referred patients in a French Carribean island (Martinique). Epilepsia 40:1103-1109.

Jandó G, Carpi D, Kandel A, Urioste R, Horvath Z, Pierre E, Vadi D, Vadasz C, and Buzsáki G (1995) Spike-and-wave epilepsy in rats: sex differences and inheritance of physiological traits. Neuroscience 64:301-317.

Jansen C, Francomme L, Vignal J-P, Jacquot C, Schwan R, Tyvaert L, Maillard L, and Hingray C (2019) Interictal psychiatric comorbidities of drug-resistant focal epilepsy: prevalence and influence of the localization of the epilepsy. Epilepsy Behav 94:288-296.

Janszky J, Schulz R, Janszky I, and Ebner A (2004) Medial temporal lobe epilepsy: gender differences. $J$ Neurol Neurosurg Psychiatry 75:773-775.

Jensen P, Jensen SB, Sørensen PS, Bjerre BD, Rizzi DA, Sørensen AS, Klysner R, Brinch K, Jespersen B, and Nielsen H (1990) Sexual dysfunction in male and female patients with epilepsy: a study of 86 outpatients. Arch Sex Behav 19:1-14

Jia JL, Chen S, Sivarajah V, Stephens D, and Cortez MA (2018) Latitudinal differences on the global epidemiology of infantile spasms: systematic review and metaanalysis. Orphanet $J$ Rare Dis 13:216.

Joëls M (2009) Stress, the hippocampus, and epilepsy. Epilepsia 50:586-597.

Johnson EL and Kaplan PW (2017) Caring for transgender patients with epilepsy. Epilepsia 58:1667-1672.

Johnson RT, Breedlove SM, and Jordan CL (2008) Sex differences and laterality in astrocyte number and complexity in the adult rat medial amygdala. J Comp Neurol 511:599-609.

Josephson CB and Jetté N (2017) Psychiatric comorbidities in epilepsy. Int Rev Psychiatry 29:409-424.

Kalinin VV and Zheleznova EV (2007) Chronology and evolution of temporal lobe epilepsy and endocrine reproductive dysfunction in women: relationships to side of focus and catameniality. Epilepsy Behav 11:185-191.

Kalkbrenner KA and Standley CA (2003) Estrogen modulation of NMDA-induced seizures in ovariectomized and non-ovariectomized rats. Brain Res 964:244-249.
Kaminski RM, Marini H, Kim WJ, and Rogawski MA (2005) Anticonvulsant activity of androsterone and etiocholanolone. Epilepsia 46:819-827.

Kang HJ, Kawasawa YI, Cheng F, Zhu Y, Xu X, Li M, Sousa AM, Pletikos M, Meyer KA, Sedmak G, et al. (2011) Spatio-temporal transcriptome of the human brain. Nature 478:483-489.

Kang SK, Hawkins NA, and Kearney JA (2018) C57BL/6J and C57BL/6N substrains differentially influence phenotype severity in the $\mathrm{Scn} 1 \mathrm{a}^{+/-}$mouse model of Dravet syndrome. Epilepsia Open 4:164-169.

Kang SK, Markowitz GJ, Kim ST, Johnston MV, and Kadam SD (2015) Age- and sexdependent susceptibility to phenobarbital-resistant neonatal seizures: role of chloride co-transporters. Front Cell Neurosci 9:173.

Kanner AM (2003) Depression in epilepsy: prevalence, clinical semiology, pathogenic mechanisms, and treatment. Biol Psychiatry 54:388-398.

Kanner AM (2009) Depression and epilepsy: a review of multiple facets of their close relation. Neurol Clin 27:865-880.

Kanner AM (2011) Anxiety disorders in epilepsy: the forgotten psychiatric comorbidity. Epilepsy Curr 11:90-91.

Karaali-Savrun F, Göksan B, Yeni SN, Ertan S, and Uzun N (2002) Seizure-related headache in patients with epilepsy. Seizure 11:67-69.

Kawakami M, Kimura F, and Higuchi T (1973a) Effects of electrical stimulation of the brain on gonadotropin secretion in male rats. Endocrinol Jpn 20:447-454

Kawakami M, Terasawa E, Kimura F, and Wakabayashi K (1973b) Modulating effect of limbic structures on gonadotropin release. Neuroendocrinology 12:1-16.

Khakh BS and Sofroniew MV (2015) Diversity of astrocyte functions and phenotypes in neural circuits. Nat Neurosci 18:942-952.

Kim EC, Patel J, Zhang J, Soh H, Rhodes JS, Tzingounis AV, and Chung HJ (2020) Heterozygous loss of epilepsy gene KCNQ2 alters social, repetitive and exploratory behaviors. Genes Brain Behav 19:e12599.

Kipnis PA, Sullivan BJ, and Kadam SD (2019) Sex-dependent signaling pathways underlying seizure susceptibility and the role of chloride cotransporters. Cells 13: 488.

Kishk N, Mourad H, Ibrahim S, Shamloul R, Al-Azazi A, and Shalaby N (2019) Sex differences among epileptic patients: a comparison of epilepsy and its impacts on demographic features, clinical characteristics, and management patterns in a tertiary care hospital in Egypt. Egypt $J$ Neurol Psychiat Neurosurg 55:39.

Kleveland G and Engelsen BA (1998) Juvenile myoclonic epilepsy: clinical characteristics, treatment and prognosis in a Norwegian population of patients. Seizure 7: $31-38$

Klintsova A, Levy WB, and Desmond NL (1995) Astrocytic volume fluctuates in the hippocampal CA1 region across the estrous cycle. Brain Res 690:269-274.

Knake S, Rosenow F, Vescovi M, Oertel WH, Mueller HH, Wirbatz A, Katsarou N, and Hamer HM; Status Epilepticus Study Group Hessen (SESGH) (2001) Incidence of status epilepticus in adults in Germany: a prospective, population-based study. Epilepsia 42:714-718

Kobau R, Zahran H, Thurman DJ, Zack MM, Henry TR, Schachter SC, and Price PH; Centers for Disease Control and Prevention (CDC) (2008) Epilepsy surveillance among adults--19 States, Behavioral Risk Factor Surveillance System, 2005. MMWR Surveill Summ 57:1-20.

Kokka N, Sapp DW, Witte U, and Olsen RW (1992) Sex differences in sensitivity to pentylenetetrazol but not in GABAA receptor binding. Pharmacol Biochem Behav 43:441-447.

Kommajosyula SP, Randall ME, and Faingold CL (2016) Inhibition of adenosine metabolism induces changes in post-ictal depression, respiration, and mortality in genetically epilepsy prone rats. Epilepsy Res 119:13-19.

Kondziella D, Alvestad S, Vaaler A, and Sonnewald U (2007) Which clinical and experimental data link temporal lobe epilepsy with depression? $J$ Neurochem 103: $2136-2152$

Koppel BS and Harden CL (2014) Gender issues in the neurobiology of epilepsy: a clinical perspective. Neurobiol Dis 72 (Pt B):193-197.

Koss WA, Haertel JM, Philippi SM, and Frick KM (2018) Sex Differences in the Rapid Cell Signaling Mechanisms Underlying the Memory-Enhancing Effects of 17ß-Estradiol. eNeuro 5:ENEURO.0267-18.2018.

Krebs-Kraft DL, Hill MN, Hillard CJ, and McCarthy MM (2010) Sex difference in cell proliferation in developing rat amygdala mediated by endocannabinoids has implications for social behavior. Proc Natl Acad Sci USA 107: $20535-20540$

Kros L, Lykke-Hartmann K, and Khodakhah K (2018) Increased susceptibility to cortical spreading depression and epileptiform activity in a mouse model for FHM2. Sci Rep 8:16959.

Kuba R, Pohanka M, Zákopcan J, Novotná I, and Rektor I (2006) Sexual dysfunctions and blood hormonal profile in men with focal epilepsy. Epilepsia 47: $2135-2140$

Kurtz BS, Lehman J, Garlick P, Amberg J, Mishra PK, Dailey JW, Weber R, and Jobe PC (2001) Penetrance and expressivity of genes involved in the development of epilepsy in the genetically epilepsy-prone rat (GEPR). J Neurogenet 15:233-244.

Kwan P and Brodie MJ (2000) Early identification of refractory epilepsy. $N$ Engl J Med 342:314-319.

Kwon O-Y and Park S-P (2014) Depression and anxiety in people with epilepsy. $J$ Clin Neurol 10:175-188.

LaFrance WC, Kanner AM, and Hermann B (2008) Psychiatric comorbidities in epilepsy, Int Rev Neurobiol 83, pp 347-383.

Lai C-W and Trimble MR (1997) Stress and epilepsy. J Epilepsy 10:177-186.

Larsson K and Eeg-Olofsson O (2006) A population based study of epilepsy in children from a Swedish county. Eur J Paediatr Neurol 10:107-113.

Leite JP, Bortolotto ZA, and Cavalheiro EA (1990) Spontaneous recurrent seizures in rats: an experimental model of partial epilepsy. Neurosci Biobehav Rev 14: $511-517$.

Leitinger M, Trinka E, Giovannini G, Zimmermann G, Florea C, Rohracher A, Kalss G, Neuray C, Kreidenhuber R, Höfler J, et al. (2019) Epidemiology of status epilepticus in adults: a population-based study on incidence, causes, and outcomes. Epilepsia 60:53-62. 
Lemmens EM, Lubbers T, Schijns OE, Beuls EA, and Hoogland G (2005) Gender differences in febrile seizure-induced proliferation and survival in the rat dentate gyrus. Epilepsia 46:1603-1612.

Leniger T, Isbruch K, von den Driesch S, Diener HC, and Hufnagel A (2001) Seizureassociated headache in epilepsy. Epilepsia 42:1176-1179.

Leranth C, Hajszan T, and MacLusky NJ (2004) Androgens increase spine synapse density in the CA1 hippocampal subfield of ovariectomized female rats. J Neurosci 24:495-499.

Leranth C, Petnehazy O, and MacLusky NJ (2003) Gonadal hormones affect spine synaptic density in the CA1 hippocampal subfield of male rats. $J$ Neurosci 23 : $1588-1592$.

Leussis MP and Heinrichs SC (2006) Routine tail suspension husbandry facilitates onset of seizure susceptibility in EL mice. Epilepsia 47:801-804

$\mathrm{Li} \mathrm{F}$ and Liu L (2019) Comparison of kainate-induced seizures, cognitive impairment and hippocampal damage in male and female mice. Life Sci 232:116621.

Li H, Huguenard JR, and Fisher RS (2007) Gender and age differences in expression of GABAA receptor subunits in rat somatosensory thalamus and cortex in an absence epilepsy model. Neurobiol Dis 25:623-630.

Li J, Kim JS, Abejuela VA, Lamano JB, Klein NJ, and Christian CA (2016) Disrupted female estrous cyclicity in the intrahippocampal kainic acid mouse model of temporal lobe epilepsy. Epilepsia Open 2:39-47.

Li J, Robare JA, Gao L, Ghane MA, Flaws JA, Nelson ME, and Christian CA (2018) Dynamic and sex-specific changes in gonadotropin-releasing hormone neuron activity and excitability in a mouse model of temporal lobe epilepsy. eNeuro $\mathbf{5}$ e0273.

Li M, Masugi-Tokita M, Takanami K, Yamada S, and Kawata M (2012) Testosterone has sublayer-specific effects on dendritic spine maturation mediated by BDNF and PSD-95 in pyramidal neurons in the hippocampus CA1 area. Brain Res 1484:76-84.

Lin JJ, Mula M, and Hermann BP (2012) Uncovering the neurobehavioural comorbidities of epilepsy over the lifespan. Lancet 380:1180-1192.

Liu H, Kaur J, Dashtipour K, Kinyamu R, Ribak CE, and Friedman LK (2003) Suppression of hippocampal neurogenesis is associated with developmental stage number of perinatal seizure episodes, and glucocorticosteroid level. Exp Neurol 184:196-213

Liu M, Hurn PD, Roselli CE, and Alkayed NJ (2007) Role of P450 aromatase in sexspecific astrocytic cell death. J Cereb Blood Flow Metab 27:135-141.

Löfgren E, Mikkonen K, Tolonen U, Pakarinen A, Koivunen R, Myllyla VV, Tapanainen JS, and Isojärvi JI (2007) Reproductive endocrine function in women with epilepsy: the role of epilepsy type and medication. Epilepsy Behav 10:77-83.

Logothetis J, Harner R, Morrell F, and Torres F (1959) The role of estrogens in catamenial exacerbation of epilepsy. Neurology 9:352-360.

Loram LC, Sholar PW, Taylor FR, Wiesler JL, Babb JA, Strand KA, Berkelhammer D, Day HE, Maier SF, and Watkins LR (2012) Sex and estradiol influence glial proinflammatory responses to lipopolysaccharide in rats. Psychoneuroendocrinology 37:1688-1699.

Lucke-Wold BP, Nguyen L, Turner RC, Logsdon AF, Chen YW, Smith KE, Huber JD Matsumoto R, Rosen CL, Tucker ES, et al. (2015) Traumatic brain injury and epilepsy: underlying mechanisms leading to seizure. Seizure 33:13-23.

Luef $\mathrm{G}$ and Madersbacher H (2015) Sexual dysfunction in patients with epilepsy. Handb Clin Neurol 130:383-394.

Luquin S, Naftolin F, and Garcia-Segura LM (1993) Natural fluctuation and gonadal hormone regulation of astrocyte immunoreactivity in dentate gyrus. $J$ Neurobiol 24:913-924.

Lúthvígsson P, Olafsson E, Sigurthardóttir S, and Hauser WA (1994) Epidemiologic features of infantile spasms in Iceland. Epilepsia 35:802-805.

Macdonald RL and Olsen RW (1994) GABAA receptor channels. Annu Rev Neurosci 17:569-602.

MacLusky NJ, Clark AS, Naftolin F, and Goldman-Rakic PS (1987) Estrogen formation in the mammalian brain: possible role of aromatase in sexual differentiation of the hippocampus and neocortex. Steroids 50:459-474.

Maguire J and Salpekar JA (2013) Stress, seizures, and hypothalamic-pituitary-adrenal axis targets for the treatment of epilepsy. Epilepsy Behav 26:352-362.

Maguire JL, Stell BM, Rafizadeh M, and Mody I (2005) Ovarian cycle-linked changes in $\mathrm{GABA}(\mathrm{A})$ receptors mediating tonic inhibition alter seizure susceptibility and anxiety. Nat Neurosci 8:797-804.

Mainieri G, Cevoli S, Giannini G, Zummo L, Leta C, Broli M, Ferri L, Santucci M, Posar A, Avoni P, et al. (2015) Headache in epilepsy: prevalence and clinical features. J Headache Pain 16:556.

Mameniškienè R, Guk J, and Jatužis D (2017) Family and sexual life in people with epilepsy. Epilepsy Behav 66:39-44.

Mameniškienè R, Karmonaite I, and Zagorskis R (2016) The burden of headache in people with epilepsy. Seizure 41:120-126.

Manandhar M, Hawkes S, Buse K, Nosrati E, and Magar V (2018) Gender, health and the 2030 agenda for sustainable development. Bull World Health Organ 96: $644-653$.

Manford M, Hart YM, Sander JW, and Shorvon SD (1992) The National General Practice Study of Epilepsy. The syndromic classification of the International League Against Epilepsy applied to epilepsy in a general population. Arch Neurol 49: 801-808.

Marino SE, Birnbaum AK, Leppik IE, Conway JM, Musib LC, Brundage RC, Ramsay RE, Pennell PB, White JR, Gross CR, et al. (2012) Steady-state carbamazepine pharmacokinetics following oral and stable-labeled intravenous administration in epilepsy patients: effects of race and sex. Clin Pharmacol Ther 91:483-488.

Martin-McGill KJ, Jackson CF, Bresnahan R, Levy RG, and Cooper PN (2018) Ketogenic diets for drug-resistant epilepsy. Cochrane Database Syst Rev 11: CD001903

Martínez-Levy GA, Rocha L, Lubin FD, Alonso-Vanegas MA, Nani A, BuentelloGarcía RM, Pérez-Molina R, Briones-Velasco M, Recillas-Targa F, Pérez-Molina A, et al. (2016) Increased expression of BDNF transcript with exon VI in hippocamp of patients with pharmaco-resistant temporal lobe epilepsy. Neuroscience 314: $12-21$
Martini L, Melcangi RC, and Maggi R (1993) Androgen and progesterone metabolism in the central and peripheral nervous system. J Steroid Biochem Mol Biol 47: 195-205.

Matagne A and Klitgaard H (1998) Validation of corneally kindled mice: a sensitive screening model for partial epilepsy in man. Epilepsy Res 31:59-71.

May T, Adesina I, McGillivray J, and Rinehart NJ (2019) Sex differences in neurodevelopmental disorders. Curr Opin Neurol 32:622-626.

Mazarati A, Siddarth P, Baldwin RA, Shin D, Caplan R, and Sankar R (2008) Depression after status epilepticus: behavioural and biochemical deficits and effects of fluoxetine. Brain 131:2071-2083.

Mazarati AM, Shin D, Kwon YS, Bragin A, Pineda E, Tio D, Taylor AN, and Sankar R (2009) Elevated plasma corticosterone level and depressive behavior in experimental temporal lobe epilepsy. Neurobiol Dis 34:457-461.

McCabe BK, Silveira DC, Cilio MR, Cha BH, Liu X, Sogawa Y, and Holmes GL (2001) Reduced neurogenesis after neonatal seizures. J Neurosci 21:2094-2103.

McCarthy MM and Arnold AP (2011) Reframing sexual differentiation of the brain Nat Neurosci 14:677-683.

McFadyen-Leussis MP and Heinrichs SC (2005) Seizure-prone EL/Suz mice exhibit physical and motor delays and heightened locomotor activity in response to novelty during development. Epilepsy Behav 6:312-319.

McHugh JC and Delanty N (2008) Epidemiology and classification of epilepsy: gender comparisons. Int Rev Neurobiol 83:11-26.

McNamara JO and Scharfman HE (2012) Temporal lobe epilepsy and the BDNF receptor, TrkB, in Jasper's Basic Mechanisms of the Epilepsies (Noebels JL, Avoli M, Rogawski MA, Olsen RW, and Delgado-Escueta AV, National Center for Biotechnology Information (US), Bethesda, MD.

McQueen JK, Dow RC, and Fink G (1992) Gonadal steroids regulate number of astrocytes immunostained for glial fibrillary acidic protein in mouse hippocampus. Mol Cell Neurosci 3:482-486.

Meador KJ, Baker GA, Browning N, Cohen MJ, Clayton-Smith J, Kalayjian LA Kanner A, Liporace JD, Pennell PB, Privitera M, et al.; NEAD Study Group (2011) Foetal antiepileptic drug exposure and verbal versus non-verbal abilities at three years of age. Brain 134:396-404

Meador KJ and Loring DW (2016) Developmental effects of antiepileptic drugs and the need for improved regulations. Neurology 86:297-306.

Medina AE, Manhães AC, and Schmidt SL (2001) Sex differences in sensitivity to seizures elicited by pentylenetetrazol in mice. Pharmacol Biochem Behav 68: $591-596$

Meinhardt U and Mullis PE (2002) The essential role of the aromatase/p450arom Semin Reprod Med 20:277-284.

Mejías-Aponte CA, Jiménez-Rivera CA, and Segarra AC (2002) Sex differences in models of temporal lobe epilepsy: role of testosterone. Brain Res 944: $210-218$

Melcangi RC, Poletti A, Cavarretta I, Celotti F, Colciago A, Magnaghi V, Motta M, Negri-Cesi P, and Martini L (1998) The 5alpha-reductase in the central nervous system: expression and modes of control. J Steroid Biochem Mol Biol 65:295-299

Meo R, Bilo L, Nappi C, Tommaselli AP, Valentino R, Nocerino C, Striano S, and Buscaino GA (1993) Derangement of the hypothalamic GnRH pulse generator in women with epilepsy. Seizure 2:241-252.

Michetti C, Castroflorio E, Marchionni I, Forte N, Sterlini B, Binda F, Fruscione F, Baldelli P, Valtorta F, Zara F, et al. (2017) The PRRT2 knockout mouse recapitulates the neurological diseases associated with PRRT2 mutations. Neurobiol Dis 99:66-83.

Mikkonen K, Tapanainen P, Pakarinen AJ, Päivänsalo M, Isojärvi JI, and Vainionpää LK (2004) Serum androgen levels and testicular structure during pubertal maturation in male subjects with epilepsy. Epilepsia 45: $769-776$

Min JW, Peng BW, He X, Zhang Y, and Li JX (2013) Gender difference in epileptogenic effects of 2-BFI and BU224 in mice. Eur J Pharmacol 718:81-86.

Mirza MA, Ritzel R, Xu Y, McCullough LD, and Liu F (2015) Sexually dimorphic outcomes and inflammatory responses in hypoxic-ischemic encephalopathy. $J$ Neuroinflammation 12:32.

Mishra PK, Dailey JW, Reigel CE, and Jobe PC (1988a) Brain norepinephrine and convulsions in the genetically epilepsy-prone rat: sex-dependent responses to Ro 4 1284 treatment. Life Sci 42:1131-1137.

Mishra PK, Dailey JW, Reigel CE, and Jobe PC (1989) Audiogenic convulsions in moderate seizure genetically epilepsy-prone rats (GEPR-3s). Epilepsy Res 3 191-198.

Mishra PK, Dailey JW, Reigel CE, Tomsic ML, and Jobe PC (1988b) Sex-specific distinctions in audiogenic convulsions exhibited by severe seizure genetically epilepsy-prone rats (GEPR-9s). Epilepsy Res 2:309-316.

Mitev YA, Darwish M, Wolf SS, Holsboer F, Almeida OF, and Patchev VK (2003) Gender differences in the regulation of 3 alpha-hydroxysteroid dehydrogenase in rat brain and sensitivity to neurosteroid-mediated stress protection. Neuroscience 120:541-549.

Morizawa Y, Sato K, Takaki J, Kawasaki A, Shibata K, Suzuki T, Ohta S, and Koizumi S (2012) Cell-autonomous enhancement of glutamate-uptake by female astrocytes. Cell Mol Neurobiol 32:953-956.

Morrell MJ, Giudice L, Flynn KL, Seale CG, Paulson AJ, Doñe S, Flaster E, Ferin M, and Sauer MV (2002) Predictors of ovulatory failure in women with epilepsy. Ann Neurol 52:704-711.

Morrell MJ and Guldner GT (1996) Self-reported sexual function and sexual arousability in women with epilepsy. Epilepsia 37:1204-1210.

Morrell MJ, Sperling MR, Stecker M, and Dichter MA (1994) Sexual dysfunction in partial epilepsy: a deficit in physiologic sexual arousal. Neurology 44:243-247.

Mróz K, Mróz T, Wielosz M, and Tutka P (2009) Effects of androsterone on convulsions in various seizure models in mice. Pharmacol Rep 61:564-569.

Müller CJ, Gröticke I, Hoffmann K, Schughart K, and Löscher W (2009) Differences in sensitivity to the convulsant pilocarpine in substrains and sublines of C57BL/6 mice. Genes Brain Behav 8:481-492. 
Mullins GM, O'sullivan SS, Neligan A, McCarthy A, McNamara B, Galvin RJ, and Sweeney BJ (2007) A study of idiopathic generalised epilepsy in an Irish population. Seizure 16:204-210.

Murguía-Castillo J, Beas-Zárate C, Rivera-Cervantes MC, Feria-Velasco AI, and Ureña-Guerrero ME (2013) NKCC1 and KCC2 protein expression is sexually dimorphic in the hippocampus and entorhinal cortex of neonatal rats. Neurosci Lett 552:52-57.

Murialdo G, Galimberti CA, Fonzi S, Manni R, Costelli P, Parodi C, Solinas GP, Amoretti G, and Tartara A (1995) Sex hormones and pituitary function in male epileptic patients with altered or normal sexuality. Epilepsia 36:360-365.

Murialdo G, Galimberti CA, Magri F, Sampaolo P, Copello F, Gianelli MV, Gazzerro E, Rollero A, Deagatone C, Manni R, et al. (1997) Menstrual cycle and ovary alterations in women with epilepsy on antiepileptic therapy. $J$ Endocrinol Invest 20:519-526.

Murray KD, Isackson PJ, Eskin TA, King MA, Montesinos SP, Abraham LA and Roper SN (2000) Altered mRNA expression for brain-derived neurotrophic factor and type II calcium/calmodulin-dependent protein kinase in the hippocampus of patients with intractable temporal lobe epilepsy. J Comp Neurol 418:411-422.

Nakken KO, Solaas MH, Kjeldsen MJ, Friis ML, Pellock JM, and Corey LA (2005) Which seizure-precipitating factors do patients with epilepsy most frequently report? Epilepsy Behav 6:85-89.

Neugebauer R, Paik M, Hauser WA, Nadel E, Leppik I, and Susser M (1994) Stressful life events and seizure frequency in patients with epilepsy. Epilepsia $\mathbf{3 5}$ 336-343.

Newmark ME and Penry JK (1980) Catamenial epilepsy: a review. Epilepsia 21: 281-300.

Niibori Y, Lee SJ, Minassian BA, and Hampson DR (2020) Sexually divergent mortality and partial phenotypic rescue after gene therapy in a mouse model of dravet syndrome. Hum Gene Ther 31:339-351.

Noda A, Hashizume R, Maihara T, Tomizawa Y, Ito Y, Inoue M, Kobayashi K, Asano Y, Sasa M, and Serikawa T (1998) NER rat strain: a new type of genetic model in epilepsy research. Epilepsia 39:99-107.

Noebels JL, Qiao X, Bronson RT, Spencer C, and Davisson MT (1990) Stargazer: a new neurological mutant on chromosome 15 in the mouse with prolonged cortical seizures. Epilepsy Res 7:129-135.

O'Brien MD and Guillebaud J (2010) Contraception for women taking antiepileptic drugs. J Fam Plann Reprod Health Care 36:239-242.

Ocek L, Tarhan H, Uludağ FI, Sariteke A, Köse C, Colak A, Zorlu F, and Zorlu Y (2018) Evaluation of sex hormones and sperm parameters in male epileptic patients. Acta Neurol Scand 137:409-416.

Oliveira CV, Grigoletto J, Funck VR, Ribeiro LR, Royes LF, Fighera MR, Furian AF, and Oliveira MS (2015) Evaluation of potential gender-related differences in behavioral and cognitive alterations following pilocarpine-induced status epilepticus in C57BL/6 mice. Physiol Behav 143:142-150.

Olsen RW and Sieghart W (2009) GABA A receptors: subtypes provide diversity of function and pharmacology. Neuropharmacology 56:141-148.

O'Toole KK, Hooper A, Wakefield S, and Maguire J (2014) Seizure-induced disinhibition of the HPA axis increases seizure susceptibility. Epilepsy Res 108: $29-43$

Painter MJ, Scher MS, Stein AD, Armatti S, Wang Z, Gardiner JC, Paneth N, Minnigh B, and Alvin J (1999) Phenobarbital compared with phenytoin for the treatment of neonatal seizures. N Engl J Med 341:485-489.

Pan J, Zhang L, Wang F, Liu D, Li PA, and Sun T (2013) Amygdala kindling alters estrus cycle and ovarian morphology in the rat. Int $J$ Sci 2:12-21.

Panayiotopoulos CP (2008) Typical absence seizures and related epileptic syndromes: assessment of current state and directions for future research. Epilepsia 49: 2131-2139.

Pandya M, Palpagama TH, Turner C, Waldvogel HJ, Faull RL, and Kwakowsky A (2019) Sex- and age-related changes in GABA signaling components in the human cortex. Biol Sex Differ 10:5.

Pappalardo LW, Samad OA, Liu S, Zwinger PJ, Black JA, and Waxman SG (2018) Nav1.5 in astrocytes plays a sex-specific role in clinical outcomes in a mouse model of multiple sclerosis. Glia 66:2174-2187.

Parent JM, Yu TW, Leibowitz RT, Geschwind DH, Sloviter RS, and Lowenstein DH (1997) Dentate granule cell neurogenesis is increased by seizures and contributes to aberrant network reorganization in the adult rat hippocampus. $J$ Neurosci $\mathbf{1 7}$ : 3727-3738.

Patel DC, Tewari BP, Chaunsali L, and Sontheimer H (2019) Neuron-glia interactions in the pathophysiology of epilepsy. Nat Rev Neurosci 20:282-297.

Paus T (2010) Sex differences in the human brain: a developmental perspective. Prog Brain Res 186:13-28.

Pavlovic JM, Akcali D, Bolay H, Bernstein C, and Maleki N (2017) Sex-related influences in migraine. J Neurosci Res 95:587-593.

Pearce PS, Friedman D, Lafrancois JJ, Iyengar SS, Fenton AA, Maclusky NJ, and Scharfman HE (2014) Spike-wave discharges in adult Sprague-Dawley rats and their implications for animal models of temporal lobe epilepsy. Epilepsy Behav 32:121-131.

Pellock JM, Hrachovy R, Shinnar S, Baram TZ, Bettis D, Dlugos DJ, Gaillard WD, Gibson PA, Holmes GL, Nordl DR, et al. (2010) Infantile spasms: a U.S. consensus report. Epilepsia 51:2175-2189.

Pennell PB (2003) Antiepileptic drug pharmacokinetics during pregnancy and lactation. Neurology 61 (6 Suppl 2):S35-S42.

Pericić D and Bujas M (1997) Sex differences in bicuculline-induced convulsions: interaction with stress and ligands of benzodiazepine binding sites. Brain Res $\mathbf{7 5 2}$ : 279-284.

Pericić D, Manev H, and Bujas M (1996) Gonadal hormones and picrotoxin-induced convulsions in male and female rats. Brain Res 736:174-179.

Pericić D, Manev H, and Geber J (1986) Sex related differences in the response of mice, rats and cats to administration of picrotoxin. Life Sci 38:905-913.

Pericić D, Manev H, and Lakić N (1985) Sex differences in the response of rats to drugs affecting GABAergic transmission. Life Sci 36:541-547.
Perrot-Sinal TS, Sinal CJ, Reader JC, Speert DB, and McCarthy MM (2007) Sex differences in the chloride cotransporters, NKCC1 and KCC2, in the developing hypothalamus. J Neuroendocrinol 19:302-308.

Persad V, Cortez MA, and Snead OC III (2002) A chronic model of atypical absence seizures: studies of developmental and gender sensitivity. Epilepsy Res 48:111-119.

Persinger MA, Makarec K, and Bradley JC (1988) Characteristics of limbic seizures evoked by peripheral injections of lithium and pilocarpine. Physiol Behav 44:27-37.

Perucca E, Battino D, and Tomson T (2014) Gender issues in antiepileptic drug treatment. Neurobiol Dis 72 (Pt B):217-223.

Pesce ME, Acevedo X, Bustamante D, Miranda HE, and Pinardi G (2000) Progesterone and testosterone modulate the convulsant actions of pentylenetetrazol and strychnine in mice. Pharmacol Toxicol 87:116-119.

Peternel S, Pilipović K, and Zupan G (2009) Seizure susceptibility and the brain regional sensitivity to oxidative stress in male and female rats in the lithiumpilocarpine model of temporal lobe epilepsy. Prog Neuropsychopharmacol Biol Psychiatry 33:456-462.

Phoenix CH, Goy RW, Gerall AA, and Young WC (1959) Organizing action of prenatally administered testosterone propionate on the tissues mediating mating behavior in the female guinea pig. Endocrinology 65:369-382.

Pike CJ (2017) Sex and the development of Alzheimer's disease. J Neurosci Res 95: $671-680$

Pineda E, Shin D, Sankar R, and Mazarati AM (2010) Comorbidity between epilepsy and depression: experimental evidence for the involvement of serotonergic, glucocorticoid, and neuroinflammatory mechanisms. Epilepsia 51 (Suppl 3):110-114.

Pitkänen A, Roivainen R, and Lukasiuk K (2016) Development of epilepsy after ischaemic stroke. Lancet Neurol 15:185-197.

Porter BE (2008) Neurogenesis and epilepsy in the developing brain. Epilepsia 49 (Suppl 5):50-54.

Porter BE, Maronski M, and Brooks-Kayal AR (2004) Fate of newborn dentate granule cells after early life status epilepticus. Epilepsia 45:13-19.

Potschka H and Löscher W (1999) Corneal kindling in mice: behavioral and pharmacological differences to conventional kindling. Epilepsy Res 37:109-120.

Prasad AN, Burneo JG, and Corbett B (2014) Epilepsy, comorbid conditions in Canadian children: analysis of cross-sectional data from cycle 3 of the National Longitudinal Study of Children and Youth. Seizure 23:869-873.

Prendergast BJ, Onishi KG, and Zucker I (2014) Female mice liberated for inclusion in neuroscience and biomedical research. Neurosci Biobehav Rev 40:1-5.

Pressler RM, Boylan GB, Marlow N, Blennow M, Chiron C, Cross JH, de Vries LS, Hallberg B, Hellström-Westas L, Jullien V, et al.; NEonatal seizure treatment with Medication Off-patent (NEMO) consortium (2015) Bumetanide for the treatment of seizures in newborn babies with hypoxic ischaemic encephalopathy (NEMO): an open-label, dose finding, and feasibility phase 1/2 trial. Lancet Neurol 14:469-477.

Pritchard PB III, Wannamaker BB, Sagel J, and Daniel CM (1985) Serum prolactin and cortisol levels in evaluation of pseudoepileptic seizures. Ann Neurol 18: 87-89.

Quigg M, Kiely JM, Shneker B, Veldhuis JD, and Bertram EH III (2002) Interictal and postictal alterations of pulsatile secretions of luteinizing hormone in temporal lobe epilepsy in men. Ann Neurol 51:559-566.

Quigg M, Smithson SD, Fowler KM, Sursal T, and Herzog AG; NIH Progesterone Trial Study Group (2009) Laterality and location influence catamenial seizure expression in women with partial epilepsy. Neurology 73:223-227.

Racine RJ (1972) Modification of seizure activity by electrical stimulation. I. Afterdischarge threshold. Electroencephalogr Clin Neurophysiol 32:269-279.

Ramantani G and Holthausen H (2017) Epilepsy after cerebral infection: review of the literature and the potential for surgery. Epileptic Disord 19:117-136.

Ravizza T, Friedman LK, Moshé SL, and Velísková J (2003) Sex differences in GABA(A)ergic system in rat substantia nigra pars reticulata. Int $J$ Dev Neurosci 21:245-254.

Reddy DS (2004a) Anticonvulsant activity of the testosterone-derived neurosteroid 3alpha-androstanediol. Neuroreport 15:515-518.

Reddy DS (2004b) Role of neurosteroids in catamenial epilepsy. Epilepsy Res 62 99-118.

Reddy DS (2004c) Testosterone modulation of seizure susceptibility is mediated by neurosteroids 3alpha-androstanediol and 17beta-estradiol. Neuroscience 129: 195-207.

Reddy DS (2009) The role of neurosteroids in the pathophysiology and treatment of catamenial epilepsy. Epilepsy Res 85:1-30.

Reddy DS (2013) Role of hormones and neurosteroids in epileptogenesis. Front Cell Neurosci 7:115.

Reddy DS (2016) Catamenial epilepsy: discovery of an extrasynaptic molecular mechanism for targeted therapy. Front Cell Neurosci 10:101.

Reddy DS, Carver CM, Clossen B, and Wu X (2019) Extrasynaptic $\gamma$-aminobutyric acid type A receptor-mediated sex differences in the antiseizure activity of neurosteroids in status epilepticus and complex partial seizures. Epilepsia 60:730-743.

Reddy DS, Castaneda DC, O'Malley BW, and Rogawski MA (2004) Anticonvulsant activity of progesterone and neurosteroids in progesterone receptor knockout mice. $J$ Pharmacol Exp Ther 310:230-239.

Reddy DS, Gangisetty O, and Briyal S (2010) Disease-modifying activity of progesterone in the hippocampus kindling model of epileptogenesis. Neuropharmacology 59:573-581.

Reddy DS, Gould J, and Gangisetty O (2012) A mouse kindling model of perimenstrual catamenial epilepsy. J Pharmacol Exp Ther 341:784-793.

Reddy DS and Jian K (2010) The testosterone-derived neurosteroid androstanediol is a positive allosteric modulator of GABAA receptors. J Pharmacol Exp Ther 334: 1031-1041

Reddy DS, Kim HY, and Rogawski MA (2001) Neurosteroid withdrawal model of perimenstrual catamenial epilepsy. Epilepsia 42:328-336.

Reibel S, André V, Chassagnon S, André G, Marescaux C, Nehlig A, and Depaulis A (2000) Neuroprotective effects of chronic estradiol benzoate treatment on hippocampal cell loss induced by status epilepticus in the female rat. Neurosci Lett $\mathbf{2 8 1}$ : $79-82$. 
Reigel CE, Jobe PC, Dailey JW, and Savage DD (1989) Ontogeny of sound-induced seizures in the genetically epilepsy-prone rat. Epilepsy Res 4:63-71.

Rennie J and Boylan G (2007) Treatment of neonatal seizures. Arch Dis Child Fetal Neonatal Ed 92:F148-F150.

Riazi K, Honar H, Homayoun H, Rashidi N, Dehghani M, Sadeghipour H, Gaskari SA, and Dehpour AR (2004) Sex and estrus cycle differences in the modulatory effects of morphine on seizure susceptibility in mice. Epilepsia 45:1035-1042.

Rogawski MA (2012) Migraine and Epilepsy-Shared Mechanisms within the Family of Episodic Disorders, in Jasper's Basic Mechanisms of the Epilepsies (Noebels JL, Avoli M, Rogawski MA, Olsen RW, and Delgado-Escueta AV, National Center for Biotechnology Information (US), Bethesda, MD.

Røste LS, Taubøll E, Haugen TB, Bjørnenak T, Saetre ER, and Gjerstad L (2003) Alterations in semen parameters in men with epilepsy treated with valproate or carbamazepine monotherapy. Eur J Neurol 10:501-506.

Røste LS, Taubøll E, Mørkrid L, Bjørnenak T, Saetre ER, Mørland T, and Gjerstad L (2005) Antiepileptic drugs alter reproductive endocrine hormones in men with epilepsy. Eur J Neurol 12:118-124.

Routledge PA, Stargel WW, Kitchell BB, Barchowsky A, and Shand DG (1981) Sexrelated differences in the plasma protein binding of lignocaine and diazepam. $B r$ $J$ Clin Pharmacol 11:245-250.

Rucklidge JJ (2010) Gender differences in attention-deficit/hyperactivity disorder. Psychiatr Clin North Am 33:357-373.

Ruskin DN, Fortin JA, Bisnauth SN, and Masino SA (2017) Ketogenic diets improve behaviors associated with autism spectrum disorder in a sex-specific manner in the EL mouse. Physiol Behav 168:138-145.

Ryan A and Frye CA (2008) Antiseizure effects of $5^{*}$-androstane-3*,7beta-diol may be independent of actions at estrogen receptor beta. Epilepsy Behav 13 $32-35$.

Saberi M and Pourgholami MH (2003) Estradiol alters afterdischarge threshold and acquisition of amygdala kindled seizures in male rats. Neurosci Lett 340:41-44.

Sakai F and Igarashi H (1997) Prevalence of migraine in Japan: a nationwide survey. Cephalalgia 17:15-22.

Salpekar JA and Mula M (2018) Common psychiatric comorbidities in epilepsy: how big of a problem is it? Epilepsy Behav 98 (Pt B):293-297.

Sankar R, Shin D, Liu H, Katsumori H, and Wasterlain CG (2000) Granule cell neurogenesis after status epilepticus in the immature rat brain. Epilepsia 41 (Suppl 6):S53-S56

Santana MT, Jackowski AP, Britto FDOSS, Sandim GB, Caboclo LO, Centeno RS, Carrete H Jr., and Yacubian EM (2014) Gender and hemispheric differences in temporal lobe epilepsy: a VBM study. Seizure 23:274-279.

Santos VR, Kobayashi I, Hammack R, Danko G, and Forcelli PA (2018) Impact of strain, sex, and estrous cycle on gamma butyrolactone-evoked absence seizures in rats. Epilepsy Res 147:62-70.

Savic I (2014) Sex differences in human epilepsy. Exp Neurol 259:38-43.

Savic I and Engel J Jr. (1998) Sex differences in patients with mesial temporal lobe epilepsy. J Neurol Neurosurg Psychiatry 65:910-912.

Scharfman HE, Goodman JH, Rigoulot MA, Berger RE, Walling SG, Mercurio TC, Stormes K, and Maclusky NJ (2005) Seizure susceptibility in intact and ovariectomized female rats treated with the convulsant pilocarpine. Exp Neurol 196: $73-86$.

Scharfman HE, Goodman JH, and Sollas AL (2000) Granule-like neurons at the hilar/ CA3 border after status epilepticus and their synchrony with area CA3 pyramidal cells: functional implications of seizure-induced neurogenesis. $J$ Neurosci 20 $6144-6158$

Scharfman HE, Kim M, Hintz TM, and MacLusky NJ (2008) Seizures and reproductive function: insights from female rats with epilepsy. Ann Neurol 64: 687-697.

Scharfman HE and MacLusky NJ (2006) The influence of gonadal hormones on neuronal excitability, seizures, and epilepsy in the female. Epilepsia 47 1423-1440.

Scharfman HE and MacLusky NJ (2014a) Differential regulation of BDNF, synaptic plasticity and sprouting in the hippocampal mossy fiber pathway of male and female rats. Neuropharmacology 76:696-708

Scharfman HE and MacLusky NJ (2014b) Sex differences in the neurobiology of epilepsy: a preclinical perspective. Neurobiol Dis 72 (Pt B)):180-192.

Scharfman HE, Malthankar-Phatak GH, Friedman D, Pearce P, McCloskey DP, Harden CL, and Maclusky NJ (2009) A rat model of epilepsy in women: a tool to study physiological interactions between endocrine systems and seizures. Endocrinology 150:4437-4442.

Scharfman HE, Mercurio TC, Goodman JH, Wilson MA, and MacLusky NJ (2003) Hippocampal excitability increases during the estrous cycle in the rat: a potential role for brain-derived neurotrophic factor. J Neurosci 23:11641-11652.

Scheffer IE, Berkovic S, Capovilla G, Connolly MB, French J, Guilhoto L, Hirsch E Jain S, Mathern GW, Moshé SL, et al. (2017) ILAE classification of the epilepsies: position paper of the ILAE Commission for Classification and Terminology. Epilepsia 58:512-521.

Schwartz-Giblin S, Korotzer A, and Pfaff DW (1989) Steroid hormone effects on picrotoxin-induced seizures in female and male rats. Brain Res 476:240-247.

Semple BD, Zamani A, Rayner G, Shultz SR, and Jones NC (2019) Affective, neurocognitive and psychosocial disorders associated with traumatic brain injury and post-traumatic epilepsy. Neurobiol Dis 123:27-41.

Sen A, Capelli V, and Husain M (2018) Cognition and dementia in older patients with epilepsy. Brain 141:1592-1608.

Shansky RM (2018) Sex differences in behavioral strategies: avoiding interpretational pitfalls. Curr Opin Neurobiol 49:95-98.

Shiono S, Williamson J, Kapur J, and Joshi S (2019) Progesterone receptor activation regulates seizure susceptibility. Ann Clin Transl Neurol 6:1302-1310.

Silveira DC, Souza EA, Carvalho JF, and Guerreiro CA (2001) Interictal hyposexuality in male patients with epilepsy. Arq Neuropsiquiatr 59:23-28.

Smith AL, Alexander M, Rosenkrantz TS, Sadek ML, and Fitch RH (2014) Sex differences in behavioral outcome following neonatal hypoxia ischemia: insights from a clinical meta-analysis and a rodent model of induced hypoxic ischemic brain injury, Exp Neurol 254:54-67.

Smith ML, Elliott I, and Naguiat A (2009) Sex differences in episodic memory among children with intractable epilepsy. Epilepsy Behav 14:247-249.

Smith MS, Freeman ME, and Neill JD (1975) The control of progesterone secretion during the estrous cycle and early pseudopregnancy in the rat: prolactin, gonadotropin and steroid levels associated with rescue of the corpus luteum of pseudopregnancy. Endocrinology 96:219-226.

Snigdha S, Neill JC, McLean SL, Shemar GK, Cruise L, Shahid M, and Henry B (2011) Phencyclidine (PCP)-induced disruption in cognitive performance is gender-specific and associated with a reduction in brain-derived neurotrophic factor (BDNF) in specific regions of the female rat brain. $J$ Mol Neurosci 43 $337-345$

Socanski D, Aurlien D, Herigstad A, Thomsen PH, and Larsen TK (2013) Epilepsy in a large cohort of children diagnosed with attention deficit/hyperactivity disorders (ADHD). Seizure 22:651-655.

Solum DT and Handa RJ (2002) Estrogen regulates the development of brain-derived neurotrophic factor mRNA and protein in the rat hippocampus. $J$ Neurosci 22 2650-2659.

Sperling MR, Pritchard PB III, Engel J Jr., Daniel C, and Sagel J (1986) Prolactin in partial epilepsy: an indicator of limbic seizures. Ann Neurol 20:716-722.

Sperling MR, Schilling CA, Glosser D, Tracy JI, and Asadi-Pooya AA (2008) Selfperception of seizure precipitants and their relation to anxiety level, depression, and health locus of control in epilepsy. Seizure 17:302-307.

Sprenger T, Viana M, and Tassorelli C (2018) Current Prophylactic Medications for Migraine and Their Potential Mechanisms of Action. Neurotherapeutics 15: $313-323$

Stewart WF, Lipton RB, Celentano DD, and Reed ML (1992) Prevalence of migraine headache in the United States. Relation to age, income, race, and other sociodemographic factors. JAMA 267:64-69.

Stewart WF, Wood C, Reed ML, Roy J, and Lipton RB; AMPP Advisory Group (2008) Cumulative lifetime migraine incidence in women and men. Cephalalgia 28 $1170-1178$.

Strauss E, Wada J, and Hunter M (1992) Sex-related differences in the cognitive consequences of early left-hemisphere lesions. J Clin Exp Neuropsychol 14: $738-748$

Suzuki J and Nakamoto Y (1982) Abnormal plastic phenomena of sensoryprecipitated epilepsy in the mutant El mouse. Exp Neurol 75:440-452.

Swerdloff RS, Dudley RE, Page ST, Wang C, and Salameh WA (2017) Dihydrotestosterone: biochemistry, physiology, and clinical implications of elevated blood levels. Endocr Rev 38:220-254

Syvertsen M, Helde G, Stovner LJ, and Brodtkorb E (2007) Headaches add to the burden of epilepsy. J Headache Pain 8:224-230.

Szapacs ME, Mathews TA, Tessarollo L, Ernest Lyons W, Mamounas LA and Andrews AM (2004) Exploring the relationship between serotonin and brainderived neurotrophic factor: analysis of BDNF protein and extraneuronal 5-HT in mice with reduced serotonin transporter or BDNF expression. $J$ Neurosci Methods 140:81-92.

Tan M and Tan U (2001) Sex difference in susceptibility to epileptic seizures in rats: importance of estrous cycle. Int $J$ Neurosci 108:175-191.

Taneja N, Kucheria K, Jain S, and Maheshwari MC (1994) Effect of phenytoin on semen. Epilepsia 35:136-140.

Tenney JR and Glauser TA (2013) The current state of absence epilepsy: can we have your attention? Epilepsy Curr 13:135-140.

Teskey GC, Hutchinson JE, and Kolb B (1999) Sex differences in cortical plasticity and behavior following anterior cortical kindling in rats. Cereb Cortex $\mathbf{9}$ : $675-682$

Thomas J and Yang YC (1991) Allylglycine-induced seizures in male and female rats. Physiol Behav 49:1181-1183.

Thorneycroft IH, Mishell DR Jr., Stone SC, Kharma KM, and Nakamura RM (1971) The relation of serum 17-hydroxyprogesterone and estradiol-17-beta levels during the human menstrual cycle. Am J Obstet Gynecol 111:947-951.

Tomson T, Battino D, Bonizzoni E, Craig J, Lindhout D, Perucca E, Sabers A, Thomas SV, and Vajda F; EURAP Study Group (2018) Comparative risk of major congenital malformations with eight different antiepileptic drugs: a prospective cohort study of the EURAP registry. Lancet Neurol 17:530-538.

Tonini MC, Giordano L, Atzeni L, Bogliun G, Perri G, Saracco MG, Tombini M, Torelli P, Turazzini M, Vernieri F, et al.; EPICEF Group (2012) Primary headache and epilepsy: a multicenter cross-sectional study. Epilepsy Behav 23 $342-347$.

Torgrimson BN and Minson CT (2005) Sex and gender: what is the difference? J Appl Physiol (1985) 99:785-787.

Trenerry MR, Jack CR Jr., Cascino GD, Sharbrough FW, and Ivnik RJ (1995) Gender differences in post-temporal lobectomy verbal memory and relationships between MRI hippocampal volumes and preoperative verbal memory. Epilepsy Res 20: $69-76$

Trevathan E, Murphy CC, and Yeargin-Allsopp M (1999) The descriptive epidemiology of infantile spasms among Atlanta children. Epilepsia 40:748-751.

Trimble MR (1978) Serum prolactin in epilepsy and hysteria. BMJ 2:1682.

Turski WA, Cavalheiro EA, Schwarz M, Czuczwar SJ, Kleinrok Z, and Turski L (1983) Limbic seizures produced by pilocarpine in rats: behavioural, electroencephalographic and neuropathological study. Behav Brain Res 9:315-335.

Tuveri A, Paoletti AM, Orrù M, Melis GB, Marotto MF, Zedda P, Marrosu F, Sogliano C, Marra C, Biggio G, et al. (2008) Reduced serum level of THDOC, an anticonvulsant steroid, in women with perimenstrual catamenial epilepsy. Epilepsia 49 1221-1229

Twele F, Töllner K, Brandt C, and Löscher W (2016) Significant effects of sex, strain, and anesthesia in the intrahippocampal kainate mouse model of mesial temporal lobe epilepsy. Epilepsy Behav 55:47-56.

van Luijtelaar EL and Coenen AM (1986) Two types of electrocortical paroxysms in an inbred strain of rats. Neurosci Lett 70:393-397. 
van Luijtelaar EL, Dirksen R, Vree TB, and van Haaren F (1996) Effects of acute and chronic cocaine administration on EEG and behaviour in intact and castrated male and intact and ovariectomized female rats. Brain Res Bull 40:43-50.

van Luijtelaar G, Budziszewska B, Jaworska-Feil L, Ellis J, Coenen A, and Lasoń W (2001) The ovarian hormones and absence epilepsy: a long-term EEG study and pharmacological effects in a genetic absence epilepsy model. Epilepsy Res 46: $225-239$.

van Luijtelaar G, Onat FY, and Gallagher MJ (2014) Animal models of absence epilepsies: what do they model and do sex and sex hormones matter? Neurobiol Dis 72 (Pt B): 167-179.

Vathy I, Velísková J, and Moshé SL (1998) Prenatal morphine exposure induces agerelated changes in seizure susceptibility in male rats. Pharmacol Biochem Behav 60:635-638.

Veatch LM, Wright TM, and Randall CL (2007) Only male mice show sensitization of handling-induced convulsions across repeated ethanol withdrawal cycles. Alcohol Clin Exp Res 31:477-485.

Velasco ME and Taleisnik S (1969) Effect of hippocampal stimulation on the release of gonadotropin. Endocrinology 85:1154-1159.

Velioğlu SK, Boz C, and Ozmenoğlu M (2005) The impact of migraine on epilepsy: a prospective prognosis study. Cephalalgia 25:528-535.

Velíšek L, Shang E, Velíšková J, Chachua T, Macchiarulo S, Maglakelidze G, Wolgemuth DJ, and Greenberg DA (2011) GABAergic neuron deficit as an idiopathic generalized epilepsy mechanism: the role of BRD2 haploinsufficiency in juvenile myoclonic epilepsy. PLoS One 6: 23656.

Velísková J and Moshé SL (2001) Sexual dimorphism and developmental regulation of substantia nigra function. Ann Neurol 50:596-601.

Venzi M, Di Giovanni G, and Crunelli V (2015) A critical evaluation of the gamma-hydroxybutyrate (GHB) model of absence seizures. CNS Neurosci Ther 21:123-140.

Vergnes M, Marescaux C, Micheletti G, Reis J, Depaulis A, Rumbach L, and Warter JM (1982) Spontaneous paroxysmal electroclinical patterns in rat: a model of generalized non-convulsive epilepsy. Neurosci Lett 33:97-101.

Vetvik KG and MacGregor EA (2017) Sex differences in the epidemiology, clinical features, and pathophysiology of migraine. Lancet Neurol 16:76-87.

Vignatelli L, Rinaldi R, Galeotti M, de Carolis P, and D'Alessandro R (2005) Epidemiology of status epilepticus in a rural area of northern Italy: a 2-year populationbased study. Eur J Neurol 12:897-902.

Vignatelli L, Tonon C, and D'Alessandro R; Bologna Group for the Study of Status Epilepticus (2003) Incidence and short-term prognosis of status epilepticus in adults in Bologna, Italy. Epilepsia 44:964-968.

Villapol S, Loane DJ, and Burns MP (2017) Sexual dimorphism in the inflammatory response to traumatic brain injury. Glia 65:1423-1438.

von Bartheld CS, Bahney J, and Herculano-Houzel S (2016) The search for true numbers of neurons and glial cells in the human brain: a review of 150 years of cell counting. J Comp Neurol 524:3865-3895.

Waaler PE, Blom BH, Skeidsvoll H, and Mykletun A (2000) Prevalence, classification, and severity of epilepsy in children in western Norway. Epilepsia 41: $802-810$

Walmer DK, Wrona MA, Hughes CL, and Nelson KG (1992) Lactoferrin expression in the mouse reproductive tract during the natural estrous cycle: correlation with circulating estradiol and progesterone. Endocrinology 131:1458-1466.
Wang C, Shimizu-Okabe C, Watanabe K, Okabe A, Matsuzaki H, Ogawa T, Mori N, Fukuda A, and Sato K (2002) Developmental changes in KCC1, KCC2, and NKCC1 mRNA expressions in the rat brain. Brain Res Dev Brain Res 139:59-66.

Webber MP, Hauser WA, Ottman R, and Annegers JF (1986) Fertility in persons with epilepsy: 1935-1974. Epilepsia 27:746-752.

Will TR, Proano SB, Thomas AM, Kunz LM, Thompson KC, Ginnari LA, Jones CH, Lucas SC, Reavis EM, Dorris DM, et al. (2017) Problems and progress regarding sex bias and omission in neuroscience research. eNeuro 4:ENEURO.0278-17.2017.

Williams AE, Giust JM, Kronenberger WG, and Dunn DW (2016) Epilepsy and attention-deficit hyperactivity disorder: links, risks, and challenges. Neuropsychiatr Dis Treat 12:287-296.

Wilner AN, Sharma BK, Soucy A, Thompson A, and Krueger A (2014) Common comorbidities in women and men with epilepsy and the relationship between number of comorbidities and health plan paid costs in 2010. Epilepsy Behav 32: $15-20$

Wilson MA and Biscardi R (1997) Influence of gender and brain region on neurosteroid modulation of GABA responses in rats. Life Sci 60:1679-1691.

Wolbold R, Klein K, Burk O, Nüssler AK, Neuhaus P, Eichelbaum M, Schwab M, and Zanger UM (2003) Sex is a major determinant of CYP3A4 expression in human liver. Hepatology 38:978-988.

Woolley CS (2000) Estradiol facilitates kainic acid-induced, but not flurothyl-induced, behavioral seizure activity in adult female rats. Epilepsia 41:510-515.

Woolley DE and Timiras PS (1962a) Estrous and circadian periodicity and electroshock convulsions in rats. Am $J$ Physiol 202:379-382.

Woolley DE and Timiras PS (1962b) Gonad-brain relationship: effects of castration and testosterone on electroshock convulsions in male rats. Endocrinology 71: 609-617.

Woolley DE and Timiras PS (1962c) The gonad-brain relationship: effects of female sex hormones on electroshock convulsions in the rat. Endocrinology 70:196-209.

Woolley DE, Timiras PS, Rosenzweig MR, Krech D, and Bennett EL (1961) Sex and strain differences in electroshock convulsions of the rat. Nature 190:515-516.

Younus I and Reddy DS (2016) Seizure facilitating activity of the oral contraceptive ethinyl estradiol. Epilepsy Res 121:29-32.

Zeidler Z, Brandt-Fontaine M, Leintz C, Krook-Magnuson C, Netoff T, and KrookMagnuson E (2018) Targeting the mouse ventral hippocampus in the intrahippocampal kainic acid model of temporal lobe epilepsy. eNeuro 5: ENEURO.0158-0118.2018.

Zhang XM, Zhu SW, Duan RS, Mohammed AH, Winblad B, and Zhu J (2008) Gender differences in susceptibility to kainic acid-induced neurodegeneration in aged C57BL/6 mice. Neurotoxicology 29:406-412.

Zhu WJ and Roper SN (2001) Brain-derived neurotrophic factor enhances fast excitatory synaptic transmission in human epileptic dentate gyrus. Ann Neurol 50: 188-194.

Zobel A, Wellmer J, Schulze-Rauschenbach S, Pfeiffer U, Schnell S, Elger C, and Maier W (2004) Impairment of inhibitory control of the hypothalamic pituitary adrenocortical system in epilepsy. Eur Arch Psychiatry Clin Neurosci 254:303-311.

Zwain IH and Yen SS (1999) Neurosteroidogenesis in astrocytes, oligodendrocytes, and neurons of cerebral cortex of rat brain. Endocrinology 140:3843-3852.

Zwain IH, Yen SS, and Cheng CY (1997) Astrocytes cultured in vitro produce estradiol-17beta and express aromatase cytochrome P-450 (P-450 AROM) mRNA. Biochim Biophys Acta 1334:338-348. 